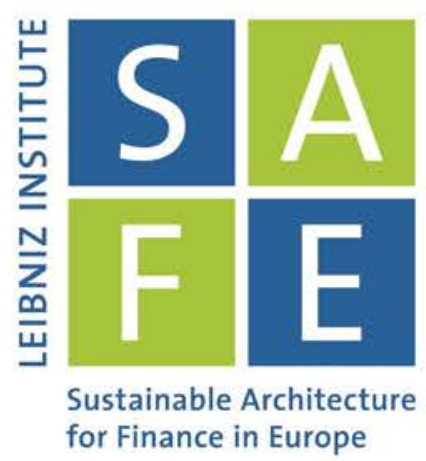

Christian Schlag | Julian Thimme | Rüdiger Weber

\title{
Implied Volatility Duration: A Measure for the Timing of Uncertainty Resolution
}

SAFE Working Paper No. 265

\section{Leibniz Institute for Financial Research SAFE} Sustainable Architecture for Finance in Europe 


\title{
Implied Volatility Duration: A Measure for the Timing of Uncertainty Resolution
}

\author{
Christian Schlag* $\quad$ Julian Thimme ${ }^{\dagger} \quad$ Rüdiger Weber ${ }^{\ddagger}$
}

First version: December 7, 2016

This version: January 27, 2020

\begin{abstract}
We introduce Implied Volatility Duration (IVD) as a new measure for the timing of uncertainty resolution, with a high IVD corresponding to late resolution. Portfolio sorts on a large cross-section of stocks indicate that investors demand on average more than five percent return per year as a compensation for a late resolution of uncertainty. In a general equilibrium model, we show that 'late' stocks can only have higher expected returns than 'early' stocks, if the investor exhibits a preference for early resolution of uncertainty. Our empirical analysis thus provides a purely market-based assessment of the timing preferences of the marginal investor.
\end{abstract}

Keywords: Preference for early resolution of uncertainty, implied volatility, cross-section of expected stock returns, asset pricing

JEL: G12, E44, D81

${ }^{*}$ Goethe University and Leibniz Institute for Financial Research SAFE, Theodor-W.-Adorno-Platz 3, 60323 Frankfurt am Main, Germany. E-mail: schlag@finance.uni-frankfurt.de

$\dagger$ Institute for Finance, Karlsruhe Institute of Technology, Blücherstraße 17, 76185 Karlsruhe, Germany. E-Mail: thimme@kit.edu

$\ddagger$ WU Vienna University of Economics and Business and VGSF, Welthandelsplatz 1, 1020 Vienna, Austria. E-mail: ruediger.weber@wu.ac.at

A previous version of this paper was titled "Implied Volatility Duration and the Early Resolution Premium". The authors would like to thank Bjarne Astrup Jensen (discussant), Robert Dittmar, Bruce Grundy, Alexander Hillert, Stephan Jank (discussant), Travis Johnson (discussant), Holger Kraft, Alexander Kraftschik (discussant), Christoph Meinerding, Philippe Mueller, Christian Opp, Bryan Routledge (discussant), Robert Stambaugh, Amir Yaron, Shaojun Zhang (discussant), participants of the 16th Colloquium on Financial Markets in Cologne, the 34th International Conference of the French Finance Association, the 2017 European Economics Association Meeting, the 2017 European Finance Association Meeting, the 2017 German Finance Association Meeting, the 2018 American Economic Association Meeting, the 2018 SFS Cavalcade Meeting and seminar participants at Frankfurt (Goethe), Zurich (UZH), Philadelphia (Wharton), and Vancouver (UBC Sauder) for valuable comments and suggestions. Christian Schlag gratefully acknowledges research and financial support from SAFE, funded by the State of Hessen initiative for research LOEWE. 


\title{
Implied Volatility Duration: A Measure for the Timing of Uncertainty Resolution
}

First version: December 7, 2016

This version: January 27, 2020

\begin{abstract}
We introduce Implied Volatility Duration (IVD) as a new measure for the timing of uncertainty resolution, with a high IVD corresponding to late resolution. Portfolio sorts on a large cross-section of stocks indicate that investors demand on average more than five percent return per year as a compensation for a late resolution of uncertainty. In a general equilibrium model, we show that 'late' stocks can only have higher expected returns than 'early' stocks, if the investor exhibits a preference for early resolution of uncertainty. Our empirical analysis thus provides a purely market-based assessment of the timing preferences of the marginal investor.
\end{abstract}

Keywords: Preference for early resolution of uncertainty, implied volatility, cross-section of expected stock returns, asset pricing

JEL: G12, E44, D81 


\section{Introduction}

Asset pricing is about explaining how risk and attitudes towards risk translate into market prices. For example, if riskier stocks have higher average returns, one would conclude that the marginal investor is risk averse. In this paper we focus on the timing of uncertainty resolution. We investigate when uncertainty is resolved, rather than how much of what type of uncertainty the investor is exposed to. ${ }^{1}$ Investors with non-neutral preferences concerning the timing of uncertainty resolution prefer specific uncertainty resolution profiles, which must be reflected in asset prices in equilibrium. Using options data, we characterize stocks as exhibiting early or late resolution of uncertainty. An average return differential between late and early resolution stocks of more than five percent per year suggests that investors have a preference for early resolution of uncertainty (PERU). This premium is not due to different exposures of late and early resolution stocks to standard risk factors.

Whether the marginal investor indeed exhibits PERU is of major importance in many asset pricing models. In particular, this includes applications of Epstein and Zin (1989) utility such as Bansal and Yaron (2004) or Wachter (2013). Technically, the representative agent exhibits PERU when the coefficient of relative risk aversion is greater than the inverse of the elasticity of intertemporal substitution. It is, however, notoriously difficult to obtain reliable empirical estimates for these two preference parameters (see Havránek, 2015; Thimme, 2016). Consequently, there is an intense debate about whether recursive preferences with their distinction between risk aversion and the inverse of the intertemporal elasticity of substitution (as opposed to, e.g., time-additive constant relative risk aversion (CRRA)) are relevant at all.

Our contribution to this debate is that we offer evidence concerning timing preferences that does not require the estimation of an elaborate model. Instead, our evidence comes from measuring the return differential between stocks featuring late and early resolution of uncertainty. We interpret the difference as an indication for PERU and aim at quantifying the compensation investors require to hold late resolution stocks.

\footnotetext{
${ }^{1}$ We do not investigate issues related to ambiguity, so we use the terms uncertainty and risk interchangeably.
} 
We illustrate the basic idea behind our empirical exercise via a simple example in the spirit of Epstein and Zin (1989) presented graphically in Figure 1. There are two claims $E$ and $L$, which, as seen from time $t=0$, both pay off one dollar with probability $p$ at time $t=2$. The difference between the claims is that, for claim $E$, all uncertainty about the outcome is resolved at $t=1$, whereas uncertainty about the payoff of claim $L$ is resolved only at $t=2$. Put differently, the variance for the payoff of claim $E$ narrows down from its initial value $p(1-p)$ at $t=0$ to zero at $t=1$, whereas the variance of claim $L$ stays at $p(1-p)$ until $t=2$. An agent exhibiting PERU prefers claim $E$ over claim $L$ and would therefore be willing to pay a higher price for $E$ than for $L$. Thus, in this case, the expected return on E must be less than that on $L$, with the opposite being true in the case of a preference for late resolution.

Our empirical strategy is to identify stocks of types $E$ or $L$ in the cross section. To identify pairs of stocks with the above properties we use option-implied volatilities $(\mathrm{IVs}){ }^{2}$ More precisely, we consider two stocks whose IVs over a long horizon from $t$ to $T$ are very close to each other. Since the variances over the long horizon are almost the same, the two stocks exhibit basically the same amount of long-term uncertainty. Then, among all such pairs, we only consider those where the IVs over a shorter horizon from $t$ to $\tau<T$ are markedly different. This means that, for the stock with the higher short-horizon IV, a greater share of overall uncertainty is resolved early. The (almost) equal long-term IV in the data corresponds to the exactly equal volatility of $\sqrt{p(1-p)}$ in the introductory example. Claim $L$ in the example had no uncertainty resolved after the first period, corresponding to a low short-term IV in the data. Conversely, claim $E$ had all of its uncertainty resolved in the first period, resulting in a high short-term volatility such that very little of the initial volatility of $\sqrt{p(1-p)}$ is left after the first period. This corresponds to a high short-term IV. In accordance with our motivating example in Figure 1 we label the stock with the higher short-horizon IV among the two stocks in the pair a type $E$ ('early') claim, while the other one is of type $L$ ('late').

\footnotetext{
${ }^{2}$ We are aware that an IV is a quantity given under the risk-neutral measure $\mathbb{Q}$, while our theoretical argument refers to the physical probability measure $\mathbb{P}$. We show that IVs are closely related to physical volatilites in Section 4.2, and that our empirical results are not driven by variance risk premiums, i.e., by differences between variances under the physical and the risk-neutral measure in Section 4.4 .
} 
The average return difference between $L$ and $E$ stocks in the respective pairs in our sample is positive and amounts to 5.2 percent per year with a $t$-statistic of 3.1 . This return difference cannot be explained by the exposures to the usual set of factors proposed by Fama and French $(1996,2015)$. In general we find that the larger the spread in short term IVs, the more pronounced is the return difference but the smaller is the number of stocks which can be matched with a respective counterpart. With moderate short-term IV differences between 5 and 15 percent we can classify about $70 \%$ of the stocks in our sample as exhibiting late or early resolution. The resulting return differential is lower but statistically significant at 1.3 percent on average.

The above investment strategy is a direct way of bringing the notion of early resolution of uncertainty to the data. As a more convenient absolute measure for the timing of uncertainty resolution, which can be computed for any stock with traded options, we introduce the concept of Implied Volatility Duration (IVD). Perfectly analogous to the well-known Macaulay duration in the area of fixed income, it represents a time-weighted average of the IVs for different subperiods of a total period from $t$ to $T$. So, ceteris paribus, the higher the IVD, the larger the share of total uncertainty that is resolved later.

We then perform a double sort of the stocks in our sample into quintiles for 365-day IV as a measure of total uncertainty and IVD as a measure for the timing of its resolution. We call the extreme portfolios with the highest and the lowest-IVD stocks 'late' and 'early', respectively. Within the stocks with high IV, we find a significantly positive average return of around seven percent on the 'late-minus-early' (LME) portfolio. The fact that we find a significant LME return in the group of stocks with high IV is not surprising: When the overall level of uncertainty is high, its resolution over time naturally is more relevant to the investor. Indeed, we do not expect to find a timing premium among stocks that are not uncertain to begin with.

The excess return on the LME portfolio varies over time and is higher in times of high economic uncertainty and in periods with negative realized returns on the aggregate stock market. 
Similar to the investment strategy based on pairs of stocks described before, the loadings of the LME portfolio on various factors are small. We also control for a large number of characteristics that have been shown to be related to expected returns but none of them explains our results. As an example, the effect is distinct from cash-flow duration, recently studied by Weber (2018). I.e., stocks exhibiting late resolution do not have longer cash-flow duration. Conceptually, cash flow duration refers to the timing of first moments of cash flows, whereas IVD refers to the evolution of second moments of returns over time. Moreover, our results are also robust to explanations based on shorting fees (see Drechsler and Drechsler, 2016), idiosyncratic volatility (see Ang et al., 2006), and mispricing (see Stambaugh and Yuan, 2016).

To investigate the explanatory power of IVD for the cross-section of expected returns we include an interaction term of 365 -day IV $^{2}$ and IVD as a characteristic in cross-sectional regressions. We find that it has strong explanatory power for cross-sectional variation in expected returns.

Our empirical findings are interesting in their own right and can be considered independent of their theoretical motivation. However, we do offer a possible explanation by considering a rational Epstein and Zin investor in a frictionless general equilibrium model. In this model we price type- $E$ and type- $L$ dividend claims. The key result of our analysis is that in order to generate a pronounced spread between expected returns on the $L$ stock and the $E$ stock, the investor's degree of relative risk aversion must exceed the inverse of her elasticity of intertemporal substitution by a considerable amount, i.e., the investor must exhibit PERU. ${ }^{3}$

\footnotetext{
${ }^{3}$ PERU only refers to the psychic effect of early uncertainty resolution (see Strzalecki, 2013) but not the instrumental value of early information that would for example allow to sell stocks earlier if their future performance is revealed to be weak. In equilibrium, any asset must be held by a market participant due to market clearing. In a representative agent setup, or, if all market participants have PERU, there is no instrumental value in early resolution.
} 


\section{Related Literature}

Our paper is related to several strands of the literature. The issue of whether the representative agent exhibits PERU is of key importance in asset pricing models with recursive preferences, since only under PERU the sign of the market price of risk for key state variables is such that these models can match the data. Prominent examples for models of this type are Bansal and Yaron (2004) and Drechsler and Yaron (2011). Epstein et al. (2014) criticize these long-run risk models because they would imply an immense discount for early resolution of uncertainty. For example, the dynamics of Bansal and Yaron (2004) imply that the investor would be willing to forgo 31 percent of lifetime wealth to eliminate all uncertainty about future consumption. A preference for early resolution of uncertainty alone does not necessarily lead to such high values, and the key driver for the results obtained by Epstein et al. (2014) are the assumed consumption dynamics. Our paper only makes a statement about timing preferences and neither refutes nor confirms other aspects of the long-run risk model such as, in particular, a highly persistent but latent component in consumption growth.

In the context of Epstein and Zin (1989) preferences, an agent exhibits PERU if the degree of relative risk aversion, $\gamma$, exceeds the inverse of the elasticity of intertemporal substitution (EIS), $\psi$. So all one would basically need is estimates of these two parameters to make a statement about the representative investor's timing preferences. In the literature, special attention has been devoted to the EIS. Hall (1988) estimates the EIS from the consumption Euler equation in a time-additive CRRA model. He concludes that it is most likely very small and not much greater than zero, if at all. Epstein and Zin (1991) estimate the EIS in a recursive utility

model where the relation $\gamma=\frac{1}{\psi}$ need not hold. They find estimates of $\gamma$ around one and the EIS to be roughly in the range of 0.2 to 0.9 . These results would imply that the representative agent has a preference for late resolution of uncertainty. But also the opposite result has been found in empirical studies. For example, Attanasio and Weber (1989) find a $\gamma$ of about five and an EIS around two, which is in favor of a preference for early resolution of uncertainty.

Other authors estimate preference parameters based on survey data, using the socio- 
economic background of survey respondents. Vissing-Jørgensen and Attanasio (2003) and more recently Crump et al. (2015) provide evidence that, among wealthy individuals and stockholders, the EIS is well above one, which together with the usually assumed values for risk aversion of $\gamma>1$ would imply PERU. Relatedly, D'Acunto et al. (2016) find that shocks to inflation expectations raise the willingness to consume, indicating a marked willingness to substitute consumption intertemporally. There is also some experimental evidence in favor of PERU provided by, e.g., Brown and Kim (2014) and Meissner and Pfeiffer (2018). In an earlier study, Ahlbrecht and Weber (1996) find that some participants prefer early and others late resolution. In an asset pricing context it is of key importance whether survey respondents or subjects in experiments could at least potentially represent the marginal investor. Since we use prices of traded assets, our approach is informative about the timing preferences of the marginal investor, which, however, does not necessarily imply PERU on part of every single investor or even the average investor. In general equilibrium asset pricing models with a representative agent, it is crucial to consider the preferences of the marginal investor, since it is her behavior that ultimately affects asset prices.

Instead of estimating preference parameters directly, Ai and Bansal (2018) study the impact of intertemporal preferences on announcement premiums. Intuitively, investors with time-additive expected utility do not claim an announcement premium, since they only price covariation with current consumption, not the arrival of news about future consumption. In contrast to this, Ai and Bansal (2018) find that only 30 days with important announcements per year account for more than half of the total equity premium. They argue that such premiums can only arise in the presence of so-called risk-sensitive preferences such as those suggested by Epstein and Zin (1989).

Our findings complement those of $\mathrm{Ai}$ and Bansal nicely. While they focus on the exact moment of uncertainty resolution itself and study realized stock returns at that moment, we look at expected stock returns during the period before uncertainty resolution. Importantly, our approach is to compare stocks which differ with respect to the amount of uncertainty that 
is resolved at different points in time. Our economic interpretation of our findings is based precisely on the rationale put forward by Ai and Bansal (2018).

Somewhat related to our paper, Jagannathan and Liu (2019) provide evidence in favor of PERU based on a model with learning. Depending on the preferences for early or late resolution of uncertainty, new information about the persistence of dividend growth results in either an increase or a decrease of the price-dividend ratio. However, while also using market prices, their approach requires much stronger parametric assumptions. In contrast, our analysis is model-free.

Our paper also relates to the literature on option-implied information about the crosssection of stock returns, represented by papers such as An et al. (2014) and much of the work cited there. The work by Johnson (2017) and Xie (2014) is in a certain sense similar to ours, since they also consider the asset pricing implications of implied volatilities across maturities. However, they focus on the term structure of the VIX volatility index, i.e., a characteristic of market-wide implied volatility, whereas we focus on the timing pattern of uncertainty resolution in individual stocks and its implications for expected returns.

\section{An investment strategy}

\subsection{Pairs of stocks}

Our main idea in this paper is to identify stocks that provide an early or a late resolution of uncertainty. Comparing their subsequent returns then shows whether either type of stock commands a premium over the other, indicating a premium for the timing of uncertainty resolution. To take this idea to the data, we use option implied volatilities (IVs) for different maturities as a representation of the uncertainty associated with the returns on this stock over different horizons. Using end-of-month data on the IV surface provided by OptionMetrics IvyDB for the period from January 1996 to August 2015, we identify pairs of stocks with basically 
identical 365-day IV $\left(\mathrm{IV}_{365}\right)$ but rather different 30 day-IV $\left(\mathrm{IV}_{30}\right)$. In particular, we look for stocks for which the $\mathrm{IV}_{365}$ values differ by at most 1 percentage point (e.g., 30\% vs. 31\%), while the difference between the respective (annualized) $I_{30}$ values is at least 25 percentage points. ${ }^{4}$ In the spirit of the motivating example in Figure 1, we go long in the stock with lower $\operatorname{IV}_{30}$ and short in the stock with higher $\mathrm{IV}_{30} \cdot{ }^{5}$ At every point in time we compute the average return difference within the pairs. ${ }^{6,7}$

When we hold the long and the short portfolio over twelve months, the return differential between the two amounts to a highly significant value of 5.17 percentage points, as shown in Table 1. In this setting, we cover on average about ten percent of the stocks in our sample at a given point in time. Table C.1 in the Internet Appendix shows that the spread in returns increases in the required distance between $\mathrm{IV}_{30}$ of the two stocks. Panel $\mathrm{D}$ of that table shows that, considering pairs with moderate differences in $\mathrm{IV}_{30}$ of for example 5 to 15 percent yields a premium of 1.26 percent which is smaller in magnitude compared to the benchmark case but still significantly positive. This specification allows us to assign about 70 percent of the stocks to a pair. Hence, the return differential is not just a phenomenon of a few select stocks. ${ }^{8}$ Moreover, it becomes consistently insignificant when there is no restriction regarding the $\mathrm{IV}_{365}$-values for the stocks in a pair. Thus, the effect is not driven by the difference in short-term IVs alone. This suggests that our effect is distinct from well-established low volatility anomalies such as the low idiosyncratic volatility puzzle. Moreover, it has been shown in the literature that sorting on idiosyncratic volatility only yields significant return differentials over short-term horizons

\footnotetext{
${ }^{4}$ For liquidity reasons, we only use the IVs for at-the-money (ATM) calls.

${ }^{5}$ For a discussion of the robustness of this procedure and the associated summary statistics see Appendix A.

${ }^{6}$ We use monthly return and market capitalization data for actively traded common shares from the Center for Research in Security Prices (CRSP) database. Stocks with a market price of $\$ 1$ or less are excluded in the respective month. Delisting returns are included wherever available. This leaves us with more than 7,100 stocks, which are in the sample for at least one month. On average, there are more than 2,300 stocks in our sample in a month. Data on the monthly risk-free rate are taken from Kenneth French's website. Accounting-related data are taken from the CRSP-Compustat merged database.

${ }^{7}$ This corresponds to equal weighting across pairs. In Appendix A, we discuss different weighting schemes. The results are robust to different choices.

${ }^{8}$ Considering extremely low short-end IV differences of 0.01 to 5 percent, yields a coverage of about $95 \%$ and a significantly positive, but not surprisingly, low average return differential of 0.64 percent. With 15 to 25 percent short-end IV difference yields a coverage of about $20 \%$ and a significant mean return of 3.17 percent.
} 
(Huang et al., 2011) and can be explained by short-term reversals (Fu, 2009). ${ }^{9}$ As shown in Table C.2, the average returns on the trading strategy remain positive for all twelve months within the holding period, with significance waning after about six months. In particular, the returns are largest in the second month after portfolio formation, which suggests that the return differential is not due to short-term reversals.

As further indicated by the numbers in Table 2, the returns on our trading strategy cannot be explained by standard risk factors. As a matter of fact, the strategy exhibits substantial alphas relative to the factor models. Furthermore, the loadings on the factors are not very pronounced. Only for the market factor we obtain a significant coefficient, but it is negative. Appendix A contains further analyses as well as a number of robustness checks for the trading strategy based on pairs. For example, the result is robust to using non-overlapping holding periods which require less trading (see Table C.6 in the appendix), for a variety of different IV cut-off points (Table C.1) and maturities (Table C.5).

We also investigate the combinations of implied volatility term structures in the respective pairs. Table C.7 in the Appendix shows that for the majority of pairs the term structure of the 'late' stock is downward sloping (meaning that the annualized 30-day IV exceeds the 1year IV), while that of the 'early' stock is upward sloping. As expected, the average return difference for these pairs is statistically and economically significant. With the baseline cut-off points, other types of pairs occur rarely, but they all yield positive return differentials. In case of the combination downward sloping/flat, the spread is even significant, despite the small number of stocks.

\subsection{Discussion}

A natural economic interpretation of the profitability of the investment strategy described above is that the observed return difference is a premium for early resolution of uncertainty.

\footnotetext{
${ }^{9}$ Huang et al. (2011) show that when dropping the month after portfolio formation, idiosyncratic volatility strategies do not yield significant returns.
} 
Consider two stocks with the same return variance over the total horizon $T$. If one of the stocks has a higher variance over a short horizon $\tau<T$, it must have lower variance over the period from $\tau$ to $T$. In terms of the timing of uncertainty resolution, this means that the stock with the higher short term variance exhibits early resolution of uncertainty relative to the stock with the lower variance from $t$ to $\tau$. In other words, the variance over a certain time horizon corresponds to the expected resolution of uncertainty over that period. ${ }^{10}$ As we are going to formally derive in the context of a general equilibrium model in Section 5, if the marginal investor exhibits PERU, the expected return on the stock with the later resolution needs to be higher to compensate the investor for having to wait longer until uncertainty is resolved. The fact that the return spread increases in the short-end IV difference is in line with this idea. The more uncertainty is expected to be resolved, the higher the premium that is paid for its late resolution.

In this spirit, the positive return on the investment strategy described above is in line with a positive premium for stocks with a late resolution of uncertainty. Moreover, the negative estimates of market beta from Table 2 point to another interesting aspect. In times of market downturns, returns on our strategy are particularly high. It thus seems that it is especially in these periods, when investors demand a substantial premium for bearing uncertainty for a longer period. This feature can also be seen from Figure 2, which shows the returns on the market and on the investment strategy. For instance, during the two recessions in our sample (marked gray), the investment strategy described above earned substantial positive returns.

The notion that volatility over a certain time interval corresponds to expected resolution of uncertainty refers to volatility under the physical measure $\mathbb{P}$, while IV measures volatility under the risk-neutral measure $\mathbb{Q}$. Our use of IV as a forward looking measure could mean that our result picks up a phenomenon related to cross-sectional differences in the spread between $\mathbb{Q}$ - and $\mathbb{P}$-volatilities. Note that as long as our sort on $\mathbb{Q}$-volatilities yields the same result as a sort on $\mathbb{P}$-volatilities, our approach is entirely innocuous. As shown in greater detail in Section

\footnotetext{
${ }^{10}$ Here, variance includes both diffusive and jump risk.
} 
4.2 , sorting on IV indeed generates a strictly monotonic pattern in (realized) $\mathbb{P}$-volatilities. In line with the literature on the predictive properties of implied volatility, ${ }^{11}$ we find that there is a strong positive relation between IV and realized volatility in our sample. We perform crosssectional regressions of the realized variance, estimated from daily returns over 30 and 365 days, on the respective implied variances over those time horizons. The slope coefficients are always positive, with an average coefficient of 0.45 for 30 days and 0.52 for 365 days and average $R^{2}$ values of 18 and 31 percent, respectively. Finally, to make sure that our results are not driven by individual variance risk premiums, i.e., by the differences between $\mathbb{P}$ - and $\mathbb{Q}$-variances, we control for these premiums in Fama-MacBeth regressions (see Section 4.4).

Apart from the impact of variance risk premiums, IV could deviate from forward looking return volatility (as assessed by stock market participants), when the beliefs of stock and option market participants differ with respect to their volatility assessment over different horizons. The more pronounced these differences between the two groups of investors, the noisier our forwardlooking measure of beliefs about volatility in the stock market will be. Market segmentation in combination with such differences in belief would, however, most likely work against the strong return patterns we find in Table 1. For our results to be in line with a preference for late resolution of uncertainty, it would be necessary that stock market investors have the exact opposite belief concerning the term structure of return variances than option market participants. It seems unlikely that such opposing beliefs are the explanation for our result.

\section{Implied Volatility Duration}

\subsection{Definition}

The trading strategy from the previous section is based on pairs of stocks satisfying the criteria described above with respect to short- and long-term IV. This strategy is a direct way

\footnotetext{
${ }^{11}$ See for example Christensen and Prabhala (1998) and Busch et al. (2011). Poon and Granger (2003) survey the volatility forecasting literature and conclude that forecasting methods that use IV outperform methods that rely on historical volatility, GARCH, or related time series models.
} 
to implement a test for the existence of a premium for the timing of uncertainty resolution that does not require the estimation of a full model (and is in this sense model-free). However, it would nevertheless be preferable to cover a larger share of the overall sample. Moreover, it would be desirable to have a characteristic that directly indicates how early or late uncertainty is expected to be resolved and which can be assigned to every single stock at every point in time.

The characteristic we suggest for this purpose is Implied Volatility Duration (IVD). The IVD of stock $i$ at time $t$, denoted by $\operatorname{IVD}_{i t}$, is defined as follows:

$$
\mathrm{IVD}_{i t}=\sum_{j=1}^{J} \frac{\Delta I V_{i, t, j}^{2}}{\sum_{j=1}^{J} \Delta I V_{i, t, j}^{2}} \cdot \tau_{j}
$$

where $\Delta I V_{t, i, j}^{2} \equiv I V_{i, t, t+\tau_{j}}^{2}-I V_{i, t, t+\tau_{j-1}}^{2}$ is the difference at time $t$ between the (non-annualized) squared IVs for call options maturing at $t+\tau_{j}$ and those maturing at day $t+\tau_{j-1} \cdot{ }^{12}$ We set $\tau_{0}=0$ so that $I V_{i, t, t+\tau_{0}}^{2}=I V_{i, t, t}^{2} \equiv 0$. For our empirical exercise, we use maturities of up to one year available in OptionMetrics, i.e., $J=8$ and $\left(\tau_{1}, \ldots, \tau_{8}\right)=(30,60,91,122,152,182,273,365)$ (days).

The interpretation of IVD is similar to that of the well-known Macaulay duration in the area of fixed income instruments. The denominator of the right-hand side of (1) is simply equal to $I V_{i, t, t+\tau_{J}}^{2}$ (analogous to the bond price as the normalizing quantity in the Macaulay duration), so that the increments $\Delta I V_{i, t, j}^{2}$ are normalized by the implied variance over the total horizon (analogous to the present values of the individual cash flows). We can thus interpret the terms $\frac{\Delta I V_{i, t, j}^{2}}{\sum_{j=1}^{J} \Delta I V_{i, t, j}^{2}}$ as weights for the respective horizon $\tau_{j}$, meaning that IVD is an implied variance-weighted average time over which uncertainty is resolved. If for example the difference between $\mathrm{IV}_{60}^{2}$ and $\mathrm{IV}_{30}^{2}$ makes up 5 percent of total $\mathrm{IV}_{365}^{2}$, then 60 days is assigned a weight of 5 percent in IVD. Comparing IVD across stocks then tells us for which stock uncertainty is expected to be resolved earlier.

\footnotetext{
${ }^{12}$ OptionMetrics reports annualized values, so we multiply the implied variance for options maturing at date $t+\tau_{j}$ by $\tau_{j} / 365$ to undo the annualization.
} 
Figure 3 presents two stylized cases for short and long IVD, representing early and late resolution of uncertainty. The larger the area above the piecewise linear function, the more of the total $\mathrm{IV}_{365}$ comes from longer-term IV, and consequently, the higher IVD.

\subsection{Portfolio sorts}

To investigate how IVD is related to other quantities such as future returns, implied volatility, and other characteristics, we group the stocks in our sample into portfolios according to their IVD. More precisely, at the end of every month we perform an independent double sort of all stocks into 25 portfolios based on IVD and $\mathrm{IV}_{365}$ as a measure for the overall 'amount' of uncertainty.

As shown in Table 3, IVD typically varies between slightly more than 190 and around 220 days, a spread of about one calendar month. While 30 days do not seem large at first sight note that, as an average, it can correspond to pronounced differences in timing of uncertainty resolution. Consider for example two firms A and B whose stock prices evolve as jump diffusions with daily diffusive volatility of 0.01 (corresponding to an annual return volatility of 19.1\%). Over the next year both firms will experience important news, say the possible approval of a drug by the FDA. These decisions cause independent and normally distributed jumps with mean zero and volatility 0.4 in the respective stock price. For firm A, the approval decision will be made deterministically on day 5 while for firm B this will happen deterministically on day 275. Then the IVDs will be about 269 (days) for stock A and 298 for stock B but the decisive events for the stock prices will occur nine months apart.

Across any given column, there is hardly any variation in IVD. An analogous picture emerges for $\mathrm{IV}_{365}$. In general, there is a large variation of this characteristic across stocks with values between 22 and 79 percentage points, but across each individual row in Panel $\mathrm{B}, \mathrm{IV}_{365}$ does not vary much. All in all, this indicates that IVD as a measure of resolution timing is essentially independent of IV as a measure of the level of uncertainty. ${ }^{13}$

\footnotetext{
${ }^{13}$ To investigate this more formally, we compute the correlation coefficient between the two measures for each
} 
We now study the returns on what we call the 'late-minus-early' (LME) portfolios, which are formed in every $\mathrm{IV}_{365}$-quintile by going long 'late' (high IVD) and shorting 'early' (low IVD) stocks. The different panels of Table 4 show value-weighted and equally-weighted returns for the quintile and the LME portfolios over a holding period of twelve months. Our most important finding is that in the quintile of high $\mathrm{IV}_{365}$ stocks, returns on the LME portfolio are significantly positive and large for both weighting schemes. For example, Panel A shows that forming a new value weighted LME portfolio from high $\mathrm{IV}_{365}$ stocks every month and holding this portfolio for twelve months results in a statistically significant average return of more than seven percent per year. In the spirit of the discussion so far, we interpret this significantly positive average return on the LME portfolio as a premium for the early resolution of uncertainty. The premium becomes even more pronounced when we consider stocks with even higher $\operatorname{IV}_{365}$. The average return on the LME portfolio held for 12 months is about 10 percent in the top $\mathrm{IV}_{365}$-decile, and 13 percent when we consider the five percent of stocks with the highest $\operatorname{IV}_{365}$ (not tabulated).

For stocks with low overall uncertainty, the timing of uncertainty resolution is obviously not as relevant, so one would not expect a pronounced premium for early resolution in the first place. This is indeed what we find: For the quintiles of stocks with lower $\mathrm{IV}_{365}$, the return differential between late and early resolution stocks is not significant. In our model in Section 5, we also only find strong return differentials among highly volatile stocks.

Table 5 shows the returns on portfolios double sorted on market beta and IVD. The distinction between systematic (undiversifiable) risk and idiosyncratic, i.e., (at least theoretically) diversifiable risk is broadly discussed in the literature. IV could potentially pick up cross-sectional variation in both of these risks. Table 5 shows that the return differences across stocks with different IVD can also be observed when conditioning on a high level of purely systematic risk, as measured by market betas. Although smaller in magnitude compared to the results in Table 4, the LME portfolio in the top beta quintile has significantly positive mean returns. This corroborates our results from Table 4.

month in our sample. The time-series average of these correlation coefficients is close to zero. 
The results in Table 6 further support the view that it is not the absolute amount of risk, but rather the timing of its resolution that matters. Like in the case of a 12-month holding period, value-weighted and equally-weighted LME returns in the highest $\mathrm{IV}_{365}$-quintile are significantly positive also over a horizon of one month. If one ignored the effect of timing preferences, one could expect a negative sign for this return differential, since early resolution stocks have higher short term uncertainty than late resolution stocks.

As discussed above, the use of $\mathbb{Q}$-volatilities as a forward-looking measure for uncertainty under physical probabilities is based on the conjecture that $\mathbb{P}$ - and $\mathbb{Q}$-volatilities are closely related in the cross-section. Table 7 shows the realized return variances for our 25 doublesorted portfolios. Most importantly, realized variances increase monotonically in $\mathrm{IV}_{365}$, showing that IV indeed predicts realized variance. Furthermore, we expect early resolution stocks to have higher realized variances over the first month than their late resolution counterparts in a given IV group, and this is indeed the case. ${ }^{14}$ Over 12 months, on the other hand, realized variances should be roughly the same for the late and early resolution portfolios, and this is also supported by the data. ${ }^{15}$

As suggested by the above results and discussed in more detail in Section 4.3, $\mathrm{IV}_{365}$ is strongly related to measures of systematic risk. However, just as in the case of the trading strategy based on pairs, standard factor models are not able to explain the high returns on the LME portfolio within the high $\mathrm{IV}_{365}$ quintile. The alphas in the regressions presented in Table 8 are large and statistically significant. As before, there are only very few significant loadings across the different specifications. The only exception is the market factor, on which LME loads negatively, albeit with an insignificant coefficient in the case of the Fama and French (2015) five factor model.

\footnotetext{
${ }^{14} \mathrm{An} F$-test rejects the null hypothesis of equal variances of the late and early portfolio in the highest IV quintile for the one month holding period for both equally and value-weighted returns.

${ }^{15}$ The null hypothesis of equal variances cannot be rejected based on Levene's test with $p$-values of 0.76 and 0.57 for value-weighted and equally weighted returns, respectively. The $F$-test is not applicable here, since 12-month returns in successive months overlap to a large degree.
} 


\subsection{Portfolio characteristics}

Panel A in Table 9 displays a number of descriptive statistics for the five IVD-sorted portfolios in the top $\mathrm{IV}_{365}$ quintile, while the last column shows the time series average of the cross-sectional median of each characteristic over the entire sample. ${ }^{16}$ The betas of these portfolios with respect to standard risk factors are shown in Panel B.

As expected, $\mathrm{IV}_{365}$ is related to a number of other characteristics. In line with our discussion in Section 4.2, market betas in the high IV quintile are substantially greater than 1 , indicating that high implied volatility proxies for high systematic uncertainty. High $\mathrm{IV}_{365}$ stocks also tend to have relatively low market capitalization and high book-to-market ratios (both indicating high expected returns). On the other hand, however, they exhibit low profitability and high investment (indicating low expected returns). This is mirrored in the corresponding factor betas of the stocks in the high IV quintile portfolios. SMB and HML betas are positive, CMA and RMW betas negative. Taking all this together, it does not seem surprising that, as shown in Tables 4 and 6, high IV stocks do not have significantly higher average returns than low IV stocks. In general, a stock with a strong absolute exposure to a risk factor has high IV ceteris paribus. Depending on the market price of factor risk the expected return on that stock can be higher or lower than the expected return on a stock without exposure to the factor. The common intuition that more volatile stocks should have higher expected returns can be misleading. For example, Kogan and Papanikolaou (2014) discuss investment-specific technology shocks which have a negative market price of risk. In case of these shocks, more volatile stocks have lower expected returns. Notwithstanding the sign of the respective market price of risk, IV constitutes a measure of overall uncertainty and an investor with PERU wants all uncertainty to be resolved early, irrespective of the sign of the market price of risk.

Importantly, there is hardly any variation in risk characteristics in the IVD-dimension within the top $\mathrm{IV}_{365}$ quintile. Thus, these characteristics cannot explain the return differential

\footnotetext{
${ }^{16}$ Table C.10 in the Internet Appendix provides details about the construction and the data sources of the different characteristics.
} 
between the late and early resolution high $\mathrm{IV}_{365}$ stocks.

Some features of the stocks in the high IV quintile, however, merit further discussion. For example, given that IVD is a duration-based uncertainty measure, it appears natural to look at the relation between this characteristic and cash-flow duration (CFD). Table 9 shows that there is no systematic variation in CFD, computed as in Weber (2018), along the IVD dimension. In the end this result is not that surprising, given that IVD is based on second moments, while CFD measures first moments, to provide an estimate of the average dividend payout date.

High implied volatility stocks also have high idiosyncratic volatility as measured relative to the Fama and French (1992) three factor model. Because short IVD stocks tend to have high $\mathrm{IV}_{30}$ which includes idiosyncratic volatility, it is not surprising that idiosyncratic volatility decreases in IVD. Table C.11 in the Internet Appendix shows the average idiosyncratic volatility for each of the IV-IVD double sorted portfolios. Idiosyncratic volatility differences are much more pronounced across the IV quintiles than within IV quintiles in the IVD dimension. In Section 4.4 below, by controlling for idiosyncratic volatility in cross-sectional regressions, we provide further support for our claim that the return differential between late and early stocks is not driven by an idiosyncratic volatility effect.

In Table 9 we also report two versions of the variance risk premium for the five IVD portfolios in the top IV quintile. The ex ante measure is computed as the difference between the realized return variance (estimated from daily returns and scaled appropriately) over the previous month and the squared implied volatility at the end of that month. The realized version uses the same squared implied volatility, but the realized variance is computed over the next instead of the previous month.

Variance risk premiums are decreasing in absolute value with increasing IVD. This is not surprising. Among high $\mathrm{IV}_{365}$ stocks, those with a higher $\mathrm{IV}_{30}$ are typically sorted into the short IVD portfolio. Thus, if the 30-day variance risk premium is high (in absolute terms) for high $\mathrm{IV}_{30}$ stocks, then a shorter IVD is related to a more negative variance risk premium. Below, we show that variance risk premiums do not drive our results. 
$\mathrm{SIR}_{\mathrm{IO}}$ is the ratio of short interest over institutional ownership as computed in Drechsler and Drechsler (2016) and serves as a proxy for shorting fees. We find that stocks in the top $\mathrm{IV}_{365}$ quintile tend to have high $\mathrm{SIR}_{\mathrm{IO}}$. Drechsler and Drechsler (2016) show that stocks with higher shorting fees have lower average returns. However, just as many other characteristics, the spread in average $\mathrm{SIR}_{\mathrm{IO}}$ within the high $\mathrm{IV}_{365}$ quintile is very small compared to the spread across $\mathrm{IV}_{365}$ quintiles. Moreover, there is no monotonic pattern within the top $\mathrm{IV}_{365}$ quintile. This is consistent with the finding in Drechsler and Drechsler (2016) that shorting fees are a persistent characteristic of stocks whereas IVD is a rather transitory feature (see below). Importantly, the low IVD portfolio has lower $\mathrm{SIR}_{\mathrm{IO}}$ (and thus presumably lower shorting fees) than the late portfolio, which, given the results in Drechsler and Drechsler (2016), should imply a lower return for the late portfolio. We further address this issue in Section 4.4 below.

We also study if stocks from certain industries are more prevalent in some portfolios than in others. Table C.9 shows the relative number of stocks within industries as classified by Fama and French. Similar to many of the firm characteristics discussed above, there is not much variation in industry classification across IVD portfolios, but rather marked patterns in terms of IV in turn. For example, stocks in the high-tech industry are overrepresented in the top IV quintile, which is in line with our notion of IV being an uncertainty measure.

In Panel B of Table 9, we report factor betas for the IVD quintile portfolios. Similar to the investment strategy based on pairs, discussed in Section 3, there is a negative relation between IVD and market betas, which makes the high positive returns on the LME portfolio even more striking. The other betas do not exhibit any pronounced pattern across IVD sorted portfolios. This suggests that the return differential between late and early resolution stocks is not due to differences in the exposure to known risk factors.

Table 10 shows the migration of stocks across IVD quintile portfolios for both the entire sample and the stocks in the top IV quintile. The timing of uncertainty resolution appears to be a rather transitory characteristic. All relative frequencies in Table 10 are below 0.5, which means that the average stock is more likely to move out of a given portfolio by the end of the 
month than to remain there. In line with this, we do not find pronounced relations between IVD and other, more persistent characteristics (see Table 9). An early resolution stock can become a late resolution stock as soon as uncertainty-resolving information arrives. Likewise, a late can become an early resolution stock, as the time of uncertainty resolution draws near. If there is something like an early resolution premium, stocks will only trade at a discount for as long as they exhibit late resolution.

\subsection{IVD and the cross section of returns}

We now study if the variation in IVD can explain cross-sectional variation in expected returns by running monthly Fama-MacBeth regressions of single stock excess returns on a number of characteristics as well as on IVD. In Section 4.2 we found that the return differential between late and early resolution stocks is higher for stocks with higher uncertainty as measured by $\mathrm{IV}_{365}^{2}$. To take this into account, we consider the interaction term $\operatorname{IVD} \times \operatorname{IV}_{365}^{2}$ as a characteristic.

The results of the Fama-MacBeth regressions are presented in Table 11. The interaction term between IVD and $\mathrm{IV}_{365}^{2}$ is highly significant and explains cross-sectional variation in expected returns. Concerning economic significance, multiplying an estimated coefficient for the characteristic of 0.05 percent by the average implied variance in the top $\mathrm{IV}_{365}$ quintile of around $0.77^{2} \approx 0.6$ (see Table 9 ) yields a value of 0.03 percent. I.e. an increase in IVD of one day ceteris paribus leads to a higher abnormal return of three basis points per month. The average IVD-spread between the high and the low IVD quintile in our sample is around 30 days (see again Table 9), implying a return difference of around one percent per month between the quintile portfolios, which is well in line with the findings presented in Section 4.2.

To control for possible differences in the variance risk premiums of stocks with high and low $\mathrm{IVD} \times \mathrm{IV}^{2}$, we include measures of the stock-specific variance risk premium for different maturities. As can be seen in Table C.12 in the Internet Appendix, this does not change our results. The coefficient of the interaction term remains practically the same, with respect to 
both magnitude and significance.

As pointed out in the previous subsection, 30 day idiosyncratic volatility is higher for early than for late resolution stocks. In the Internet Appendix, we present the results of the Fama-MacBeth regression when controlling for idiosyncratic volatility (Table C.13) and idiosyncratic variance (Table C.14) in a variety of specifications. In light of the results of Stambaugh et al. (2015), we interact idiosyncratic variance (volatility) with (a function of) the authors' mispricing characteristic MISP. As Stambaugh et al. (2015) show, the effect of idiosyncratic volatility on expected return changes sign in mispricing (negative for overvalued stocks and positive for undervalued stocks). In the baseline setting, to maintain our linear framework, we simply demean MISP such that idiosyncratic volatility is interacted with a negative value for undervalued stocks and with a positive value for overvalued stocks. ${ }^{17}$ Given the results of Stambaugh et al. (2015), we would expect a negative coefficient of IVol $\times$ MISP, and this is indeed what we obtain. However, including this characteristic (or including IVol or IVar alone) leaves our results significant and qualitatively unaltered.

As a further robustness check, we repeat the double sort of stocks on $\mathrm{IV}_{365}$ and IVD for the 20 percent of stocks with the lowest Stambaugh et al. (2012) mispricing measure (which the authors of that paper labeled "most underpriced" stocks). As shown in Stambaugh et al. (2015), for these stocks, the relation between idiosyncratic volatility and expected returns is positive, i.e., higher idiosyncratic volatility is related to higher rather than lower expected returns. As can be seen from Table C.15 in the Internet Appendix, a positive premium for early resolution in the top IV quintile still prevails, even though the idiosyncratic volatility effect would suggest the opposite return differential in this particular subsample. ${ }^{18}$

Stocks with high implied volatility tend to be stocks which are expensive to short as indicated by the high values of $\mathrm{SIR}_{\mathrm{IO}}$ in this quintile relative to the total sample. Drechsler and Drechsler (2016) show that stocks that are expensive to short have on average lower returns

\footnotetext{
${ }^{17}$ Using piecewise linear functions of the form $f(\mathrm{MISP})=\mathbb{1}_{\theta_{i} \leq \mathrm{MISP} \leq \theta_{i+1}}\left(a_{i}+b_{i} \cdot \mathrm{MISP}\right)$ for different sets of cutoffs $\theta_{i}$, intercepts $a_{i}$ and slope coefficients $b_{i}$ calibrated to the results in Stambaugh et al. (2015) yields similar results and leaves the coefficient of $\mathrm{IV}^{2} \times \mathrm{IVD}$ unaltered.

${ }^{18}$ We thank Robert Stambaugh for suggesting this robustness check.
} 
to compensate arbitrageurs for the risks involved in shorting stocks, i.e. the low returns of expensive-to-short stocks constitute a systematic risk premium. With respect to our results, the important point is that - unlike for the anomalies considered in Drechsler and Drechsler (2016) - it is not the case that stocks in the short leg of the LME portfolio (early stocks) are substantially more difficult to short than those in the long leg. If anything, the average values of SIR $_{\text {IO }}$ would suggest the opposite (see Table 9). In other words, given the characteristics of the stocks in the top IV quintile, the 'shorting premium' documented in Drechsler and Drechsler (2016) would not imply the return differential between late and early stocks that we observe.

As a further test whether our results are driven by the shorting premium, we control for our sample equivalent of Drechsler and Drechsler's E-factor that serves as a factor-mimicking portfolio for the shorting premium risk factor (see Table C.16 in the Internet Appendix). We moreover include for a proxy version of the authors' cheap-minus-expensive (CME) factor, where, instead of sorting on the unavailable shorting fee data we sort on the proxy $\mathrm{SIR}_{\mathrm{IO}}$ (see Table C.17 in the Internet Appendix). Both robustness checks leave our results unaltered, suggesting that the return differential we find is not driven by the shorting premium.

\section{Rationalizing the early resolution premium}

\subsection{Model}

In the following we analyze the impact of timing preferences on cross-sectional expected return variation in the context of a general equilibrium model. In order to model non-trivial uncertainty resolution, one needs to introduce somewhat more involved consumption and dividend dynamics. We do this in the popular way by modeling conditional means and variances as first-order autoregressive processes. We show that a preference for early resolution of uncertainty in the sense of Epstein and Zin (1989) generates a return differential between late and early resolution stocks. The model solution is described in detail in Appendix B. 
Consider an agent with preferences described by the recursive value function

$$
U_{t}=\left[\left(1-e^{-\delta}\right) C_{t}^{1-\frac{1}{\psi}}+e^{-\delta}\left(E_{t}\left[U_{t+1}^{1-\gamma}\right]\right)^{\frac{1-\frac{1}{\psi}}{1-\gamma}}\right]^{\frac{1}{1-\frac{1}{\psi}}} .
$$

Here, $\gamma, \psi$, and $\delta$ denote the agent's coefficient of relative risk aversion, her elasticity of intertemporal substitution, and her time preference parameter, respectively. In the case $\gamma=\frac{1}{\psi}$, the above specification reduces to time-additive CRRA preferences.

Log consumption growth exhibits the following dynamics:

$$
\Delta c_{t+1}=\mu_{c}+\sum_{i=1}^{n} \phi_{c i} x_{i, t}+\sigma_{c} \varepsilon_{t+1}^{c},
$$

The processes $x_{i}$ are state variables modeling different cycles. Their dynamics are given as

$$
x_{i, t+1}=\rho_{i} x_{i, t}+\sqrt{v_{i, t}} \varepsilon_{t+1}^{i} .
$$

Our model is similar to the long-run risk model of Bansal and Yaron (2004). The major difference is that we consider multiple cycles instead of just one. The focus of the long-run risks model is on aggregate consumption and dividend claims, not on the cross-section of firms. Our approach to introduce a cross-section in the model is to allow firms' cash flows to depend to different degrees on different cycles. As an example, certain firms may benefit more from innovations in certain production technologies than others.

The time-varying volatilities have dynamics

$$
v_{i, t+1}=\bar{v}+\rho_{v}\left(v_{i, t}-\bar{v}\right)+\sigma_{v} \varepsilon_{t+1}^{v i} .
$$

For simplicity, we assume that all innovations $\varepsilon$ are i.i.d. standard normal. Furthermore, the economic uncertainties (i.e., time-varying volatilities) $v_{i}$ associated with the different cycles have the same long-run mean $\bar{v}$, persistence $\rho_{v}$, and volatility $\sigma_{v}$. These assumptions can easily 
be generalized and would not change our conclusions qualitatively. The difference between the cycles is their persistence, i.e. the innovations to a given cycle $i$ can have a more transitory or a longer-lasting effect on aggregate consumption, depending on the respective persistence $\rho_{i}$. Real life examples of such processes $x_{i}$ are business cycles in different sectors, political cycles, and innovation waves in different industries.

In our model, all uncertainty is "bad", with the implication that more volatile stocks have higher expected returns in equilibrium. We assume this structure for simplicity. In reality, there is likely also "good" uncertainty, such that stocks with an exposure to the respective shocks should command lower risk premiums (see Bekaert and Engstrom, 2017; Segal et al., 2015). Such a structure would be in line with our results from Section 4.3, where we found that high IV stocks do not necessarily have higher expected returns. Irrespective of the kind of uncertainty, an agent with PERU prefers an early resolution.

We assume that firm $j$ pays dividends $d^{j}$ with dynamics

$$
\Delta d_{t+1}^{j}=\mu_{j}+\sum_{i=1}^{n} \phi_{j i} x_{i, t}+\sigma_{j} \varepsilon_{t+1}^{j}
$$

where the innovations $\varepsilon_{t+1}^{j}$ are mutually independent and independent of the innovations in consumption and the state variables. For each asset $j$, representing the claim on dividend $d^{j}$, we calculate the conditional term structure of expected excess returns:

$$
\mathbb{E}_{t}\left[r_{t \rightarrow t+\tau}^{j}-r_{t \rightarrow t+\tau}^{f}\right]+\frac{1}{2} \operatorname{Var}_{t}\left(r_{t \rightarrow t+\tau}^{j}\right)=\pi_{0, \tau}^{j}+\sum_{i=1}^{n} \pi_{i, \tau}^{j} v_{i, t} .
$$

Here, $r_{t \rightarrow t+\tau}^{j}$ denotes the $\log$ return on asset $j$ between time $t$ and time $t+\tau$, and $r_{t \rightarrow t+\tau}^{f}$ is the corresponding risk-free rate. The conditional term structure of return variances is given by

$$
\operatorname{Var}_{t}\left(r_{t \rightarrow t+\tau}^{j}\right)=\chi_{0, \tau}^{j}+\sum_{i=1}^{n} \chi_{i, \tau}^{j} v_{i, t}
$$

The coefficients $\pi_{0}^{j}$ and $\pi_{i}^{j}$, as well as $\chi_{0}^{j}$ and $\chi_{i}^{j}$ are determined in equilibrium and their deriva- 
tions are shown in Appendices B.3 and B.4. Qualitatively, these coefficients are functions of the exposures $\phi_{j i}$ of asset $j$ 's dividend stream to innovations in cycle $i$, and the persistence $\rho_{i}$ of cycle $x_{i}$.

Equation (8) allows us to calculate asset $j$ 's implied volatility duration and, using Equation (7), we can investigate the relation between IVD and expected returns over different horizons in the cross-section of firms. In the context of the model, we consider $\mathbb{P}$-volatilities instead of implied (i.e., $\mathbb{Q}-$ ) volatilities. The difference between these two types of volatilities is negligible in our model, since variance risk premiums are virtually zero in long-run risk models without jumps (see Drechsler and Yaron, 2011).

As a direct implication of Equation (8), IVD is only a function of the variances, but not of the levels of the cycles. If a stock's dividends are particularly sensitive to cycle $i$, that stock's IVD is relatively high in periods when the variance of cycle $i$ is above its steady state. In contrast, the cash-flow duration (CFD) of this stock is a function of the level, i.e. $x_{i}$, but not the variance of cycle $i$. In empirical applications, the CFD is calculated in such a way that expected cash flows are discounted with the same discount rate over all periods and all assets. Given this procedure, it is apparent that CFD is only a function of expected dividends, i.e. the level of the cycles, but not of their variances. Thus, since $x_{i}$ and $v_{i}$ are assumed to be uncorrelated, the model implies that IVD and CFD are not correlated either. ${ }^{19}$

\subsection{Calibration}

To exemplify the main mechanism, we choose a parsimonious specification of the model with only two cycles, denoted by $x_{\text {tran }}$ and $x_{\text {pers }}$, where the latter is more persistent than the former. Our calibration follows Bansal et al. (2012), and the model parameters are shown in Table 12. We choose $\phi_{c, \text { tran }}=\phi_{c, \text { pers }}=\frac{1}{\sqrt{2}}$ to match the unconditional consumption growth

\footnotetext{
${ }^{19}$ Appendix B.5 discusses an alternative definition of the CFD that uses the price of the dividend strip for a particular period, divided by the stock price, as a weight for that period. We find in a numerical application that also for this version of the CFD it is true that the levels of the cycles have a significant influence on the dynamic behavior of CFD, while the impact of variances is negligible.
} 
variance of Bansal et al. (2012). One notable difference is that the persistence of the variance processes is lower than in their calibration which causes the variances to mean-revert more quickly to their steady state. At the same time, the persistence levels of the growth rates are high and vary across cycles with $\rho_{\text {tran }}=0.98$ and $\rho_{\text {pers }}=0.99$. These parameters allow us to match the unconditional equity premium. Qualitatively, it is only important that the cycles differ in terms of their persistence parameters.

For illustrative purposes, we consider two generic dividend claims, denoted by $e$ and $l$. The two claims differ with respect to their exposure to either the persistent or the more transitory cycle. In particular, there is one "early" claim $e$, for which we set $\phi_{e, p e r s}=\phi_{c, p e r s} / \psi$. This causes the price dividend ratio of this claim to only depend on shocks to the transitory cycle (for details see Appendix B.2). Analogously, the price of the "late" claim $l$ only moves with innovations in the persistent cycle.

We now consider a situation in which the persistent cycle is currently in a rather calm state, in particular $v_{\text {pers }, t}=0.9 \bar{v}$. We set the time $t$ variance of the transitory cycle to

$$
v_{\text {tran }, t}=\frac{\chi_{0,12}^{l}-\chi_{0,12}^{e}+\left(\chi_{\text {pers }, 12}^{l}-\chi_{\text {pers }, 12}^{e}\right) v_{\text {pers }, t}}{\chi_{\text {tran }, 12}^{e}-\chi_{\text {tran }, 12}^{l}}
$$

which makes the 12-month return variances of the two claims equal to each other.

The upper graph in Figure 4 shows the time $t$-conditional term structure of return volatilities. By construction, the volatilities of one year returns on the late and early claim are the same, but for shorter horizons, the return volatility of the early claim is higher. At time $t$, the two claims are a candidate pair for the investment strategy described in Section 3. Taking a look at the IVDs of the different claims, we find that the IVD of the early (late) claim is lower (higher) than in the steady state to which both claims will eventually return. Our model thereby highlights the important notion that IVD is a temporary characteristic of an asset. Claim $e$ is an early claim now at time $t$ because of the currently high uncertainty about the cycle that this claim is exposed to. With more cycles (i.e., when $n \gg 2$ ), there will always be 
a number of processes, for which the associated time-varying uncertainty is currently rather high, while it is low for others.

We now take a closer look at the expected returns on the different claims. Expected returns, conditional on $v_{\text {tran,t }}$ and $v_{\text {pers }, t}$ as described above, are shown in the lower graph in Figure 4 . We find that expected returns on the late claim clearly exceed expected returns on the early claim. This is true for the 12-month horizon, over which the return volatilities are equal, but also for shorter horizons, over which the return volatility of the early claim is higher than that of the late claim.

It is of key interest to analyze how this early resolution premium depends on the investor's timing preferences. Panel A of Figure 5 shows the spread between expected returns on the late and the early claim for different values of the risk aversion parameter, keeping the elasticity of intertemporal substitution fixed at 1.5. For risk aversion coefficients below 1.1 (for annual returns) and 2.2 (for monthly returns), the return spread between the late and the early claim is negative. Given these parameters, the agent has a preference for late resolution (if $\gamma<\psi^{-1}$ ) or a (weak) preference for early resolution of uncertainty (if $\gamma>\psi^{-1}$ ). In the latter case, she still requires a higher expected return on the early claim because it is actually riskier over short horizons. This effect is counterbalanced by the impact of the agent's preference for early resolution of uncertainty once the difference between $\gamma$ and $\psi^{-1}$ becomes larger, resulting in a positive expected return on the LME portfolio.

Panel B Figure 5 shows the spread as a function of $\psi^{-1}$, the inverse IES, keeping risk aversion fixed at 10. The smaller the inverse IES, the stronger is the agent's PERU, resulting in a larger return spread between the late and early claim. ${ }^{20}$

Finally, Panel C of Figure 5 shows the spread between late and early resolution stocks as a function of the return volatility of the two claims over 12 months. In our empirical analysis in Section 4.2, we found a significant return spread only among volatile stocks. To analyze the relationship between return volatility and return spreads in the model, we vary the return

\footnotetext{
${ }^{20}$ The model does not converge for values of the inverse IES larger than 1 and for very small values of $\gamma$. In these cases, the price dividend ratio of one or several claims diverges.
} 
variance by varying the leverage parameter of the two claims. In particular, we leave $\phi_{e, p e r s}$ and $\phi_{l, \text { tran }}$ unchanged but vary $\phi_{e, t r a n} \equiv \phi_{l, p e r s}$ in Equation (6). Higher leverage parameters lead to higher return variances, with the standard choices of the leverage parameters (see Table 12) corresponding to an annual return variance of $17.8 \%$ (see Figure 4) for the two claims. We find that the expected return spread between the late and early claim is almost linearly increasing in the return volatility. For stocks with return volatilities below $15 \%$ annually, the return spread is close to zero, just as in the data. When return volatilities exceed 30\%, we find return spreads as high as $7 \%$ per year.

Overall, the model is able to explain the return spread between late and early resolution stocks, both qualitatively and quantitatively. It produces the empirical patterns that we have documented in Section 4. The IVD of a stock is a temporary characteristic, it varies over time and it is not related to the stock's CFD. The return difference between late and early resolution stocks is particularly pronounced among volatile stocks and disappears among less volatile stocks. Most importantly, the model suggests that a preference for early resolution of uncertainty is necessary to generate a positive return spread.

\section{Conclusion}

Using implied volatilities of different maturities, we categorize single stocks as exhibiting late or early resolution of uncertainty. We find that late resolution stocks compensate investors with a premium of more than five percent per year.

We introduce Implied Volatility Duration (IVD) as a novel measure for the timing of uncertainty resolution. Portfolio double sorts with respect to the 365-day implied volatility and IVD result in an average return of the long-short position of more than seven percent for a holding period of one year in the highest implied volatility quintile. We interpret this differential in average returns as a premium for early resolution of uncertainty, since stocks with a short IVD can be interpreted as exhibiting early resolution of uncertainty, while the opposite is true for 
stocks with a longer IVD. Economically, this means that investors are willing to pay a premium of around seven percent a year to know about the return on their investments earlier. The return on the above long-short portfolio, which we call the 'late-minus-early' (LME) portfolio, is larger in times of market downturns. In other words, it is particularly in bad times, when investors require compensation for having to bear uncertainty for longer.

We propose a general equilibrium model to rationalize our findings. We show that in order to generate a pronounced spread between expected returns on the late and early resolution claim the investor must have a marked preference for early resolution of uncertainty, i.e., the riskaversion coefficient must exceed the inverse of the elasticity of intertemporal substitution by a sizable amount.

We thus provide empirical evidence consistent with a substantial preference for early resolution of uncertainty (PERU). As opposed to earlier work, we draw conclusions based on prices of financial assets rather than the behavior of individuals in lab experiments or parameter estimates based on macro or survey data. Because PERU on part of the marginal investor is of great importance in asset pricing, and price data is inevitably linked to the preferences of the marginal investor, we believe that our evidence is particularly valuable. 


\section{References}

Ahlbrecht, M., Weber, M., 1996. The resolution of uncertainty: An experimental study. Journal of Institutional and Theoretical Economics 152, 593-607.

Ai, H., Bansal, R., 2018. Risk preferences and the macroeconomic announcement premium. Econometrica 86, 1383-1430.

Amihud, Y., 2002. Illiquidity and stock returns: Cross-section and time-series effects. Journal of Financial Markets 5, 31-56.

An, B., Ang, A., Bali, T., Cakici, N., 2014. The joint cross section of stocks and options. Journal of Finance 69, 2279-2337.

Ang, A., Hodrick, R., Xing, Y., Zhang, X., 2006. The cross-section of volatility and expected returns. Journal of Finance 61, 259-299.

Attanasio, O., Weber, G., 1989. Intertemporal Substitution, Risk Aversion and the Euler Equation for Consumption. Economic Journal 99, 59-73.

Bansal, R., Kiku, D., Yaron, A., 2012. An empirical evaluation of the long-run risks model for asset prices. Critical Finance Review 1, 183-221.

Bansal, R., Yaron, A., 2004. Risks for the long-run: A potential resolution of asset pricing puzzles. Journal of Finance 59, 1481-1509.

Bekaert, G., Engstrom, E., 2017. Asset return dynamics under habits and bad environmentgood environment fundamentals. Journal of Political Economy 125, 713-760.

Brennan, M., Huh, S., Subrahmanyam, A., 2013. An analysis of the amihud illiquidity premium. Review of Asset Pricing Studies 3, 133-176.

Brown, A., Kim, H., 2014. Do individuals have preferences used in macro-finance models? an experimental investigation. Management Science 60, 939-958.

Busch, T., Christensen, B., Ørregaard Nielsen, M., 2011. The role of implied volatility in forecasting future realized volatility and jumps in foreign exchange, stock, and bond markets. Journal of Econometrics 160, 48-57.

Buss, A., Vilkov, G., 2012. Measuring equity risk with option-implied correlations. Review of Financial Studies 25, 3113-3140.

Christensen, B., Prabhala, N., 1998. The relation between implied and realized volatility. Journal of Financial Economics 50, 125-150.

Crump, R., Eusepi, S., Tambalotti, A., Topa, G., 2015. Subjective intertemporal substitution. FRB of New York Staff Report 734. 
D'Acunto, F., Hoang, D., Weber, M., 2016. The effect of unconventional fiscal policy on consumption expenditure. No. w22563. National Bureau of Economic Research.

Dechow, P., Sloan, R., Soliman, M., 2004. Implied equity duration: A new measure of equity risk. Review of Accounting Studies 18, 197-228.

Drechsler, I., Drechsler, Q., 2016. The shorting premium and asset pricing anomalies. No. w20282. National Bureau of Economic Research.

Drechsler, I., Yaron, A., 2011. What's vol got to do with it. Review of Financial Studies 24, $1-45$.

Epstein, L., Farhi, E., Strzalecki, T., 2014. How much would you pay to resolve long-run risk? American Economic Review 104, 2680-2697.

Epstein, L., Zin, S., 1989. Substitution, risk aversion, and the temporal behaviour of consumption and asset returns. Econometrica 57, 937-969.

Epstein, L., Zin, S., 1991. Substitution, risk aversion, and the temporal behavior of consumption and asset returns: An empirical analysis. Journal of Political Economy 99, 263-286.

Fama, E., French, K., 1992. The cross-section of expected stock returns. Journal of Finance 47, 427-465.

Fama, E., French, K., 1996. Multifactor explanations of asset pricing anomalies. Journal of Finance 51, 55-84.

Fama, E., French, K., 2015. A five-factor asset pricing model. Journal of Financial Economics $116,1-22$.

Fu, F., 2009. Idiosyncratic risk and the cross-section of expected stock returns. Journal of Financial Economics 91, 24-37.

Hall, R., 1988. Intertemporal Substitution in Consumption. Journal of Political Economy 96, $339-57$.

Havránek, T., 2015. Measuring intertemporal substitution: The importance of method choices and selective reporting. Journal of the European Economic Association 13, 1180-1204.

Huang, W., Liu, Q., Rhee, S., Zhang, L., 2011. Another look at idiosyncratic volatility and expected returns. Journal of Investment Management 4, 26-51.

Jagannathan, R., Liu, B., 2019. Dividend dynamics, learning, and expected stock index returns. Journal of Finance 74, 401-448.

Johnson, T., 2017. Risk premia and the vix term structure. Journal of Financial and Quantitative Analysis 52, 2461-2490. 
Kogan, L., Papanikolaou, D., 2014. Growth opportunities, technology shocks, and asset prices. Journal of Finance 69, 675-718.

Meissner, T., Pfeiffer, P., 2018. Measuring preferences over the temporal resolution of consumption uncertainty. Unpublished working paper. Maastricht University.

Newey, W., West, K., 1987. A simple, positive semi-definite, heteroskedasticity and autocorrelation consistent covariance matrix. Econometrica 55, 703-708.

Poon, S., Granger, C., 2003. Forecasting volatility in financial markets: A review. Journal of Economic Literature 41, 478-539.

Segal, G., Shaliastovich, I., Yaron, A., 2015. Good and bad uncertainty: Macroeconomic and financial market implications. Journal of Financial Economics 117, 369-397.

Stambaugh, R., Yu, J., Yuan, Y., 2012. The short of it: Investor sentiment and anomalies. Journal of Financial Economics 104, 288-302.

Stambaugh, R., Yu, J., Yuan, Y., 2015. Arbitrage asymmetry and the idiosyncratic volatility puzzle. Journal of Finance 70, 1903-1948.

Stambaugh, R., Yuan, Y., 2016. Mispricing factors. Review of Financial Studies 30, 1270-1315.

Strzalecki, T., 2013. Temporal resolution of uncertainty and recursive models of ambiguity aversion. Econometrica 81, 1039-1074.

Thimme, J., 2016. Intertemporal substitution in consumption: A literature review. Journal of Economic Surveys 31, 226-257.

Vissing-Jørgensen, A., Attanasio, O., 2003. Stock-market participation, intertemporal substitution, and risk-aversion. American Economic Review 93, 383-391.

Wachter, J., 2013. Can time-varying risk of rare disasters explain aggregate stock market volatility? Journal of Finance 68, 987-1035.

Weber, M., 2018. Cash flow duration and the term structure of equity returns. Journal of Financial Economics 128, 486-503.

Xie, C., 2014. Asset pricing implications of volatility term structure risk. Unpublished working paper. Columbia University, New York. 


\section{Table 1: Returns on investment strategy}

\begin{tabular}{ccc} 
Low $\mathrm{IV}_{30}$ & High $\mathrm{IV}_{30}$ & Investment strategy \\
\hline $10.86^{* *}$ & 5.70 & $5.17^{* * *}$ \\
$(2.06)$ & $(0.97)$ & $(3.10)$ \\
\hline
\end{tabular}

The table shows the average returns on the trading strategy based on pairs. Pairs are formed such that the values for $\mathrm{IV}_{365}$ of the two stocks in a pair do not differ by more than one percentage point, while $\mathrm{IV}_{30}$ must differ by at least 25 percentage points. The positions are held over the subsequent 12 months. Numbers in parentheses are Newey-West $t$-statistics with 12 lags. The sample period is 01/1996 to $12 / 2014$. The exact composition of the pairs and, consequently, the return of the strategy depend on the order in which stocks are considered for the formation of pairs (see Appendix A for details). We perform the strategy with 50,000 candidate permutations and report the median return here. For all 50,000 permutations, the investment strategy yields significantly positive returns. For more information about the distribution of returns across permutations, see Tables C.3 and C.4 in the Internet Appendix. 
Table 2: Investment strategy: factor loadings and alphas

\begin{tabular}{ccccccc}
$\alpha$ & MKT & SMB & HML & RMW & CMA & $\mathrm{R}^{2}$ \\
\hline $6.42^{* * *}$ & $-0.15^{* *}$ & & & & & $4.57 \%$ \\
$(3.38)$ & $(-2.38)$ & & & & & \\
& & & & & & \\
$6.54^{* * *}$ & $-0.15^{* * *}$ & -0.11 & 0.07 & & & \\
$(3.59)$ & $(-3.07)$ & $(-0.82)$ & $(0.64)$ & & & \\
& & & & & & \\
$7.71^{* * *}$ & $-0.22^{* * *}$ & -0.15 & 0.15 & -0.15 & -0.00 & \\
$(3.30)$ & $(-2.67)$ & $(-1.12)$ & $(1.40)$ & $(-0.91)$ & $(-0.02)$ & \\
\hline
\end{tabular}

The table shows the coefficients of a regression of 12-month returns on the investment strategy based on pairs described in Section 3 and Table 1 on the corresponding 12-month overlapping returns of the following factors: market excess return (MKT), size (SMB), value (HML), profitability (RMW), and investment (CMA) (all taken from Kenneth French's website). The sample period is 01/1996 to $12 / 2014$. $\alpha$ denotes the regression intercept and is expressed in percentage points. Numbers in parentheses are $t$-statistics according to Newey and West (1987) with 20 lags. ${ }^{* * *},{ }^{* *}$, and ${ }^{*}$ indicate significance at the $1 \%, 5 \%$, and $10 \%$ level, respectively. 
Table 3: IVD and $\mathbf{I V}_{365}$ for double-sorted portfolios

\begin{tabular}{cccccc}
\multicolumn{7}{c}{ Panel A: IVD (in days) } \\
\hline \multicolumn{7}{c}{$\begin{array}{c}\text { Low IVD } \\
\text { (early) }\end{array}$} & 2 & 3 & 4 & $\begin{array}{c}\text { High IVD } \\
\text { (late) }\end{array}$ \\
low IV & & & & 21365 \\
2 & 160.05 & 208.77 & 211.71 & 213.73 & 221.94 \\
3 & 192.83 & 208.79 & 211.70 & 213.71 & 220.15 \\
4 & 194.56 & 208.78 & 211.69 & 213.68 & 219.57 \\
high IV & 194.85 & 208.80 & 211.68 & 213.66 & 219.80 \\
& 192.95 & 208.80 & 211.67 & 213.69 & 218.99 \\
& & & & & \\
\hline & & Panel B: $I V_{365}$ & & \\
low IV & Low IVD & 2 & 3 & 4 & High IVD \\
2 & 0.2202 & 0.2442 & 0.2466 & 0.2461 & 0.2423 \\
3 & 0.3345 & 0.3343 & 0.3339 & 0.3330 & 0.3310 \\
4 & 0.4212 & 0.4209 & 0.4205 & 0.4197 & 0.4187 \\
high IV IV $_{365}$ & 0.5336 & 0.5340 & 0.5342 & 0.5336 & 0.5334 \\
\hline
\end{tabular}

The table shows implied volatility duration (IVD), computed according to Equation (1), and 365-day implied volatility $\left(\mathrm{IV}_{365}\right)$ for 25 portfolios sorted on $\mathrm{IV}_{365}$ and IVD. The values shown are the timeseries means of the equally weighted means computed at each portfolio formation date. Data are taken from OptionMetrics. The sample period is 01/1996 to 08/2015. 
Table 4: Returns on IVD-IV 365 sorted portfolios

Panel A: Value-weighted returns, holding period 12 months

\begin{tabular}{ccccccc}
\hline & $\begin{array}{c}\text { low IVD } \\
\text { (early) }\end{array}$ & 2 & 3 & 4 & $\begin{array}{c}\text { high IVD } \\
\text { (late) }\end{array}$ & LME \\
low IV 365 & $9.17^{* * *}$ & $9.72^{* * *}$ & $10.25^{* * *}$ & $10.28^{* * *}$ & $9.18^{* * *}$ & 0.00 \\
& $(3.13)$ & $(3.27)$ & $(3.59)$ & $(3.93)$ & $(3.27)$ & $(0.00)$ \\
2 & $11.01^{* *}$ & $10.86^{* * *}$ & $12.34^{* * *}$ & $11.32^{* * *}$ & $10.95^{* * *}$ & -0.06 \\
& $(2.4)$ & $(2.80)$ & $(3.49)$ & $(3.20)$ & $(3.01)$ & $(-0.04)$ \\
3 & $11.16^{*}$ & $12.78^{* * *}$ & $11.78^{* * *}$ & $12.95^{* * *}$ & $11.62^{* * *}$ & 0.46 \\
& $(1.87)$ & $(2.65)$ & $(2.69)$ & $(2.96)$ & $(2.77)$ & $(0.17)$ \\
4 & $12.24^{*}$ & $10.92^{*}$ & $11.39^{*}$ & $11.48^{*}$ & $11.23^{* *}$ & -1.01 \\
& $(1.69)$ & $(1.72)$ & $(1.86)$ & $(1.93)$ & $(2.25)$ & $(-0.37)$ \\
high IV & 4.53 & 7.56 & 6.62 & 11.86 & 11.70 & $7.17^{* *}$ \\
& $(0.55)$ & $(0.89)$ & $(0.92)$ & $(1.42)$ & $(1.43)$ & $(1.97)$
\end{tabular}

Panel B: Equally-weighted returns, holding period 12 months

\begin{tabular}{|c|c|c|c|c|c|c|}
\hline & $\begin{array}{l}\text { low IVD } \\
\text { (early) }\end{array}$ & 2 & 3 & 4 & $\underset{\text { (late) }}{\text { high IVD }}$ & LME \\
\hline low $\mathrm{IV}_{365}$ & $\begin{array}{c}10.47^{* * *} \\
(4.32)\end{array}$ & $\begin{array}{c}11.47^{* * *} \\
(4.12)\end{array}$ & $\begin{array}{c}11.99^{* * *} \\
(4.35)\end{array}$ & $\begin{array}{c}11.90^{* * *} \\
(4.40)\end{array}$ & $\begin{array}{c}11.47^{* * *} \\
(4.39)\end{array}$ & $\begin{array}{l}1.00^{*} \\
(1.65)\end{array}$ \\
\hline 2 & $\begin{array}{c}12.69^{* * *} \\
(3.78)\end{array}$ & $\begin{array}{c}12.63^{* * *} \\
(3.78)\end{array}$ & $\begin{array}{c}12.58^{* * *} \\
(3.85)\end{array}$ & $\begin{array}{c}13.24^{* * *} \\
(4.22)\end{array}$ & $\begin{array}{c}12.40^{* * *} \\
(3.94)\end{array}$ & $\begin{array}{l}-0.29 \\
(-0.39)\end{array}$ \\
\hline 3 & $\begin{array}{l}12.42^{* * *} \\
(2.93)\end{array}$ & $\begin{array}{l}12.64^{* * *} \\
(3.29)\end{array}$ & $\begin{array}{l}12.77^{* * *} \\
(3.42)\end{array}$ & $\begin{array}{l}13.44^{* * *} \\
(3.72)\end{array}$ & $\begin{array}{l}13.39^{* * *} \\
(3.72)\end{array}$ & $\begin{array}{l}0.97 \\
(0.59)\end{array}$ \\
\hline 4 & $\begin{array}{l}10.89^{*} \\
(1.93)\end{array}$ & $\begin{array}{l}11.02^{* *} \\
(2.05)\end{array}$ & $\begin{array}{l}11.93^{* *} \\
(2.26)\end{array}$ & $\begin{array}{l}11.61^{* *} \\
(2.28)\end{array}$ & $\begin{array}{l}11.40^{* *} \\
(2.52)\end{array}$ & $\begin{array}{l}0.52 \\
(0.28)\end{array}$ \\
\hline high $\mathrm{IV}_{365}$ & $\begin{array}{l}5.29 \\
(0.67)\end{array}$ & $\begin{array}{l}7.28 \\
(0.95)\end{array}$ & $\begin{array}{l}6.41 \\
(0.91)\end{array}$ & $\begin{array}{l}9.19 \\
(1.24)\end{array}$ & $\begin{array}{l}11.80 \\
(1.59)\end{array}$ & $\begin{array}{l}6.51^{* * *} \\
(2.97)\end{array}$ \\
\hline
\end{tabular}

The table shows average 12-month returns on value-weighted and equally weighted portfolios monthly sorted independently on IVD and $\mathrm{IV}_{365}$. $t$-statistics are adjusted according to Newey and West (1987) with 12 lags. ${ }^{* *},{ }^{* *}$, and ${ }^{*}$ indicate significance at the $1 \%, 5 \%$, and $10 \%$ level, respectively. The sample period is $01 / 1996$ to $12 / 2014$. 
Table 5: Returns on IVD-beta sorted portfolios

Panel A: Value-weighted returns, holding period 12 months

\begin{tabular}{ccccccc}
\hline & $\begin{array}{c}\text { low IVD } \\
\text { (early) }\end{array}$ & 2 & 3 & 4 & $\begin{array}{c}\text { high IVD } \\
\text { (late) }\end{array}$ & LME \\
low beta & $8.94^{* * *}$ & $7.89^{* *}$ & $7.95^{* *}$ & $8.61^{* * *}$ & $8.58^{* * *}$ & -0.35 \\
& $(2.87)$ & $(2.40)$ & $(2.54)$ & $(3.15)$ & $(3.29)$ & $(-0.27)$ \\
2 & $12.65^{* * *}$ & $11.57^{* * *}$ & $12.81^{* * *}$ & $12.31^{* * *}$ & $11.61^{* * *}$ & -1.04 \\
& $(3.29)$ & $(3.49)$ & $(3.94)$ & $(4.01)$ & $(3.55)$ & $(-0.92)$ \\
3 & $12.23^{* * *}$ & $13.68^{* * *}$ & $13.23^{* * *}$ & $12.51^{* * *}$ & $11.71^{* * *}$ & -0.51 \\
& $(2.63)$ & $(3.36)$ & $(3.30)$ & $(3.27)$ & $(2.92)$ & $(-0.30)$ \\
4 & $13.96^{* *}$ & $12.86^{* *}$ & $12.3^{* *}$ & $13.72^{* *}$ & $12.43^{* * *}$ & -1.53 \\
& $(2.18)$ & $(2.33)$ & $(2.41)$ & $(2.54)$ & $(2.87)$ & $(-0.58)$ \\
high beta & 6.96 & 9.06 & 9.74 & $11.92^{*}$ & $11.74^{*}$ & $4.78^{*}$ \\
& $(0.93)$ & $(1.21)$ & $(1.52)$ & $(1.66)$ & $(1.75)$ & $(1.78)$
\end{tabular}

Panel B: Equally-weighted returns, holding period 12 months

\begin{tabular}{ccccccc}
\hline & $\begin{array}{c}\text { low IVD } \\
\text { (early) }\end{array}$ & 2 & 3 & 4 & $\begin{array}{c}\text { high IVD } \\
\text { (late) }\end{array}$ & LME \\
low beta & $8.72^{* * *}$ & $8.86^{* * *}$ & $9.64^{* * *}$ & $10.01^{* * *}$ & $10.06^{* * *}$ & 1.35 \\
& $(3.17)$ & $(2.78)$ & $(3.18)$ & $(3.61)$ & $(4.04)$ & $(1.35)$ \\
2 & $11.19^{* * *}$ & $10.77^{* * *}$ & $11.30^{* * *}$ & $11.88^{* * *}$ & $11.95^{* * *}$ & 0.76 \\
& $(3.12)$ & $(3.10)$ & $(3.33)$ & $(3.69)$ & $(3.79)$ & $(0.68)$ \\
3 & $12.34^{* * *}$ & $11.81^{* * *}$ & $12.34^{* * *}$ & $13.26^{* * *}$ & $12.77^{* * *}$ & 0.44 \\
& $(3.08)$ & $(2.97)$ & $(3.25)$ & $(3.47)$ & $(3.46)$ & $(0.42)$ \\
4 & $11.82^{* *}$ & $12.51^{* *}$ & $12.25^{* *}$ & $12.67^{* * *}$ & $13.78^{* * *}$ & 1.96 \\
& $(2.22)$ & $(2.45)$ & $(2.48)$ & $(2.62)$ & $(3.11)$ & $(1.24)$ \\
high beta & 7.69 & 10.00 & 9.95 & 11.49 & $13.52^{* *}$ & $5.83^{* * *}$ \\
& $(1.05)$ & $(1.43)$ & $(1.49)$ & $(1.62)$ & $(1.97)$ & $(3.24)$ \\
& & & & & & \\
\hline
\end{tabular}

The table shows average 12-month returns on portfolios independently sorted into $5 \times 5$ portfolios based on IVD and option-implied beta as suggested by Buss and Vilkov (2012). $t$-statistics are adjusted according to Newey and West (1987) with 12 lags. ${ }^{* * *},{ }^{* *}$, and ${ }^{*}$ indicate significance at the 1\%, 5\%, and $10 \%$ level, respectively. The sample period is $01 / 1996$ to $12 / 2014$. 
Table 6: Returns on IVD-IV 365 sorted portfolios

Panel A: Value-weighted, holding period 1 month

\begin{tabular}{ccccccc}
\hline \multirow{5}{*}{ low IV 365} & $\begin{array}{c}\text { low IVD } \\
\text { (early) }\end{array}$ & 2 & 3 & 4 & $\begin{array}{c}\text { high IVD } \\
\text { (late) }\end{array}$ & LME \\
& $0.76^{* * *}$ & $0.90^{* * *}$ & $0.61^{* *}$ & $0.72^{* *}$ & $0.62^{* *}$ & -0.14 \\
2 & $(2.77)$ & $(3.09)$ & $(2.46)$ & $(2.52)$ & $(2.15)$ & $(-0.71)$ \\
& $0.95^{* *}$ & $0.81^{* *}$ & $1.10^{* * *}$ & $0.76^{* *}$ & $0.79^{* *}$ & -0.16 \\
3 & $(2.33)$ & $(2.08)$ & $(3.12)$ & $(2.07)$ & $(2.00)$ & $(-0.78)$ \\
& 0.77 & $0.94^{* *}$ & $1.19^{* * *}$ & 0.75 & 0.53 & -0.24 \\
4 & $(1.20)$ & $(2.04)$ & $(2.66)$ & $(1.57)$ & $(1.03)$ & $(-0.73)$ \\
\multirow{3}{*}{4} & 0.99 & 0.97 & 0.73 & 0.52 & 0.80 & -0.19 \\
& $(1.47)$ & $(1.48)$ & $(1.07)$ & $(0.75)$ & $(1.06)$ & $(-0.58)$ \\
high IV & -0.22 & 0.34 & 0.48 & 0.66 & 0.80 & $1.01^{* *}$ \\
& $(-0.22)$ & $(0.44)$ & $(0.57)$ & $(0.74)$ & $(0.99)$ & $(2.16)$
\end{tabular}

Panel B: Equally-weighted, holding period 1 month

\begin{tabular}{|c|c|c|c|c|c|c|}
\hline & $\begin{array}{c}\text { low IVD } \\
\text { (early) }\end{array}$ & 2 & 3 & 4 & $\underset{\text { (late) }}{\text { high IVD }}$ & LME \\
\hline low $\mathrm{IV}_{365}$ & $\begin{array}{c}0.93^{* * *} \\
(3.77)\end{array}$ & $\begin{array}{c}0.92^{* * *} \\
(3.55)\end{array}$ & $\begin{array}{c}0.86^{* * *} \\
(3.27)\end{array}$ & $\begin{array}{c}0.87^{* * *} \\
(3.36)\end{array}$ & $\begin{array}{c}0.73^{* * *} \\
(2.83)\end{array}$ & $\begin{array}{c}-0.20^{* *} \\
(-2.04)\end{array}$ \\
\hline 2 & $\begin{array}{c}1.10^{* * *} \\
(3.09)\end{array}$ & $\begin{array}{c}0.99^{* * *} \\
(3.15)\end{array}$ & $\begin{array}{c}1.06^{* * *} \\
(3.34)\end{array}$ & $\begin{array}{c}0.97^{* * *} \\
(3.33)\end{array}$ & $\begin{array}{c}0.84^{* * *} \\
(2.63)\end{array}$ & $\begin{array}{c}-0.26^{*} \\
(-1.67)\end{array}$ \\
\hline 3 & $\begin{array}{c}1.00^{* * *} \\
(2.27)\end{array}$ & $\begin{array}{c}1.05^{* * *} \\
(2.68)\end{array}$ & $\begin{array}{c}0.94^{* * *} \\
(2.66)\end{array}$ & $\begin{array}{c}0.96^{* * *} \\
(2.59)\end{array}$ & $\begin{array}{c}0.74^{* * *} \\
(1.88)\end{array}$ & $\begin{array}{l}-0.27 \\
(-1.46)\end{array}$ \\
\hline 4 & $\begin{array}{c}0.81 \\
(1.48)\end{array}$ & $\begin{array}{c}1.03^{* *} \\
(1.96)\end{array}$ & $\begin{array}{c}0.82 \\
(1.53)\end{array}$ & $\begin{array}{c}0.80 \\
(1.54)\end{array}$ & $\begin{array}{c}0.66 \\
(1.16)\end{array}$ & $\begin{array}{l}-0.15 \\
(-0.77)\end{array}$ \\
\hline high $\operatorname{IV}_{365}$ & $\begin{array}{l}0.13 \\
(0.16)\end{array}$ & $\begin{array}{c}0.31 \\
(0.42)\end{array}$ & $\begin{array}{l}0.43 \\
(0.59)\end{array}$ & $\begin{array}{c}0.38 \\
(0.49)\end{array}$ & $\begin{array}{c}0.83 \\
(1.27)\end{array}$ & $\begin{array}{c}0.70^{* *} \\
(2.16)\end{array}$ \\
\hline
\end{tabular}

The table shows the one-month average returns on value-weighted and equally weighted portfolios sorted on IVD and $\mathrm{IV}_{365}$. $t$-statistics are adjusted according to Newey and West (1987) with 12 lags. ${ }^{* * *},{ }^{* *}$, and ${ }^{*}$ indicate significance at the $1 \%, 5 \%$, and $10 \%$ level, respectively. The sample period is $01 / 1996$ to $08 / 2015$. 


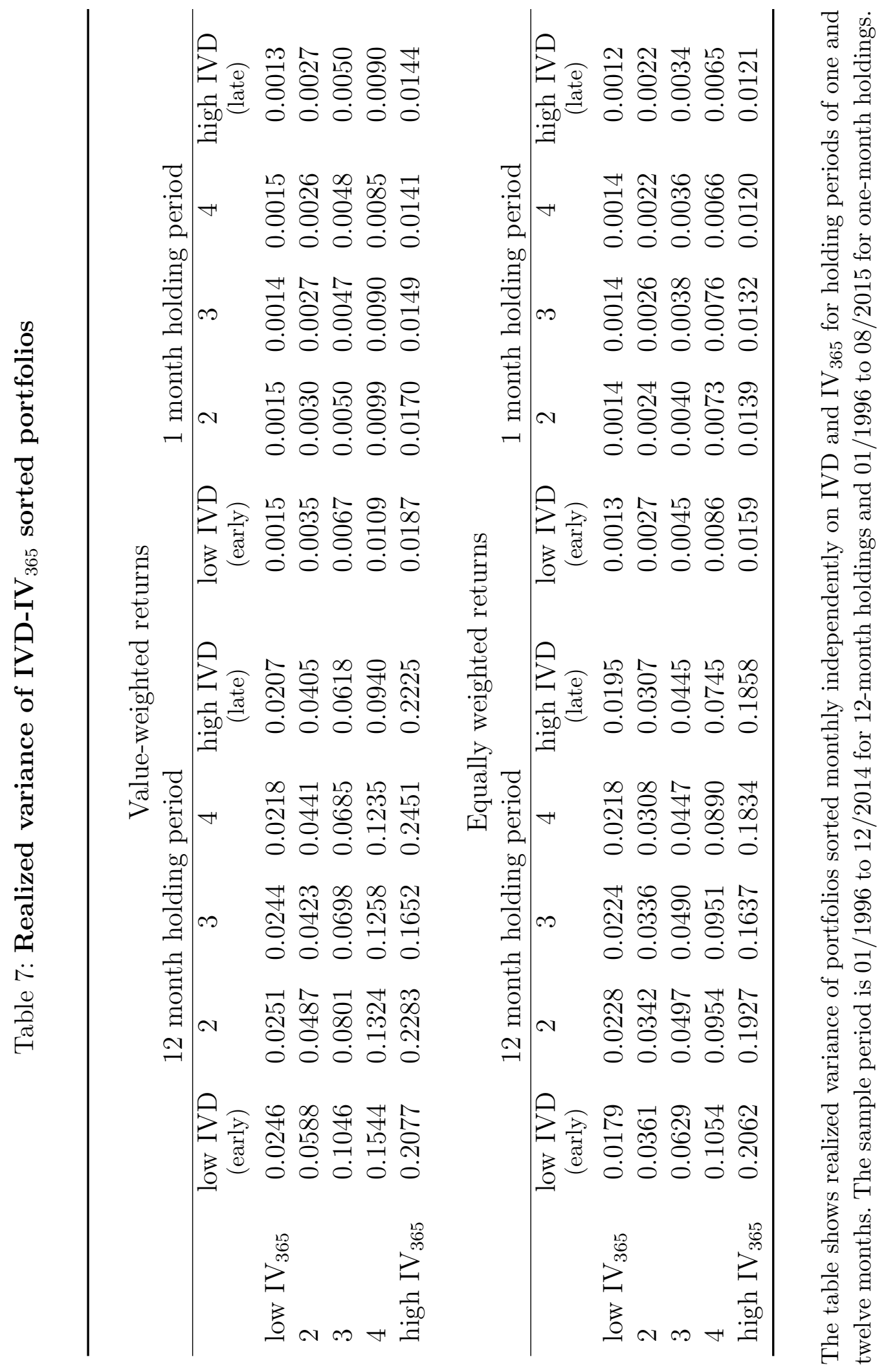


Table 8: LME portfolio: alphas and factor loadings

\begin{tabular}{ccccccc}
$\alpha$ & MKT & SMB & HML & RMW & CMA & $\mathrm{R}^{2}$ \\
\hline $\begin{array}{c}1.19^{* * *} \\
(2.80)\end{array}$ & $\begin{array}{c}-0.33^{* * *} \\
(-3.09)\end{array}$ & & & & & $4.64 \%$ \\
$1.06^{* *}$ & $-0.29^{* * *}$ & 0.10 & $0.43^{* *}$ & & & \\
$(2.57)$ & $(-2.59)$ & $(0.60)$ & $(2.32)$ & & & $8.51 \%$ \\
$0.90^{* *}$ & -0.20 & 0.14 & 0.24 & 0.19 & 0.29 & $9.18 \%$ \\
$(2.13)$ & $(-1.46)$ & $(0.81)$ & $(0.79)$ & $(0.61)$ & $(0.84)$ & \\
\hline
\end{tabular}

The table shows the coefficients of a regression of 1-month returns on the LME portfolio on the following factors: market excess return (MKT), size (SMB), value (HML), profitability (RMW), and investment (CMA) (all taken from Kenneth French's website). $\alpha$ denotes the regression intercept and is expressed in percentage points. Numbers in parentheses are $t$-statistics adjusted according to Newey and West (1987) with 12 lags. ${ }^{* * *},{ }^{* *}$, and ${ }^{*}$ indicate significance at the $1 \%, 5 \%$, and $10 \%$ level, respectively. The sample period is $01 / 1996$ to $08 / 2015$. 
Table 9: Stocks in the high $\mathbf{I V}_{365}$ quintile

\begin{tabular}{|c|c|c|c|c|c|c|}
\hline & $\begin{array}{r}\text { low IVD } \\
\text { (early) }\end{array}$ & 2 & 3 & 4 & high IVD & full sample \\
\hline IVD & 192.95 & 208.80 & 211.67 & 213.69 & 218.98 & 211.72 \\
\hline $\mathrm{IV}_{365}$ & 0.781 & 0.753 & 0.770 & 0.787 & 0.790 & 0.419 \\
\hline ME (in US-\$ m) & 924 & 657 & 610 & 560 & 662 & 1,234 \\
\hline $\mathrm{BM}$ & 0.683 & 0.587 & 0.577 & 0.630 & 0.627 & 0.438 \\
\hline $\mathrm{OP}$ & -0.093 & -0.178 & -0.099 & -0.025 & -0.0177 & 0.187 \\
\hline INV & 0.510 & 0.448 & 0.433 & 0.386 & 0.351 & 0.091 \\
\hline ILLIQ $\times 10^{5}$ & 0.295 & 0.314 & 0.333 & 0.367 & 0.335 & 0.082 \\
\hline CFD & 23.22 & 22.98 & 22.40 & 23.45 & 21.60 & 21.45 \\
\hline IVol & 0.041 & 0.038 & 0.037 & 0.037 & 0.034 & 0.019 \\
\hline $\mathrm{VRP}_{30}$ (ex-ante) & -1.089 & 0.156 & -0.008 & 0.222 & 0.281 & -0.161 \\
\hline $\mathrm{VRP}_{30}$ (realized) & -1.380 & -0.217 & 0.020 & 0.071 & 0.296 & -0.395 \\
\hline $\mathrm{SIR}_{\mathrm{IO}}$ & 0.413 & 0.450 & 0.434 & 0.392 & 0.438 & 0.054 \\
\hline
\end{tabular}

Panel B: Portfolio betas

\begin{tabular}{lrrrrr}
\hline & $\begin{array}{r}\text { low IVD } \\
\text { (early) }\end{array}$ & 2 & 3 & 4 & $\begin{array}{r}\text { high IVD } \\
\text { (late) }\end{array}$ \\
MKT & 1.694 & 1.685 & 1.493 & 1.377 & 1.481 \\
SMB & 0.555 & 0.748 & 0.750 & 0.836 & 0.688 \\
HML & -0.207 & -0.121 & -0.218 & -0.346 & 0.047 \\
RMW & -1.488 & -1.049 & -1.307 & -1.242 & -1.315 \\
CMA & -0.566 & -0.818 & -0.500 & -0.372 & -0.274 \\
LIQ & -0.179 & -0.205 & 0.072 & -0.063 & -0.117 \\
\hline
\end{tabular}

The table shows characteristics of the stocks in the high $\mathrm{IV}_{365}$ quintile. All numbers in the columns "low IVD", 2, 3, 4 and "high IVD" are equally weighted averages across stocks and time. ME is market equity, BM is the ratio of book to market equity, OP is operating profitability as defined in Fama and French (2015) as revenues minus cost of goods sold, interest expense, and selling, general, and administrative expenses (if available), all divided by book equity at the end of the previous fiscal year, INV is investment as defined in Fama and French (2015). ILLIQ is illiquidity in the sense of Amihud (2002) and Brennan et al. (2013) applied to monthly data, in particular we have $I L L I Q_{t}=\frac{\left|r_{t}\right|}{T O_{t}}$ where $T O_{t}$ is the turnover in month $t$. CFD is Dechow et al.'s (2004) estimate of stocks' cash-flow duration using the parameter estimates from Weber (2018). IVol is idiosyncratic return volatility relative to the Fama and French (1992) three factor model, computed as the daily standard deviation of the residuals from the model in the preceding month. VRP is the equally weighted average of our measure of the monthly variance risk premium, computed either ex ante as the difference $\mathbb{V} \operatorname{ar}\left(r_{t, 30}\right)-\mathrm{IV}_{t, 30}^{2}$ or realized as $\operatorname{Var}\left(r_{t+1,30}\right)-\mathrm{IV}_{t, 30}^{2} . S I R_{I O}$ serves as a proxy for shorting fees and is the ratio of short interest over institutional ownership as computed in Drechsler and Drechsler (2016). With the exception of LIQ, the factors used for the computation of value-weighted betas are from Kenneth French's website. Liquidity (LIQ) is taken from Robert Stambaugh's website. The colund@ labeled 'full sample' shows the time series mean over the monthly cross-sectional medians of the full sample. The sample period is $01 / 1996$ to $08 / 2015$. 
Table 10: IVD Portfolio migration

Panel A: All IV $V_{365}$ quintiles

\begin{tabular}{|c|c|c|c|c|c|}
\hline from to & $\begin{array}{c}\text { low IVD } \\
\text { (early) }\end{array}$ & 2 & 3 & 4 & $\underset{\text { (late) }}{\text { high IVD }}$ \\
\hline low IVD & 0.4591 & 0.2085 & 0.1254 & 0.0983 & 0.1087 \\
\hline 2 & 0.1892 & 0.2638 & 0.2374 & 0.1842 & 0.1253 \\
\hline 3 & 0.1335 & 0.2250 & 0.2622 & 0.2394 & 0.1400 \\
\hline 4 & 0.1071 & 0.1792 & 0.2386 & 0.2920 & 0.1831 \\
\hline high IVD & 0.1115 & 0.1217 & 0.1325 & 0.1841 & 0.4502 \\
\hline \multicolumn{6}{|c|}{ Panel B: Top $I V_{365}$ quintile } \\
\hline from to & $\begin{array}{c}\text { low IVD } \\
\text { (early) }\end{array}$ & 2 & 3 & 4 & $\begin{array}{l}\text { high IVD } \\
\text { (late) }\end{array}$ \\
\hline low IVD & 0.4428 & 0.2015 & 0.1452 & 0.1066 & 0.1040 \\
\hline 2 & 0.1938 & 0.2626 & 0.2490 & 0.1791 & 0.1155 \\
\hline 3 & 0.1620 & 0.2231 & 0.2691 & 0.2151 & 0.1308 \\
\hline 4 & 0.1306 & 0.1748 & 0.2354 & 0.2883 & 0.1709 \\
\hline high IVD & 0.1558 & 0.1370 & 0.1501 & 0.1997 & 0.3575 \\
\hline
\end{tabular}

The table shows the relative frequency of a stock migrating from IVD quintile portfolio $i$ in month $t$ to portfolio $j$ in month $t+1$. Panels $\mathrm{A}$ and $\mathrm{B}$ show this quantity unconditionally and conditional on a stock being in the top $\mathrm{IV}_{365}$ quintile portfolio before switching, respectively. The sample period is $01 / 1996$ to $08 / 2015$. 
Table 11: Fama-MacBeth regressions: characteristic

\begin{tabular}{cccccccc} 
& $\mathrm{MKT}$ & $\ln (M E)$ & $\ln (B M)$ & OP & Inv & IV $^{2} \times$ IVD & $\mathrm{R}^{2}$ \\
\hline CAPM & 0.45 & & & & & & $0.85 \%$ \\
& $(1.32)$ & & & & & & \\
& 0.45 & & & & & $0.05^{* * *}$ & $1.09 \%$ \\
& $(1.32)$ & & & & & $(2.67)$ & \\
\hline \multirow{2}{*}{ FF3 } & 0.47 & 0.10 & 0.14 & & & & $3.05 \%$ \\
& $(1.34)$ & $(1.64)$ & $(0.85)$ & & & & \\
& 0.47 & $0.10^{*}$ & 0.14 & & & $0.06^{* * *}$ & $3.27 \%$ \\
& $(1.34)$ & $(1.65)$ & $(0.86)$ & & & $(3.57)$ & \\
\hline \multirow{2}{*}{ FF5 } & 0.50 & 0.06 & 0.11 & $0.14^{* *}$ & $-0.25^{* * *}$ & & $3.54 \%$ \\
& $(1.45)$ & $(1.10)$ & $(0.70)$ & $(2.39)$ & $(-4.40)$ & & \\
& 0.49 & 0.06 & 0.11 & $0.14^{* *}$ & $-0.25^{* * *}$ & $0.06^{* * *}$ & $3.80 \%$ \\
& $(1.44)$ & $(1.09)$ & $(0.69)$ & $(2.32)$ & $(-4.42)$ & $(3.19)$ & \\
\hline
\end{tabular}

The table shows the coefficients from a second stage Fama-MacBeth-regression of individual stock returns on the market excess return (MKT), log market capitalization (ME), log book-to-market equity ratio (BM), operating profitability (OP) and asset growth (Inv), and the stock characteristic IVD $\times \mathrm{IV}_{365}^{2}$. In using logs for ME and BM, we follow the convention in Fama and French (1992). $\mathrm{R}^{2}$ is the time-series average of the cross-sectional second-stage regressions. Numbers in parentheses are $t$-statistics adjusted according to Newey and West (1987) with four lags. All characteristics are cross-sectionally demeaned. 
Table 12: Model parameters

\begin{tabular}{|c|c|c|c|c|}
\hline Preferences & $\begin{array}{c}\delta \\
-\log (.998)\end{array}$ & $\begin{array}{c}\psi \\
1.5\end{array}$ & $\begin{array}{c}\gamma \\
1-10\end{array}$ & \\
\hline Cycles & & $\begin{array}{c}\rho_{t r a n} \\
.98\end{array}$ & $\begin{array}{c}\rho_{\text {pers }} \\
.99\end{array}$ & \\
\hline Volatility & $\begin{array}{c}\bar{v} \\
(.044 \cdot .0078)^{2}\end{array}$ & $\begin{array}{r}\rho_{v} \\
.9\end{array}$ & & $\begin{array}{c}\sigma_{v} \\
.044^{2} \cdot .23 \cdot 10^{-5}\end{array}$ \\
\hline Consumption & $\begin{array}{c}\mu_{c} \\
.0015\end{array}$ & $\begin{array}{l}\phi_{c, t r a n} \\
1 / \sqrt{2}\end{array}$ & $\begin{array}{l}\phi_{c, p e r s} \\
1 / \sqrt{2}\end{array}$ & $\begin{array}{c}\sigma_{c} \\
.0078\end{array}$ \\
\hline Market claim & $\begin{array}{c}\mu_{m} \\
.0015\end{array}$ & $\begin{array}{c}\phi_{m, t r a n} \\
3 / \sqrt{2}\end{array}$ & $\begin{array}{c}\phi_{m, p e r s} \\
3 / \sqrt{2}\end{array}$ & $\begin{array}{c}\sigma_{m} \\
4.5 \cdot .0078\end{array}$ \\
\hline Early claim & $\begin{array}{c}\mu_{e} \\
.0015\end{array}$ & $\begin{array}{c}\phi_{e, t \operatorname{tran}} \\
6 / \sqrt{2}-\phi_{c, \operatorname{tran}} / \psi\end{array}$ & $\begin{array}{c}\phi_{e, p e r s} \\
\phi_{c, \text { tran }} / \psi\end{array}$ & $\begin{array}{c}\sigma_{e} \\
4.5 \cdot .0078\end{array}$ \\
\hline Late claim & $\begin{array}{c}\mu_{l} \\
.0015\end{array}$ & $\begin{array}{c}\phi_{l, t r a n} \\
\phi_{c, p e r s} / \psi\end{array}$ & $\begin{array}{c}\phi_{l, p e r s} \\
6 / \sqrt{2}-\phi_{c, p e r s} / \psi\end{array}$ & $\begin{array}{c}\sigma_{l} \\
4.5 \cdot .0078\end{array}$ \\
\hline
\end{tabular}

The tables shows the parameters used in the analysis of our model as described in Section 5. 


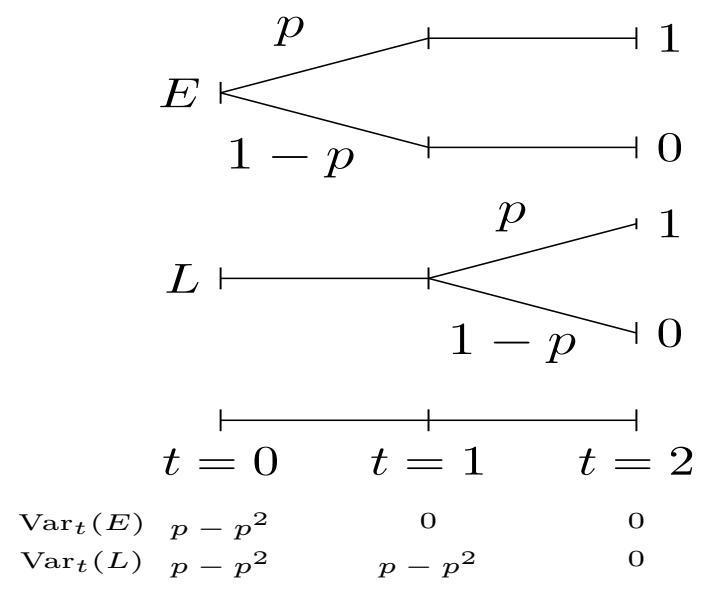

Fig. 1. Late and early resolution claim 


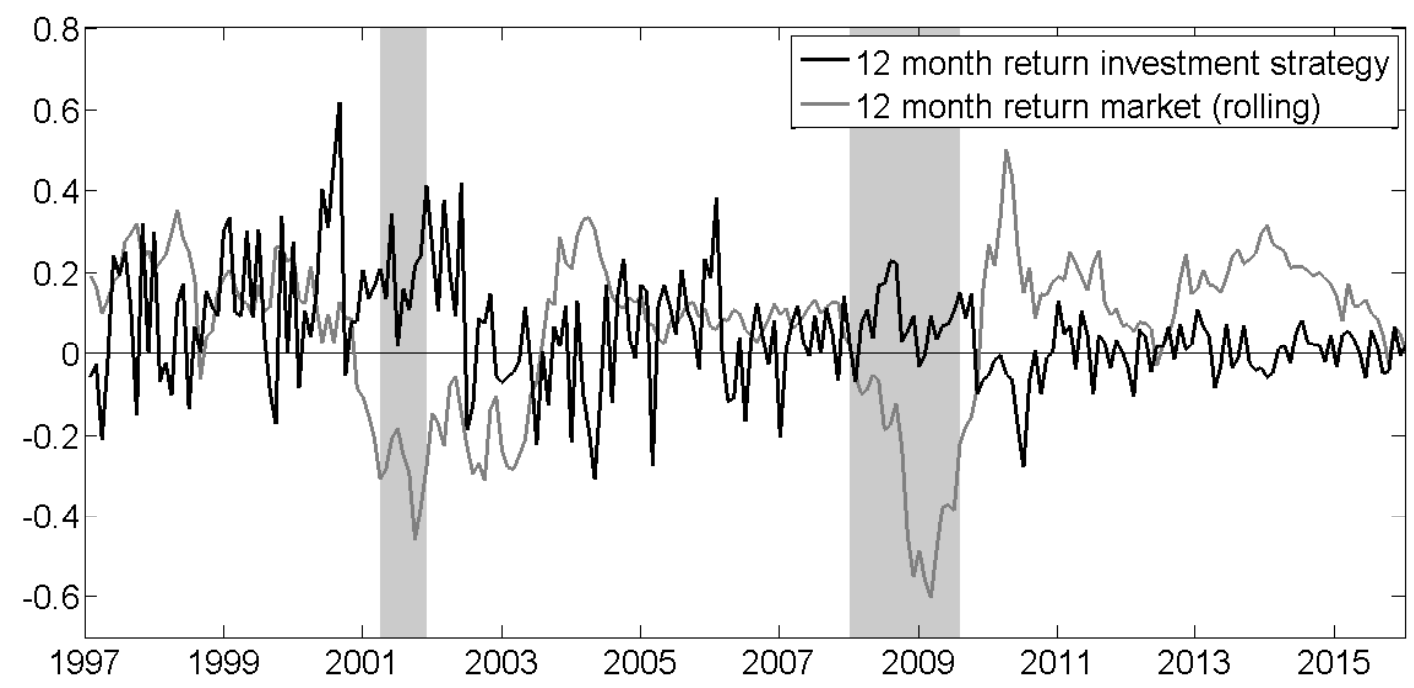

Fig. 2. Returns on the market (computed on a rolling basis for each month and the subsequent 12 months) and on the investment strategy based on pairs. The areas shaded in gray denote NBER recessions. 

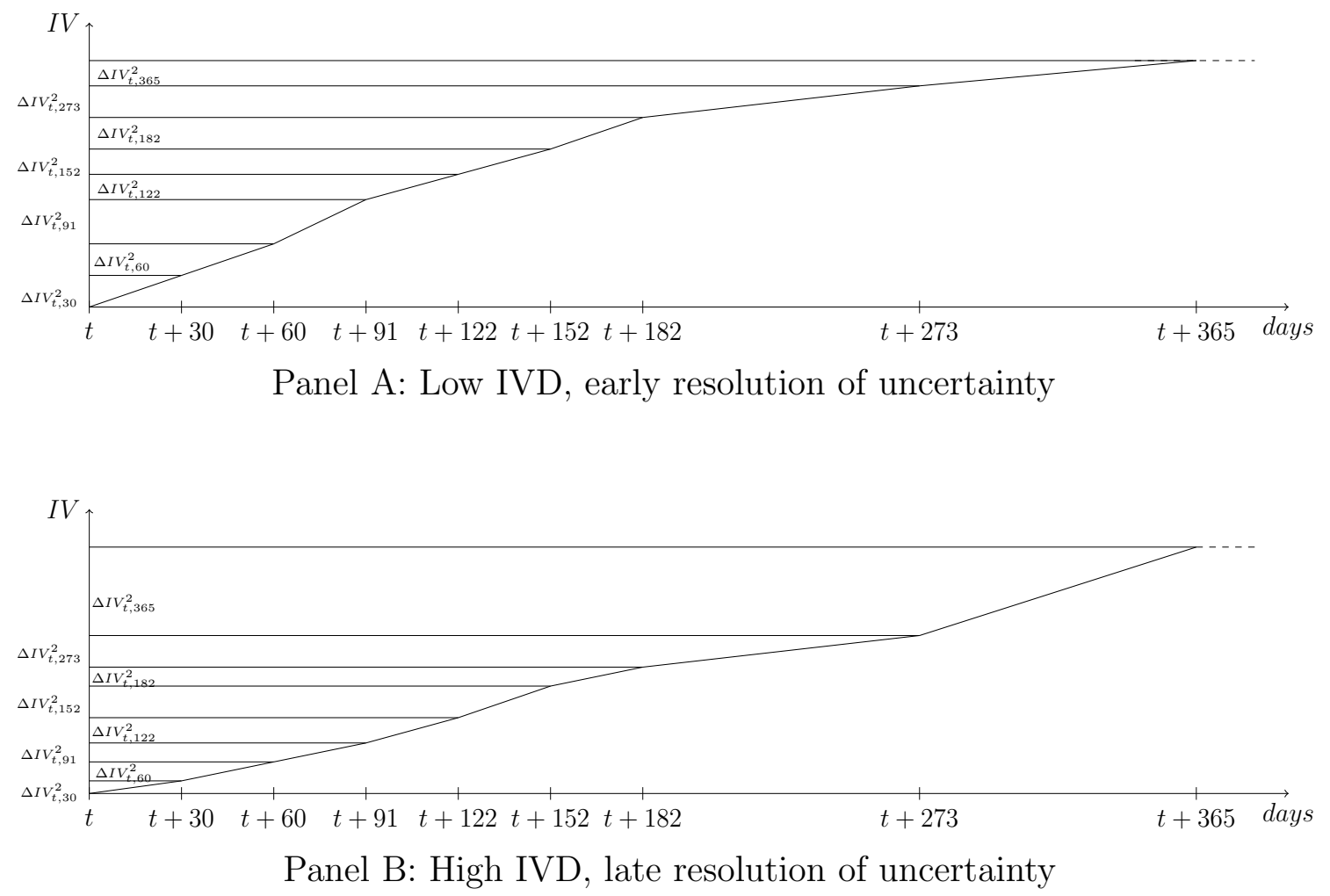

Fig. 3. Graphical representation of IVD 

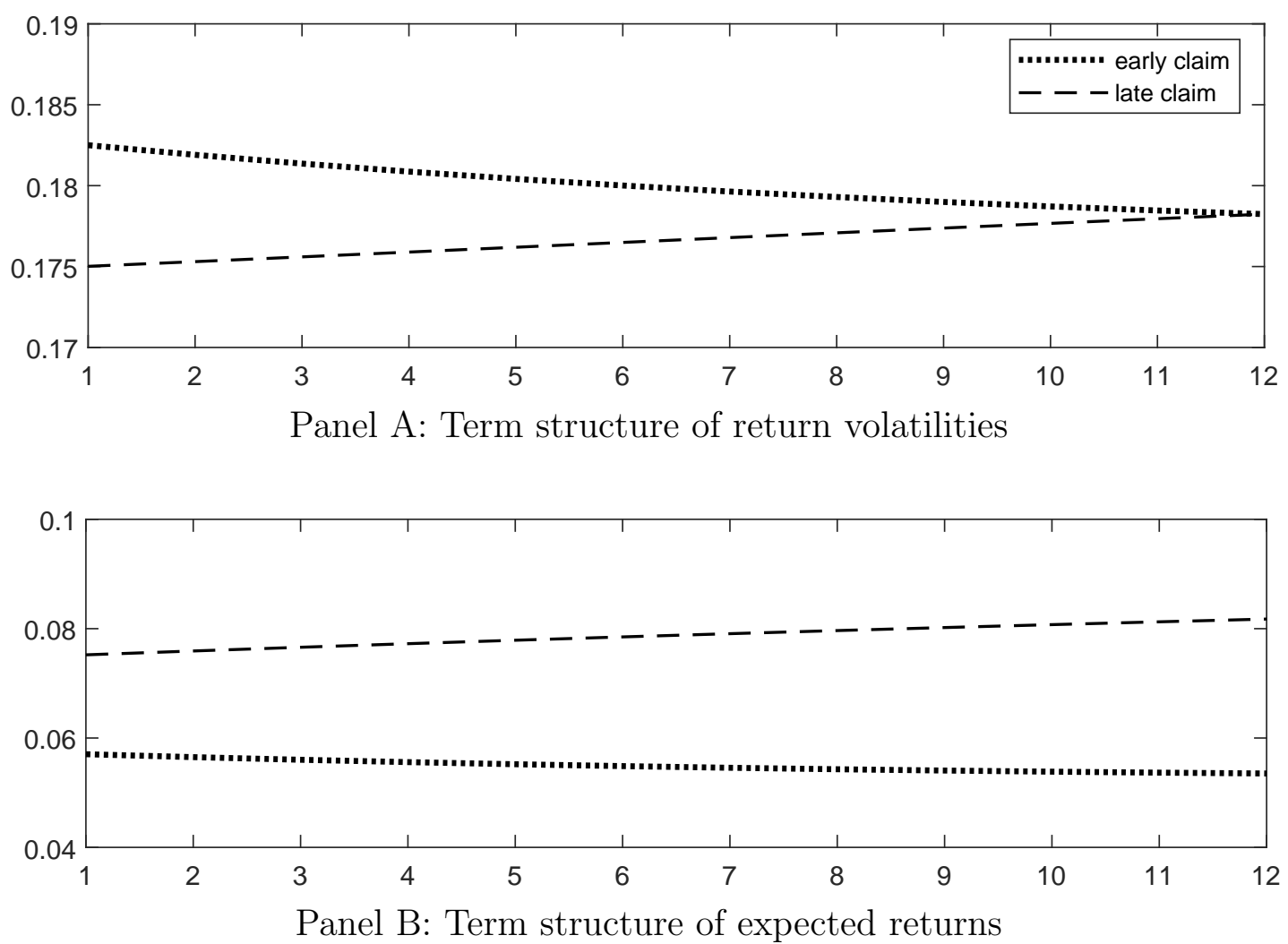

Fig. 4. The figure shows model-implied term structures of return volatilities (Panel A) and expected returns (Panel B). The return horizon on the horizontal axis is expressed in months. Return volatilities and expected returns are expressed in annual terms. The figures show conditional term structures, i.e. the time 0 values of the state variables are chosen as described in Section 5 . 


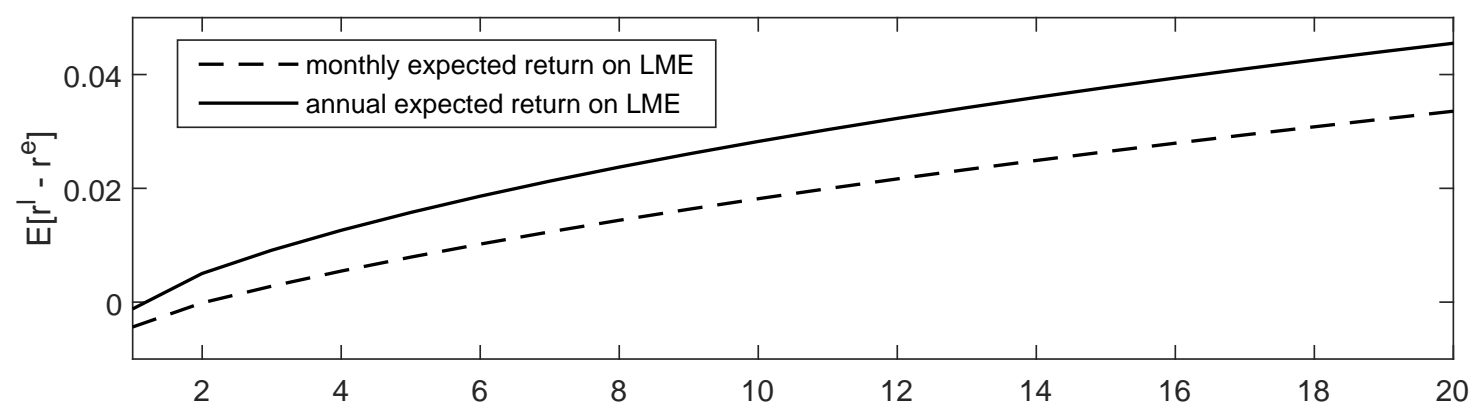

Panel A: Spread in expected returns between late and early claim as a function of $\gamma$

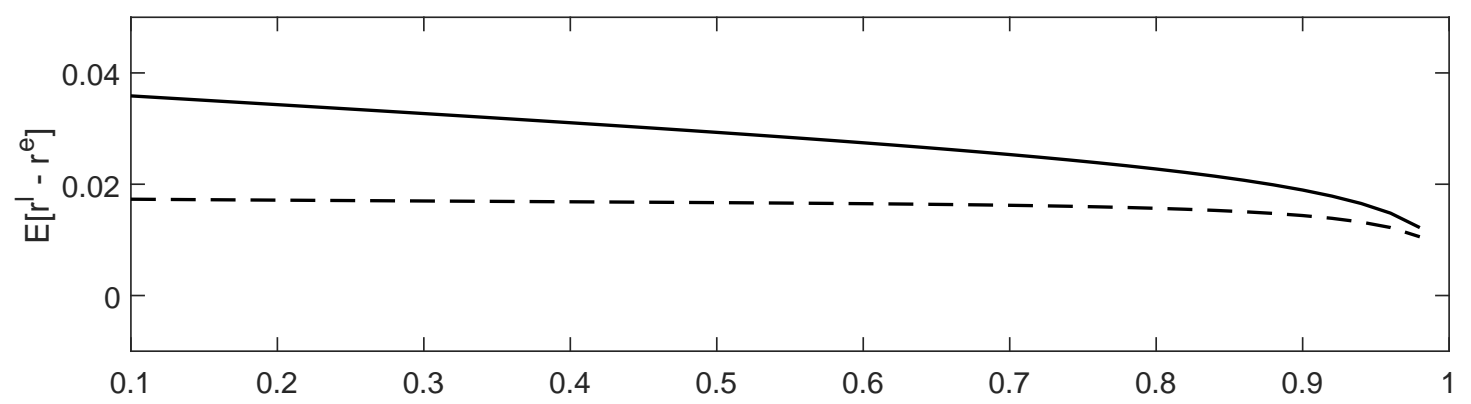

Panel B: Spread in expected returns between late and early claim as a function of $\psi^{-1}$

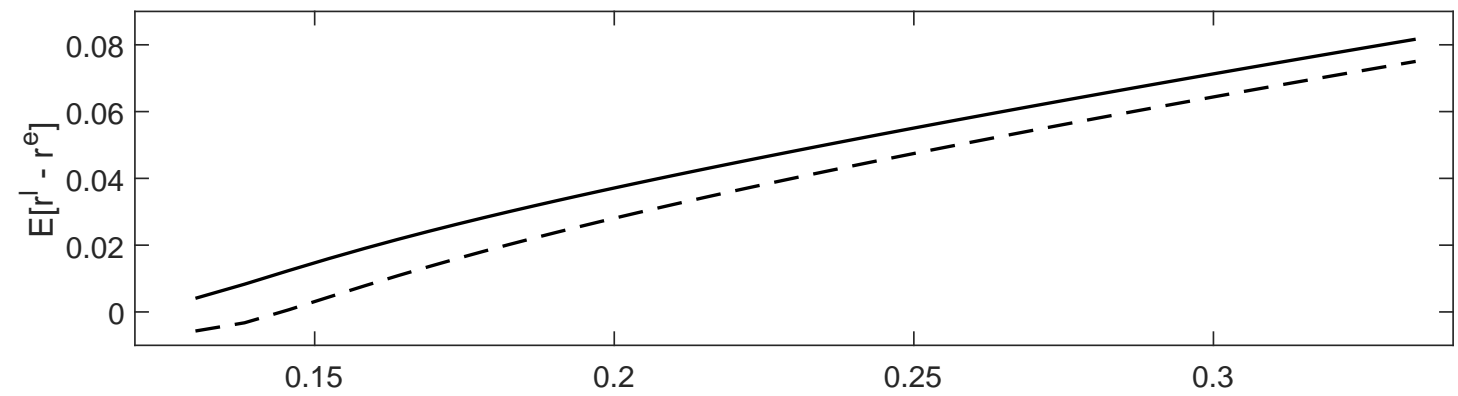

Panel C: Spread in expected returns between late and early claim as a function of the 12-months return volatility

Fig. 5. This figure shows the model-implied expected spread between the return on the late and the early claim. Expected returns are expressed in annual terms. In Panel A, the elasticity of intertemporal substitution is set to 1.5 and risk aversion $\gamma$ varies from 1 to 20. In Panel B, risk aversion is set to 10 and the inverse IES varies from 0.1 to 1 . In Panel C, we choose $\gamma=10$, $\psi=1.5$ and vary the leverage parameters. We vary $\phi_{e, t r a n}$ and $\phi_{l, p e r s}$ while leaving $\phi_{e, p e r s}$ and $\phi_{l, \text { tran }}$ unchanged (see Table 12), and plot the return spread against the 12-months volatility of the two claims. All other parameters are shown in Table 12. 


\title{
Appendix A. Details regarding the investment strategy
}

\author{
A.1. Selection of stocks, permuations, and variants of the strategy
}

This appendix provides further details on the trading strategy described in Section 3. To find pairs of early and late resolution stocks, we proceed as follows:

1. We put stocks in our sample in a random order.

2. Starting with the first stock, we identify all stocks with an $\mathrm{IV}_{365}$ differing from the original stock's $\mathrm{IV}_{365}$ by no more than 0.01 in absolute value.

3. From this set of stocks, we select the one whose $\mathrm{IV}_{30}$ differs most in absolute value from the original stock's $\mathrm{IV}_{30}$. If this difference is larger than 0.25 , we add this pair to the sample of pairs for the given month. We exclude the two stocks from the list of candidates.

4. We repeat step 2 with the second stock on the list of candidates and continue until all stocks have been considered or excluded because of selection into pairs.

Obviously, putting stocks in a different order could result in a different set of pairs, since a stock excluded previously is no longer available. Still, we do not want to allow a stock to appear in the sample for a given month more than once, since otherwise a small number of stocks with special characteristics might drive our results.

To make sure that the success of the strategy does not depends on the order in which we consider the stocks in the base sample, we rerun the strategy 50,000 times with the order of the stocks being chosen randomly. Tables 1 and 2 report the strategy with the median average return. In all of the 50,000 cases the average return on the investment strategy is significantly positive. Table C.3 in the Internet Appendix contains means, medians, and $95 \%$ confidence bounds from these 50,000 strategies.

We also vary the critical thresholds for the IV difference in the process of identifying pairs described above. Table C.1 in the Internet Appendix shows the results of this robustness check. We show portfolio return for minimum $\mathrm{IV}_{30}$ spreads of $5 \%, 10 \%, \ldots, 35 \%$ and for maximum $\mathrm{IV}_{365}$ spreads of $1 \%$ (Panel A) and $0.1 \%$ (Panel B). In general, the strategy is very robust and becomes more profitable when more extreme spreads are chosen. For example, choosing a maximum $\mathrm{IV}_{365}$ difference of $1 \%$ and a minimum $\mathrm{IV}_{30}$ difference of $35 \%$ results in average returns of $7.65 \%$ with a $t$-statistic of 3.46 . Using only moderate short-end IV differences also yields significantly positive (albeit smaller) average returns. The results are presented in Panel D of Table C.1.

In December 2003, there is no pair of stocks meeting the requirements of a difference in $\mathrm{IV}_{365}$ of less than $1 \%$ (or $0.1 \%$ ), and a in $\mathrm{IV}_{30}$ difference of more than $35 \%$. In this month, we assume that there is no investment, and the strategy return is set to zero.

We also perform a placebo test by not imposing a restriction on the maximum spread in $\mathrm{IV}_{365}$ to see whether our result is purely driven by the differences in $\mathrm{IV}_{30}$ (Panel $\mathrm{C}$ ). This is not the case, since the strategy returns for this specification are all insignificant.

Table C.5 in the Internet Appendix shows that the strategy is robust to variation in the endpoint of the IV term structure used for our analysis. Using $\mathrm{IV}_{270}$ or $\mathrm{IV}_{180}$ yields results similar to the original strategy. Using $\mathrm{IV}_{60}$ as the short term implied volatility even amplifies the original effect, while based on $\mathrm{IV}_{90}$, returns are still large but lose significance. 


\section{A.2. Weighting schemes}

It is crucial to weight stocks equally within a pair. To see this, consider the following example: There is a pair of stocks E1 and L1 (with matched one-year IV and markedly different 30 day IV) and another pair of stocks, E2 and L2 (with a different matched one-year IV and markedly different 30 day IV). Assume E1 and L2 have a large market capitalization, while L1 and E2 are small. Value-weighting of the early and late stocks across pairs would effectively amount to comparing the returns of E1 and L2 whose one-year IVs can be entirely different. According to our motivation, long-end IVs need to be matched to generate a return differential. As we show in Table C.1, not matching the long-end IVs does not yield significant returns.

To be conservative with respect to the amount invested in small stocks, we also provide results where the return on each long-short pair is weighted with the market capitalization of the smaller stock in the respective pair. Results inTable C.8 show that the return differentials remain large and significant.

\section{Appendix B. General Equilibrium Model}

\section{B.1. The pricing kernel}

The general Epstein and Zin (1989) utility log pricing kernel that discounts cash flows at time $t+1$ is given by

$$
m_{t \rightarrow t+1}=-\delta \theta-\frac{\theta}{\psi} \Delta c_{t+1}+(\theta-1) r_{t+1}^{w}
$$

where $r_{t+1}^{w}$ denotes the return on the claim on total wealth (the claim that pays aggregate consumption as dividend) and $\theta=(1-\gamma) /\left(1-\psi^{-1}\right)$. We will use the convention that whenever there is only one time index attached to the pricing kernel or a return, it denotes the one-period random variable that realizes at the indexed point in time, i.e. $m_{t+\tau}=m_{t+\tau-1 \rightarrow t+\tau}$ and $r_{t+\tau}=r_{t+\tau-1 \rightarrow t+\tau}$. The return on total wealth can be approximated in terms of the yet unknown log wealth-consumption ratio $w c$, which we conjecture to be affine in the state variables, i.e.,

$$
w c_{t}=A_{0}+\sum_{i=1}^{n} A_{x_{i}} x_{i, t}+\sum_{i=1}^{n} A_{v_{i}} v_{i, t} .
$$

The Campbell-Shiller approximation for $r_{t}^{w}$ is

$$
r_{t+1}^{w} \approx \kappa_{w c, 0}+\kappa_{w c, 1} w c_{t+1}-w c_{t}+\Delta c_{t, t+1}
$$

with

$$
\kappa_{w c, 1}=\frac{\exp (\overline{w c})}{1+\exp (\overline{w c})}
$$

and

$$
\kappa_{w c, 0}=\ln (1+\exp (\overline{w c}))-\frac{\exp (\overline{w c})}{1+\exp (\overline{w c})} \overline{w c},
$$

where $\overline{w c}$ denotes the steady state log wealth-consumption ratio.

To determine $w c$, plug (B.1) and (B.3) into the Euler equation to get

$$
1=\mathbb{E}_{t}\left[e^{m_{t+1}+r_{t+1}^{w}}\right]=E_{t}\left[e^{-\delta \theta-\frac{\theta}{\psi} \Delta c_{t, t+1}+\theta\left(\kappa_{w c, 0}+\kappa_{w c, 1} w c_{t+1}-w c_{t}+\Delta c_{t, t+1}\right)}\right]
$$

Using the conjecture (B.2) for the wealth consumption ratio in Equation (B.6) yields a system of linear equations 
with solution

$$
\begin{aligned}
& A_{0}= \frac{1}{1-\kappa_{w c, 1}}\left[-\delta+\kappa_{w c, 0}+\left(1-\rho_{v}\right) \kappa_{w c, 1} \bar{v} \sum_{i=1}^{n} A_{v_{i}}+\left(1-\psi^{-1}\right) \mu_{c}\right. \\
&\left.+\frac{1}{2} \theta\left(\kappa_{w c, 1}^{2} \sigma_{v}^{2} \sum_{i=1}^{n} A_{v_{i}}^{2}+\left(1-\psi^{-1}\right)^{2} \sigma_{c}^{2}\right)\right], \\
& A_{x_{i}}= \frac{\left(1-\psi^{-1}\right) \phi_{c i}}{1-\kappa_{w c, 1} \rho_{i}}, \\
& A_{v_{i}}=\frac{1}{2} \theta \frac{\left(A_{x_{i}} \kappa_{w c, 1}\right)^{2}}{1-\kappa_{w c, 1} \rho_{v i}} .
\end{aligned}
$$

These coefficients then yield the pricing kernel representation

$$
-m_{t+1}=m_{0}+\sum_{i=1}^{n}\left(m_{x_{i}} x_{i, t}+m_{v_{i}} v_{i, t}\right)+\lambda_{c} \sigma_{c} \varepsilon_{t+1}^{c}+\sum_{i=1}^{n}\left(\lambda_{x_{i}} \sqrt{v_{i, t}} \varepsilon_{t+1}^{i}+\lambda_{v_{i}} \sigma_{v} \varepsilon_{t+1}^{v i}\right)
$$

with

$$
\begin{aligned}
m_{0} & =\delta \theta+\gamma \mu_{c}+(1-\theta)\left(\kappa_{w c, 0}+\left(\kappa_{w c, 1}-1\right) A_{0}+\left(1-\rho_{v}\right) \kappa_{w c, 1} \bar{v} \sum_{i=1}^{n} A_{v_{i}}\right), \\
m_{x_{i}} & =(1-\theta) A_{x_{i}}\left(\kappa_{w c, 1} \rho_{i}-1\right)+\gamma \phi_{c i}=\phi_{c i} / \psi, \\
m_{v_{i}} & =(1-\theta) A_{v_{i}}\left(\kappa_{w c, 1} \rho_{v i}-1\right) .
\end{aligned}
$$

This implies the following market prices of risk:

$$
\begin{aligned}
\lambda_{c} & =\gamma \\
\lambda_{x_{i}} & =(1-\theta) \kappa_{w c, 1} A_{x_{i}} \\
\lambda_{v_{i}} & =(1-\theta) \kappa_{w c, 1} A_{v_{i}} .
\end{aligned}
$$

\section{B.2. Price-dividend ratios}

As before with the return on wealth, we linearize the return $r^{j}$ on dividend claim $d^{j}$ using the CampbellShiller approximation which yields

$$
r_{t+1}^{j} \approx \kappa_{p d, j, 0}+\kappa_{p d, j, 1} p d_{j, t+1}-p d_{j, t}+\Delta d_{t+1}^{j} .
$$

where $p d_{j, t}$ denotes the time $t$ price-dividend ratio of asset $j$. The coefficients are given by

$$
\begin{aligned}
\kappa_{p d, j, 1} & =\frac{\exp \left(\overline{p d}_{j}\right)}{1+\exp \left(\overline{p d}_{j}\right)} \\
\kappa_{p d, j, 0} & =\ln \left(1+\exp \left(\overline{p d}_{j}\right)\right)-\frac{\exp \left(\overline{p d}_{j}\right)}{1+\exp \left(\overline{p d}_{j}\right)} \overline{p d}_{j},
\end{aligned}
$$


where $\overline{p d}_{j}$ is the steady state of $p d_{j}$. We conjecture that the price dividend ratio is affine in the state variables:

$$
p d_{j, t}=B_{j, 0}+\sum_{i=1}^{n} B_{j, x_{i}} x_{i, t}+\sum_{i=1}^{n} B_{j, v_{i}} v_{i, t}
$$

Proceeding in the same fashion as before with the wealth-consumption ratio yields a system of linear equations with solution

$$
\begin{aligned}
& B_{j, 0}=\frac{1}{1-\kappa_{p d, j, 1}}[-\delta \theta-(1-\theta)\left(\kappa_{w c, 0}+\left(\kappa_{w c, 1}-1\right) A_{0}+\left(1-\rho_{v}\right) \kappa_{w c, 1} \bar{v} \sum_{i=1}^{n} A_{v_{i}}\right)-\gamma \mu_{c}+\kappa_{p d, j, 0}+\mu_{j} \\
&\left.+\frac{1}{2}\left(\gamma^{2} \sigma_{c}^{2}+\sigma_{j}^{2}\right)+\sum_{i=1}^{n}\left(\left(1-\rho_{v}\right) \kappa_{p d, j, 1} \bar{v} B_{j, v_{i}}+\frac{1}{2}\left(\kappa_{p d, j, 1} B_{j, v_{i}}-(1-\theta) \kappa_{w c, 1} A_{v_{i}}\right)^{2} \sigma_{v}^{2}\right)\right] \\
& B_{j, x_{i}}= \frac{\phi_{j i}-\psi^{-1} \phi_{c i}}{1-\kappa_{p d, j, 1} \rho_{i}}, \\
& B_{j, v_{i}}=\frac{1}{2} \theta \frac{\left(B_{j, x_{i}} \kappa_{p d, j, 1}\right)^{2}}{1-\kappa_{p d, j, 1} \rho_{v i}}+\frac{1}{2}(1-\theta) \frac{\left(A_{x_{i}} \kappa_{w c, 1}-B_{j, x_{i}} \kappa_{p d, j, 1}\right)^{2}}{1-\kappa_{p d, j, 1} \rho_{v i}} .
\end{aligned}
$$

Note that $B_{j, x_{i}}=0$ whenever $\phi_{j i}=\psi^{-1} \phi_{c i}$, as argued in Section 5.2.

\section{B.3. Term structure of expected excess returns}

Using Equation (B.17), we write the log return on asset $j$ as

$$
r_{t+1}^{j}=r_{0}^{j}+\sum_{i=1}^{n} r_{x_{i}}^{j} x_{i, t}+\sum_{i=1}^{n} r_{v_{i}}^{j} v_{i, t}+\sigma_{j} \varepsilon_{t+1}^{j}+\sum_{i=1}^{n} \beta_{j, x_{i}} \sqrt{v_{i, t}} \varepsilon_{t+1}^{i}+\sum_{i=1}^{n} \beta_{j, v_{i}} \sigma_{v} \varepsilon_{t+1}^{v i}
$$

where

$$
\begin{aligned}
r_{0}^{j} & =\kappa_{p d, j, 0}+\mu_{j}+\left(\kappa_{p d, j, 1}-1\right) B_{j, 0}+\left(1-\rho_{v}\right) \kappa_{p d, j, 1} \bar{v} \sum_{i=1}^{n} B_{j, v_{i}} \\
r_{x_{i}}^{j} & =\left(\kappa_{p d, j, 1} \rho_{i}-1\right) B_{j, x_{i}}+\phi_{j i}=\phi_{c i} / \psi=m_{x_{i}} \\
r_{v_{i}}^{j} & =\left(\kappa_{p d, j, 1} \rho_{v}-1\right) B_{j, v_{i}} \\
\beta_{x_{i}}^{j} & =\kappa_{p d, j, 1} B_{j, x_{i}} \\
\beta_{v_{i}}^{j} & =\kappa_{p d, j, 1} B_{j, v_{i}}
\end{aligned}
$$

We inductively calculate the coefficients $\pi_{0, \tau}^{j}$ and $\pi_{i, \tau}^{j}$ of the term structure of expected returns on asset $j$ according to Equation 7. We start with

$$
\left.E_{t}\left[r_{t+1}^{j}-r_{t+1}^{f}\right]+\frac{1}{2} \operatorname{Var}_{t}\left(r_{t+1}^{j}\right)\right]=\operatorname{Cov}_{t}\left(-m_{t+1}, r_{t+1}^{j}\right)=\sum_{i=1}^{n} \beta_{x_{i}}^{j} \lambda_{x_{i}} v_{i, t}+\sum_{i=1}^{n} \beta_{v_{i}}^{j} \lambda_{v_{i}} \sigma_{v}^{2},
$$

such that $\pi_{0,1}^{j}=\sum_{i=1}^{n} \beta_{v_{i}}^{j} \lambda_{v_{i}} \sigma_{v}^{2}$ and $\pi_{i, 1}^{j}=\beta_{x_{i}}^{j} \lambda_{x_{i}}$. For the induction step, note that

$$
E_{t}\left[r_{t \rightarrow t+\tau}^{j}-r_{t \rightarrow t+\tau}^{f}\right]+\frac{1}{2} \operatorname{Var}_{t}\left(r_{t \rightarrow t+\tau}^{j}\right)=\operatorname{Cov}_{t}\left(-m_{t \rightarrow t+\tau}, r_{t \rightarrow t+\tau}^{j}\right),
$$


where $m_{t, t+\tau}=m_{t+1}+\cdots+m_{t+\tau}$ and $r_{t \rightarrow t+\tau}^{j}=r_{t+1}^{j}+\cdots+r_{t+\tau}^{j}$. Assume we already know

$$
\operatorname{Cov}_{t}\left(-m_{t \rightarrow t+\tau-1}, r_{t \rightarrow t+\tau-1}^{j}\right)=\pi_{0, \tau-1}^{j}+\sum_{i=1}^{n} \pi_{i, \tau-1}^{j} v_{i, t} .
$$

We can decompose the expected excess return over $\tau$ periods into

$$
\begin{aligned}
\operatorname{Cov}_{t}\left(-m_{t \rightarrow t+\tau}, r_{t \rightarrow t+\tau}^{j}\right)= & \sum_{h_{1}, h_{2}=2}^{\tau} \operatorname{Cov}_{t}\left(-m_{t+h_{1}}, r_{t+h_{2}}^{j}\right)+\sum_{h=2}^{\tau} \operatorname{Cov}_{t}\left(-m_{t+h}, r_{t+1}^{j}\right) \\
& +\sum_{h=2}^{\tau} \operatorname{Cov}_{t}\left(-m_{t+1}, r_{t+h}^{j}\right)+\operatorname{Cov}_{t}\left(-m_{t+1}, r_{t+1}^{j}\right) .
\end{aligned}
$$

The first term on the right-hand side of Equation (B.33) can be written as

$$
\begin{aligned}
& \sum_{h_{1}, h_{2}=2}^{\tau} \operatorname{Cov}_{t}\left(-m_{t+h_{1}}, r_{t+h_{2}}^{j}\right) \\
& =\sum_{h_{1}, h_{2}=2}^{\tau}\left(E_{t}\left[\operatorname{Cov}_{t+1}\left(-m_{t+h_{1}}, r_{t+h_{2}}^{j}\right)\right]+\operatorname{Cov}_{t}\left(E_{t+1}\left[-m_{t+h_{1}}\right], E_{t+1}\left[r_{t+h_{2}}^{j}\right]\right)\right)
\end{aligned}
$$

where

$$
\sum_{h_{1}, h_{2}=2}^{\tau} E_{t}\left[\operatorname{Cov}_{t+1}\left(-m_{t+h_{1}}, r_{t+h_{2}}^{j}\right)\right]=\pi_{0, \tau-1}^{j}+\left(1-\rho_{v}\right) \bar{v} \sum_{i=1}^{n} \pi_{i, \tau-1}^{j}+\rho_{v} \sum_{i=1}^{n} \pi_{i, \tau-1}^{j} v_{i, t} .
$$

For the second term on the right-hand side of Equation (B.34), assume that we already know

$$
\sum_{h_{1}, h_{2}=2}^{\tau-1} \operatorname{Cov}_{t}\left(E_{t+1}\left[-m_{t+h_{1}}\right], E_{t+1}\left[r_{t+h_{2}}^{j}\right]\right)=\xi_{0, \tau-1}^{j}+\sum_{i=1}^{n} \xi_{i, \tau-1}^{j} v_{i, t}
$$

where we start at $\tau=1$ with $\xi_{0,1}^{j}=0$ and $\xi_{i, 1}^{j}=0$ for all $i=1, \ldots, n$. Then, we can calculate

$$
\begin{aligned}
\sum_{h_{1}, h_{2}=2}^{\tau} \operatorname{Cov}_{t}\left(E_{t+1}\left[-m_{t+h_{1}}\right], E_{t+1}\left[r_{t+h_{2}}^{j}\right]\right) \\
=\sum_{h_{1}, h_{2}=3}^{\tau} \operatorname{Cov}_{t}\left(E_{t+1}\left[-m_{t+h_{1}}\right], E_{t+1}\left[r_{t+h_{2}}^{j}\right]\right)+\sum_{h=2}^{\tau} \operatorname{Cov}_{t}\left(E_{t+1}\left[-m_{t+h}\right], E_{t+1}\left[r_{t+2}^{j}\right]\right) \\
\quad+\sum_{h=2}^{\tau} \operatorname{Cov}_{t}\left(E_{t+1}\left[-m_{t+2}\right], E_{t+1}\left[r_{t+h}^{j}\right]\right)-\operatorname{Cov}_{t}\left(E_{t+1}\left[-m_{t+2}\right], E_{t+1}\left[r_{t+2}^{j}\right]\right) \\
=\rho_{v}^{2} \xi_{0, \tau-1}^{j}+\sum_{i=1}^{n}\left(\rho_{i}^{2} \xi_{i, \tau-1}^{j} v_{i, t}+2 \frac{1-\rho_{v}^{\tau-1}}{1-\rho_{v}} \sigma_{v}^{2} m_{v_{i}} r_{v_{i}}^{j}+2 \frac{1-\rho_{i}^{\tau-1}}{1-\rho_{i}} m_{x_{i}} r_{x_{i}}^{j} v_{i, t}-m_{v_{i}} r_{v_{i}}^{j} \sigma_{v}^{2}-m_{x_{i}} r_{x_{i}}^{j} v_{i, t}\right) .
\end{aligned}
$$


The remaining three terms in Equation (B.33) are

$$
\begin{aligned}
\sum_{h=2}^{\tau} \operatorname{Cov}_{t}\left(-m_{t+h}, r_{t+1}^{j}\right) & =\sum_{i=1}^{n}\left(\lambda_{v_{i}} r_{v_{i}}^{j} \frac{1-\rho_{v}^{\tau-1}}{1-\rho_{v}} \sigma_{v}^{2}+\lambda_{x_{i}} r_{x_{i}}^{j} \frac{1-\rho_{i}^{\tau-1}}{1-\rho_{i}} v_{i, t}\right) \\
\sum_{h=2}^{\tau} \operatorname{Cov}_{t}\left(-m_{t+1}, r_{t+h}^{j}\right) & =\sum_{i=1}^{n}\left(m_{v_{i}} \beta_{v_{i}}^{j} \frac{1-\rho_{v}^{\tau-1}}{1-\rho_{v}} \sigma_{v}^{2}+m_{x_{i}} \beta_{x_{i}}^{j} \frac{1-\rho_{i}^{\tau-1}}{1-\rho_{i}} v_{i, t}\right)
\end{aligned}
$$

and the latter term is given in Equation (B.30). Putting the pieces together gives

$$
\begin{aligned}
\xi_{0, \tau}^{j} & =\rho_{v}^{2} \xi_{0, \tau-1}^{j}+\left(2 \frac{1-\rho_{v}^{\tau-1}}{1-\rho_{v}}-1\right) \sum_{i=1}^{n} m_{v_{i}} r_{v_{i}}^{j} \sigma_{v}^{2} \\
\xi_{i, \tau}^{j} & =\rho_{i}^{2} \xi_{i, \tau-1}^{j}+\left(2 \frac{1-\rho_{i}^{\tau-1}}{1-\rho_{i}}-1\right) m_{x_{i}} r_{x_{i}}^{j} \\
\pi_{0, \tau}^{j} & =\pi_{0, \tau-1}^{j}+\left(1-\rho_{v}\right) \bar{v} \sum_{i=1}^{n} \pi_{i, \tau-1}^{j}+\xi_{0, \tau}^{j}+\frac{1-\rho_{v}^{\tau-1}}{1-\rho_{v}} \sigma_{v}^{2} \sum_{i=1}^{n}\left(\lambda_{v_{i}} r_{v_{i}}^{j}+m_{v_{i}} \beta_{v_{i}}^{j}\right)+\sum_{i=1}^{n} \beta_{v_{i}}^{j} \lambda_{v_{i}} \sigma_{v}^{2} \\
\pi_{i, \tau}^{j} & =\rho_{v} \pi_{i, \tau-1}^{j}+\xi_{i, \tau}^{j}+\frac{1-\rho_{i}^{\tau-1}}{1-\rho_{i}}\left(\lambda_{x_{i}} r_{x_{i}}^{j}+m_{x_{i}} \beta_{x_{i}}^{j}\right)+\beta_{x_{i}}^{j} \lambda_{x_{i}}
\end{aligned}
$$

with initial values $\xi_{0,1}^{j}=0, \xi_{i, 1}^{j}=0$ for all $i=1, \ldots, n, \pi_{0,1}^{j}=\sum_{i=1}^{n} \beta_{v_{i}}^{j} \lambda_{v_{i}} \sigma_{v}^{2}$, and $\pi_{i, 1}^{j}=\beta_{x_{i}}^{j} \lambda_{x_{i}}$ for all $i=1, \ldots, n$.

\section{B.4. Term structure of return variances and IVD}

To calculate the term structure of return variances, we can proceed similarly to Appendix B.3. We can decompose the variance of the return between time $t$ and time $t+\tau$ as follows:

$$
\operatorname{Var}_{t}\left(r_{t \rightarrow t+\tau}^{j}\right)=\sum_{h_{1}, h_{2}=2}^{\tau} \operatorname{Cov}_{t}\left(r_{t+h_{1}}^{j}, r_{t+h_{2}}^{j}\right)+2 \sum_{h=2}^{\tau} \operatorname{Cov}_{t}\left(r_{t+h}^{j}, r_{t+1}^{j}\right)+\operatorname{Var}_{t}\left(r_{t+1}^{j}\right),
$$

which is analogous to Equation (B.33). As above, we can inductively calculate the first term on the right-hand side, while the other two are straight-forward. The coefficients $\chi_{0, \tau}^{j}$ and $\chi_{i, \tau}^{j}$, for $i=1, \ldots, n$ referred to in Section 5.1 are given by

$$
\begin{aligned}
\zeta_{0, \tau}^{j} & =\rho_{v}^{2} \zeta_{0, \tau-1}^{j}+\left(2 \frac{1-\rho_{v}^{\tau-1}}{1-\rho_{v}}-1\right) \sum_{i=1}^{n}\left(r_{v_{i}}^{j} \sigma_{v}\right)^{2} \\
\zeta_{i, \tau}^{j} & =\rho_{i}^{2} \zeta_{i, \tau-1}^{j}+\left(2 \frac{1-\rho_{i}^{\tau-1}}{1-\rho_{i}}-1\right)\left(r_{x_{i}}^{j}\right)^{2} \\
\chi_{0, \tau}^{j} & =\chi_{0, \tau-1}^{j}+\left(1-\rho_{v}\right) \bar{v} \sum_{i=1}^{n} \chi_{i, \tau-1}^{j}+\zeta_{0, \tau}^{j}+2 \frac{1-\rho_{v}^{\tau-1}}{1-\rho_{v}} \sigma_{v}^{2} \sum_{i=1}^{n} \beta_{v_{i}}^{j} r_{v_{i}}^{j}+\sum_{i=1}^{n}\left(\beta_{v_{i}}^{j} \sigma_{v}\right)^{2}+\sigma_{j}^{2} \\
\chi_{i, \tau}^{j} & =\rho_{v} \chi_{i, \tau-1}^{j}+\zeta_{i, \tau}^{j}+2 \frac{1-\rho_{i}^{\tau-1}}{1-\rho_{i}} \beta_{x_{i}}^{j} r_{x_{i}}^{j}+\left(\beta_{x_{i}}^{j}\right)^{2}
\end{aligned}
$$

with initial values $\zeta_{0,1}^{j}=0, \zeta_{i, 1}^{j}=0$ for all $i=1, \ldots, n, \chi_{0,1}^{j}=\sum_{i=1}^{n}\left(\beta_{v_{i}}^{j} \sigma_{v}\right)^{2}+\sigma_{j}^{2}$ and $\chi_{i, 1}^{j}=\left(\beta_{x_{i}}^{j}\right)^{2}$ for all $i=1, \ldots, n$. 
Using these coefficients, the volatility duration of asset $j$ can be calculated according to Equation (1). In the model, we are neither limited by the availability of options with a particular maturity, nor do we have to use options to get information about the forward-looking $\mathbb{P}$ volatility. We can thus replace $\Delta I V_{j, t, k}^{2}$ in Equation (1) by $\chi_{0, t+\tau_{k}}^{j}-\chi_{0, t+\tau_{k-1}}^{j}+\sum_{i=1}^{n}\left(\chi_{i, \tau_{k}}^{j}-\chi_{i, \tau_{k-1}}^{j}\right) v_{i, t}$. In particular, this implies that the implied volatility duration is only a function of the state variables $v_{i}$, but not $x_{i}$.

\section{B.5. Cash-flow duration}

The cash-flow duration can be calculated in closed form in our model. Instead of relying on approximations as in empirical applications, we can directly generalize the Macaulay duration formula to stocks. More precisely, we define

$$
C F D_{t}^{j}=\frac{\mathbb{E}_{t}\left[\sum_{\tau=1}^{\infty} M_{t \rightarrow t+\tau} D_{t+\tau}^{j}\right]}{P_{t}^{j}} \tau
$$

The numerator in the above expression corresponds to the price of a dividend strip, i.e. a claim on the dividend of stock $j$ in period $t+\tau$. With this definition, the weights exactly add to 1 because of the sum of all dividend strips is equal to the stock price at time $t$. We can reformulate the cash-flow duration as follows:

$$
\begin{aligned}
C F D_{t}^{j} & =\sum_{\tau=1}^{\infty} \frac{\mathbb{E}_{t}\left[M_{t \rightarrow t+\tau} D_{t+\tau}^{j}\right]}{P_{t}^{j}} \tau=\sum_{\tau=1}^{\infty} \frac{\mathbb{E}_{t}\left[M_{t \rightarrow t+\tau} \frac{D_{t+\tau}^{j}}{D_{t}^{j}}\right]}{P_{t}^{j} / D_{t}^{j}} \tau=\sum_{\tau=1}^{\infty} \frac{\mathbb{E}_{t}\left[\prod_{s=t+1}^{t+\tau} M_{s} \frac{D_{s}^{j}}{D_{s-1}^{j}}\right]}{P_{t}^{j} / D_{t}^{j}} \tau \\
& =\sum_{\tau=1}^{\infty} \frac{\mathbb{E}_{t}\left[\exp \left(\sum_{s=t+1}^{t+\tau}\left(m_{s}+\Delta d_{s}^{j}\right)\right)\right]}{\exp \left(p d_{j, t}\right)} \tau
\end{aligned}
$$

The terms $\mathbb{E}_{t}\left[\exp \left(\sum_{s=t+1}^{t+\tau}\left(m_{s}+\Delta d_{s}^{j}\right)\right)\right]$ can be calculated recursively in closed form. For $\tau=1$, we have

$$
\begin{aligned}
& \mathbb{E}_{t}\left[\exp \left(m_{t+1}+\Delta d_{t+1}\right)\right] \\
&=\mathbb{E}_{t}\left[\operatorname { e x p } \left(-m_{0}-\sum_{i=1}^{n}\left(m_{x_{i}} x_{i, t}+m_{v_{i}} v_{i, t}\right)-\lambda_{c} \sigma_{c} \varepsilon_{t+1}^{c}-\sum_{i=1}^{n}\left(\lambda_{x_{i}} \sqrt{v_{i, t}} \varepsilon_{t+1}^{i}+\lambda_{v_{i}} \sigma_{v} \varepsilon_{t+1}^{v i}\right)\right.\right. \\
&\left.\left.\quad+\mu_{j}+\sum_{i=1}^{n} \phi_{i j} x_{i, t}+\sigma_{j} \varepsilon_{t+1}^{j}\right)\right] \\
&=\exp \left(-m_{0}+\frac{1}{2}\left(\left(\lambda_{c} \sigma_{c}\right)^{2}+\sigma_{j}^{2}+\sum_{i=1}^{n} \lambda_{v_{i}}^{2} \sigma_{v}^{2}\right)+\mu_{j}+\sum_{i=1}^{n}\left(\phi_{j i}-m_{x_{i}}\right) x_{i, t}+\sum_{i=1}^{n}\left(\frac{1}{2} \lambda_{x_{i}}^{2}-m_{v_{i}}\right) v_{t, t}\right)
\end{aligned}
$$

For a given $\tau>1$, assume we know

$$
\mathbb{E}_{t}\left[\exp \left(\sum_{s=t+1}^{t+\tau-1}\left(m_{s}+\Delta d_{s}^{j}\right)\right)\right]=\exp \left(\eta_{0, \tau-1}^{j}+\sum_{i=1}^{n} \eta_{x_{i}, \tau-1}^{j} x_{i, t}+\sum_{i=1}^{n} \eta_{v_{i}, \tau-1}^{j} v_{i, t}\right)
$$


for some coefficients $\eta_{0, \tau-1}^{j}, \eta_{x_{i}, \tau-1}^{j}$, and $\eta_{v_{i}, \tau-1}^{j}$ for $i=1, \ldots, n$. Then we can calculate

$$
\begin{aligned}
& \mathbb{E}_{t}[\left.\exp \left(\sum_{s=t+1}^{t+\tau}\left(m_{s}+\Delta d_{s}^{j}\right)\right)\right]=\mathbb{E}_{t} \mathbb{E}_{t+1}\left[\exp \left(m_{t+1}+\Delta d_{t+1}+\sum_{s=t+2}^{t+\tau}\left(m_{s}+\Delta d_{s}^{j}\right)\right)\right] \\
&= \mathbb{E}_{t}\left[\exp \left(m_{t+1}+\Delta d_{t+1}\right) \mathbb{E}_{t+1}\left[\exp \left(\sum_{s=t+2}^{t+\tau}\left(m_{s}+\Delta d_{s}^{j}\right)\right)\right]\right] \\
&= \mathbb{E}_{t}\left[\exp \left(m_{t+1}+\Delta d_{t+1}+\eta_{0, \tau-1}^{j}+\sum_{i=1}^{n} \eta_{x_{i}, \tau-1}^{j} x_{i, t+1}+\sum_{i=1}^{n} \eta_{v_{i}, \tau-1}^{j} v_{i, t+1}\right)\right] \\
&= \exp \left(\eta_{0, \tau-1}^{j}-m_{0}+\mu_{j}+\sum_{i=1}^{n} \eta_{v_{i}, \tau-1}^{j}\left(1-\rho_{v}\right) \bar{v}+\frac{1}{2}\left(\left(\lambda_{c} \sigma_{c}\right)^{2}+\sigma_{j}^{2}+\sum_{i=1}^{n}\left(\eta_{v_{i}, \tau-1}^{j}-\lambda_{v_{i}}\right)^{2} \sigma_{v}^{2}\right)\right. \\
&\left.\quad+\sum_{i=1}^{n}\left(\eta_{x_{i}, \tau-1}^{j} \rho_{i}+\phi_{j i}-m_{x_{i}}\right) x_{i, t}+\sum_{i=1}^{n}\left(\eta_{v_{i}, \tau-1}^{j} \rho_{v}+\frac{1}{2}\left(\eta_{x_{i}, \tau-1}^{j}-\lambda_{x_{i}}\right)^{2}-m_{v_{i}}\right) v_{i, t}\right)
\end{aligned}
$$

This implies the following recursive formulas for the coefficients for horizon $\tau$ :

$$
\begin{aligned}
\eta_{0, \tau}^{j} & =\eta_{0, \tau-1}^{j}-m_{0}+\mu_{j}+\frac{1}{2}\left(\left(\lambda_{c} \sigma_{c}\right)^{2}+\sigma_{j}^{2}+\sum_{i=1}^{n}\left(\eta_{v_{i}, \tau-1}^{j}-\lambda_{v_{i}}\right)^{2} \sigma_{v}^{2}\right)+\sum_{i=1}^{n} \eta_{v_{i}, \tau-1}^{j}\left(1-\rho_{v}\right) \bar{v} \\
\eta_{x_{i}, \tau}^{j} & =\eta_{x_{i}, \tau-1}^{j} \rho_{i}+\phi_{j i}-m_{x_{i}}, \text { for } i=1, \ldots, n \\
\eta_{v_{i}, \tau}^{j} & =\eta_{v_{i}, \tau-1}^{j} \rho_{v}+\frac{1}{2}\left(\eta_{x_{i}, \tau-1}^{j}-\lambda_{x_{i}}\right)^{2}-m_{v_{i}}, \text { for } i=1, \ldots, n
\end{aligned}
$$

with starting values

$$
\begin{aligned}
\eta_{0,1}^{j} & =-m_{0}+\mu_{j}+\frac{1}{2}\left(\left(\lambda_{c} \sigma_{c}\right)^{2}+\sigma_{j}^{2}+\sum_{i=1}^{n} \lambda_{v_{i}}^{2} \sigma_{v}^{2}\right) \\
\eta_{x_{i}, \tau}^{j} & =\phi_{j i}-m_{x_{i}}, \text { for } i=1, \ldots, n \\
\eta_{v_{i}, \tau}^{j} & =\frac{1}{2} \lambda_{x_{i}}^{2}-m_{v_{i}}, \text { for } i=1, \ldots, n
\end{aligned}
$$




\title{
Appendix C. Internet Appendix
}

\author{
C.1. Additional Tables
}

Table C.1: Alternative investment strategies

Panel A: Maximum diff. $I V_{365}: 0.01$

\begin{tabular}{|c|c|c|c|c|}
\hline Min. diff. $\mathrm{IV}_{30}$ & low $\mathrm{IV}_{30}$ & high $\operatorname{IV}_{30}$ & difference & avg. number of stocks \\
\hline 0.05 & $\begin{array}{c}11.66^{* * *} \\
(2.86)\end{array}$ & $\begin{array}{c}10.34^{* *} \\
(2.35)\end{array}$ & $\begin{array}{c}1.33^{* *} \\
(2.24)\end{array}$ & 1641 \\
\hline 0.10 & $\begin{array}{c}11.60^{* *} \\
(2.57)\end{array}$ & $\begin{array}{l}9.32^{*} \\
(1.86)\end{array}$ & $\begin{array}{l}2.28^{* *} \\
(2.50)\end{array}$ & 900 \\
\hline 0.15 & $\begin{array}{c}11.53^{* *} \\
(2.35)\end{array}$ & $\begin{array}{l}7.85 \\
(1.44)\end{array}$ & $\begin{array}{c}3.68^{* * *} \\
(2.98)\end{array}$ & 525 \\
\hline 0.20 & $\begin{array}{c}11.07^{* *} \\
(2.16)\end{array}$ & $\begin{array}{l}6.83 \\
(1.19)\end{array}$ & $\begin{array}{c}4.24^{* * *} \\
(2.83)\end{array}$ & 329 \\
\hline 0.25 & $\begin{array}{c}10.86^{* *} \\
(2.06)\end{array}$ & $\begin{array}{l}5.70 \\
(0.97)\end{array}$ & $\begin{array}{c}5.17^{* * *} \\
(3.10)\end{array}$ & 220 \\
\hline 0.30 & $\begin{array}{c}11.10^{* *} \\
(1.99)\end{array}$ & $\begin{array}{l}4.96 \\
(0.83)\end{array}$ & $\begin{array}{c}6.15^{* * *} \\
(3.30)\end{array}$ & 154 \\
\hline 0.35 & $\begin{array}{c}11.67^{* *} \\
(2.06)\end{array}$ & $\begin{array}{l}4.03 \\
(0.67)\end{array}$ & $\begin{array}{c}7.65^{* * *} \\
(3.46)\end{array}$ & 113 \\
\hline \multicolumn{5}{|c|}{ Panel B: Maximum diff. $I V_{365}: 0.001$} \\
\hline Min. diff. $\mathrm{IV}_{30}$ & low $\mathrm{IV}_{30}$ & high $\mathrm{IV}_{30}$ & difference & avg. number of stocks \\
\hline 0.05 & $\begin{array}{c}11.84^{* * *} \\
(2.94)\end{array}$ & $\begin{array}{c}10.71^{* *} \\
(2.48)\end{array}$ & $\begin{array}{l}1.13^{*} \\
(1.95)\end{array}$ & 1273 \\
\hline 0.10 & $\begin{array}{c}11.41^{* * *} \\
(2.58)\end{array}$ & $\begin{array}{c}9.50^{* *} \\
(1.97)\end{array}$ & $\begin{array}{l}1.91^{* *} \\
(2.48)\end{array}$ & 649 \\
\hline 0.15 & $\begin{array}{c}11.41^{* *} \\
(2.36)\end{array}$ & $\begin{array}{l}8.44 \\
(1.59)\end{array}$ & $\begin{array}{c}2.97^{* * *} \\
(2.37)\end{array}$ & 354 \\
\hline 0.20 & $\begin{array}{c}11.39^{* *} \\
(2.24)\end{array}$ & $\begin{array}{l}7.74 \\
(1.40)\end{array}$ & $\begin{array}{c}3.65^{* * *} \\
(2.60)\end{array}$ & 210 \\
\hline 0.25 & $\begin{array}{c}11.99^{* *} \\
(2.20)\end{array}$ & $\begin{array}{l}6.44 \\
(1.14)\end{array}$ & $\begin{array}{c}5.55^{* * *} \\
(3.07)\end{array}$ & 134 \\
\hline 0.30 & $\begin{array}{c}13.45^{* *} \\
(2.33)\end{array}$ & $\begin{array}{l}6.46 \\
(1.08)\end{array}$ & $\begin{array}{c}6.99^{* * *} \\
(3.87)\end{array}$ & 91 \\
\hline 0.35 & $\begin{array}{c}12.48^{* *} \\
(2.14)\end{array}$ & $\begin{array}{l}6.90 \\
(1.11)\end{array}$ & $\begin{array}{c}5.58^{* *} \\
(2.50)\end{array}$ & 65 \\
\hline
\end{tabular}

Table continues on next page 


\section{Continued: Alternative investment strategies}

Panel C: Maximum diff. $I V_{365}$ : no restriction

\begin{tabular}{|c|c|c|c|c|}
\hline Min. diff. $I_{30}$ & low $\mathrm{IV}_{30}$ & high $\mathrm{IV}_{30}$ & difference & avg. number of stocks \\
\hline 0.05 & $\begin{array}{c}12.47^{\text {*** }} \\
(3.97)\end{array}$ & $\begin{array}{c}10.11^{*} \\
(1.95)\end{array}$ & $\begin{array}{c}2.36 \\
(0.79)\end{array}$ & 2299 \\
\hline 0.10 & $\begin{array}{c}12.44^{* * *} \\
(4.02)\end{array}$ & $\begin{array}{l}9.93^{*} \\
(1.84)\end{array}$ & $\begin{array}{c}2.52 \\
(0.75)\end{array}$ & 2164 \\
\hline 0.15 & $\begin{array}{c}12.44^{* * *} \\
(4.10)\end{array}$ & $\begin{array}{l}9.68^{*} \\
(1.72)\end{array}$ & $\begin{array}{l}2.75 \\
(0.73)\end{array}$ & 1977 \\
\hline 0.20 & $\begin{array}{c}12.46^{* * *} \\
(4.17)\end{array}$ & $\begin{array}{l}9.35 \\
(1.59)\end{array}$ & $\begin{array}{l}3.10 \\
(0.74)\end{array}$ & 1770 \\
\hline 0.25 & $\begin{array}{c}12.42^{* * *} \\
(4.24)\end{array}$ & $\begin{array}{l}9.07 \\
(1.47)\end{array}$ & $\begin{array}{l}3.34 \\
(0.72)\end{array}$ & 1557 \\
\hline 0.30 & $\begin{array}{c}12.25^{\text {*** }} \\
(4.28)\end{array}$ & $\begin{array}{l}8.70 \\
(1.35)\end{array}$ & $\begin{array}{c}3.55 \\
(0.70)\end{array}$ & 1351 \\
\hline 0.35 & $\begin{array}{c}12.22^{* * *} \\
(4.35)\end{array}$ & $\begin{array}{l}8.25 \\
(1.23)\end{array}$ & $\begin{array}{l}3.97 \\
(0.73)\end{array}$ & 1160 \\
\hline Panel D: & \multicolumn{4}{|c|}{ Difference Brackets $I V_{30}$, Maximum diff. $I V_{365}: 0.01$} \\
\hline Diff. IV 30 & low $\mathrm{IV}_{30}$ & high $\mathrm{IV}_{30}$ & difference & avg. number of stocks \\
\hline$\leq 0.001$ & $\begin{array}{c}12.23^{* * *} \\
(3.51)\end{array}$ & $\begin{array}{c}12.32^{* * *} \\
(3.53)\end{array}$ & $\begin{array}{l}-0.09 \\
(-0.84)\end{array}$ & 1160 \\
\hline $0.001-0.05$ & $\begin{array}{c}11.78^{* * *} \\
(3.00)\end{array}$ & $\begin{array}{c}11.13^{* * *} \\
(2.78)\end{array}$ & $\begin{array}{c}0.64^{* * *} \\
(2.69)\end{array}$ & 1957 \\
\hline $0.05-0.15$ & $\begin{array}{c}11.60^{* * *} \\
(2.82)\end{array}$ & $\begin{array}{c}10.34^{* *} \\
(2.35)\end{array}$ & $\begin{array}{l}1.26^{* *} \\
(2.36)\end{array}$ & 1553 \\
\hline $0.15-0.25$ & $\begin{array}{c}11.41^{* *} \\
(2.31)\end{array}$ & $\begin{array}{c}8.24 \\
(1.51)\end{array}$ & $\begin{array}{c}3.17^{* * *} \\
(2.92)\end{array}$ & 481 \\
\hline$>0.25$ & $\begin{array}{c}10.86^{* *} \\
(2.06)\end{array}$ & $\begin{array}{l}5.70 \\
(0.97)\end{array}$ & $\begin{array}{c}5.17^{* * *} \\
(3.10)\end{array}$ & 220 \\
\hline
\end{tabular}

The table shows summary return statistics of the investment strategy for different maximum differences between $\mathrm{IV}_{365}$ and minimum differences in $\mathrm{IV}_{30}$ for candidate stocks for pairs in the context of the trading strategy described in Section 3. Numbers in parentheses are $t$-statistics adjusted according to Newey and West (1987) with 12 lags. The results reported here refer to the median strategy (see Appendix A). ${ }^{* * *},{ }^{* *}$, and ${ }^{*}$ indicate significance at the 1\%, 5\%, and $10 \%$ level, respectively. The right column shows the average number of stocks that are assigned to pairs, rounded to the nearest integer. The average absolute number of stocks in our sample is 2331 . Note that the numbers in the right column in Panel $D$ need not add up to 2331 because while the sample of pairs is split up in disjoint sets, stocks can simultaneously be part of several pairs in disjoint sets of pairs. The sample formation period is $01 / 1996$ to $12 / 2014$. 


\section{Table C.2: Returns on investment strategy based on pairs}

\begin{tabular}{|c|c|c|c|}
\hline Month & Low $\mathrm{IV}_{30}$ & High $\mathrm{IV}_{30}$ & Investment strategy \\
\hline 1 & $\begin{array}{c}0.79 \\
(1.38)\end{array}$ & $\begin{array}{c}0.35 \\
(0.54)\end{array}$ & $\begin{array}{c}0.44^{* *} \\
(1.97)\end{array}$ \\
\hline 2 & $\begin{array}{l}0.99^{*} \\
(1.67)\end{array}$ & $\begin{array}{l}-0.11 \\
(-0.16)\end{array}$ & $\begin{array}{c}1.10^{* * *} \\
(4.12)\end{array}$ \\
\hline 3 & $\begin{array}{c}0.78 \\
(1.33)\end{array}$ & $\begin{array}{c}0.26 \\
(0.40)\end{array}$ & $\begin{array}{l}0.51^{*} \\
(1.88)\end{array}$ \\
\hline 4 & $\begin{array}{c}0.74 \\
(1.24)\end{array}$ & $\begin{array}{c}0.05 \\
(0.07)\end{array}$ & $\begin{array}{c}0.69^{* * *} \\
(2.84)\end{array}$ \\
\hline 5 & $\begin{array}{c}0.82 \\
(1.45)\end{array}$ & $\begin{array}{c}0.42 \\
(0.67)\end{array}$ & $\begin{array}{c}0.40 \\
(1.54)\end{array}$ \\
\hline 6 & $\begin{array}{c}0.80 \\
(1.43)\end{array}$ & $\begin{array}{c}0.23 \\
(0.38)\end{array}$ & $\begin{array}{c}0.57^{* *} \\
(2.07)\end{array}$ \\
\hline 7 & $\begin{array}{c}0.87 \\
(1.52)\end{array}$ & $\begin{array}{c}0.52 \\
(0.83)\end{array}$ & $\begin{array}{c}0.36 \\
(1.48)\end{array}$ \\
\hline 8 & $\begin{array}{c}0.82 \\
(1.47)\end{array}$ & $\begin{array}{c}0.50 \\
(0.81)\end{array}$ & $\begin{array}{c}0.32 \\
(1.15)\end{array}$ \\
\hline 9 & $\begin{array}{c}0.83 \\
(1.48)\end{array}$ & $\begin{array}{c}0.73 \\
(1.15)\end{array}$ & $\begin{array}{c}0.10 \\
(0.42)\end{array}$ \\
\hline 10 & $\begin{array}{c}0.79 \\
(1.42)\end{array}$ & $\begin{array}{c}0.65 \\
(1.11)\end{array}$ & $\begin{array}{c}0.15 \\
(0.68)\end{array}$ \\
\hline 11 & $\begin{array}{l}0.93^{*} \\
(1.66)\end{array}$ & $\begin{array}{c}0.58 \\
(0.58)\end{array}$ & $\begin{array}{c}0.35 \\
(1.50)\end{array}$ \\
\hline 12 & $\begin{array}{l}0.96^{*} \\
(1.68)\end{array}$ & $\begin{array}{c}0.70 \\
(1.17)\end{array}$ & $\begin{array}{c}0.26 \\
(1.25)\end{array}$ \\
\hline
\end{tabular}

The table shows the average returns on the trading strategy based on pairs for each of the months in which stocks are held. Pairs are formed such that the values for $\mathrm{IV}_{365}$ of the two stocks in a pair do not differ by more than one percentage point, while $\mathrm{IV}_{30}$ must differ by at least 25 percentage points. The positions are held over the subsequent 12 months. The results reported here refer to the median strategy (see Appendix A). Numbers in parentheses are $t$-statistics adjusted according to Newey and West (1987) with 12 lags. The strategy depends on the order of stocks in our sample (see Appendix A for details). We perform the strategy with 50,000 candidate permutations and report the median return with its respective $t$-statistic in this table. The sample formation period is $01 / 1996$ to $12 / 2014$. 


\section{Table C.3: Distribution of strategy returns - 12 months}

Panel A: Return on low $I V_{30}$ portfolio

\begin{tabular}{|c|c|c|c|c|}
\hline & mean & $2.5 \%$ & median & $97.5 \%$ \\
\hline mean & 0.1091 & 0.0994 & 0.1091 & 0.1190 \\
\hline$t$-statistic & 2.0427 & 1.8823 & 2.0422 & 2.2072 \\
\hline std & 0.3172 & 0.3048 & 0.3170 & 0.3306 \\
\hline \multicolumn{5}{|c|}{ Panel B: Return on high $I V_{30}$ portfolio } \\
\hline & mean & $2.5 \%$ & median & $97.5 \%$ \\
\hline mean & 0.0574 & 0.0550 & 0.0574 & 0.0598 \\
\hline$t$-statistic & 0.9781 & 0.9409 & 0.9783 & 1.0152 \\
\hline std & 0.3432 & 0.3402 & 0.3432 & 0.3462 \\
\hline \multicolumn{5}{|c|}{ Panel C: Return on investment strategy } \\
\hline & mean & $2.5 \%$ & median & $97.5 \%$ \\
\hline mean & 0.0517 & 0.0416 & 0.0517 & 0.0621 \\
\hline$t$-statistic & 3.0018 & 2.3746 & 2.9875 & 3.7089 \\
\hline std & 0.1436 & 0.1342 & 0.1434 & 0.1535 \\
\hline
\end{tabular}

The table shows summary statistics for the returns on 50,000 repetitions for our investment strategy based on pairs (see Section 3), where for each repetition, stocks are ordered randomly. Then, pairs are formed according to the mechanism explained in Appendix A and held for twelve months. The columns show the cross-sectional mean, $2.5 \%$ quantile, median, and $97.5 \%$ quantile of the respective statistic across the 50,000 repetitions. In each repetition, $t$-statistics are adjusted according to Newey and West (1987) with 12 lags. The sample formation period is 01/1996 to 12/2014. 


\section{Table C.4: Distribution of strategy returns - 1 month}

\begin{tabular}{|c|c|c|c|c|}
\hline \multicolumn{5}{|c|}{ Panel A: Return on low $I V_{30}$ portfolio } \\
\hline & mean & $2.5 \%$ & median & $97.5 \%$ \\
\hline mean & 0.0079 & 0.0064 & 0.0079 & 0.0095 \\
\hline t-stat & 1.4205 & 1.1314 & 1.4191 & 1.7144 \\
\hline std & 0.0854 & 0.0836 & 0.0854 & 0.0873 \\
\hline \multicolumn{5}{|c|}{ Panel B: Return on high $I V_{30}$ portfolio } \\
\hline & mean & $2.5 \%$ & median & $97.5 \%$ \\
\hline mean & 0.0035 & 0.0028 & 0.0035 & 0.0041 \\
\hline t-stat & 0.5594 & 0.4553 & 0.5597 & 0.6640 \\
\hline std & 0.1002 & 0.0994 & 0.1002 & 0.1009 \\
\hline \multicolumn{5}{|c|}{ Panel C: Return on investment strategy } \\
\hline & mean & $2.5 \%$ & median & $97.5 \%$ \\
\hline mean & 0.0044 & 0.0027 & 0.0044 & 0.0061 \\
\hline t-stat & 1.9984 & 1.2001 & 1.9899 & 2.8547 \\
\hline std & 0.0416 & 0.0395 & 0.0416 & 0.0437 \\
\hline
\end{tabular}

The table shows summary statistics for the returns on 50,000 repetitions for our investment strategy based on pairs (see Section 3), where for each repetition, stocks are ordered randomly. Then, pairs are formed according to the mechanism explained in Appendix A and held for one month. The columns show the cross-sectional mean, $2.5 \%$ quantile, median, and $97.5 \%$ quantile of the respective statistic across the 50,000 repetitions. In each repetition, $t$-statistics are adjusted according to Newey and West (1987) with 12 lags. The sample formation period is 01/1996 to 08/2015. 


\section{Table C.5: Strategy returns - different IV maturities}

Panel A: Maturity IV long end: 365 days

\begin{tabular}{ccccc}
\hline Maturity IV short end & returns low IV & returns high IV & investment strategy & Avg number of stocks \\
30 days & $10.86^{* *}$ & 5.70 & $5.17^{* * *}$ & 220 \\
& $(2.06)$ & $(0.97)$ & $(3.10)$ & 144 \\
60 days & $11.91^{* *}$ & 4.93 & $6.98^{* * *}$ & \\
& $(2.17)$ & $(0.79)$ & $(3.68)$ & 70 \\
90 days & $12.42^{*}$ & 6.95 & 5.47 & $(1.63)$ \\
& $(2.03)$ & $(1.03)$ & & \\
& & Panel B: Maturity IV long end: 270 days & \\
&
\end{tabular}

\begin{tabular}{|c|c|c|c|c|}
\hline Maturity IV short end & returns low IV & returns high IV & investment strategy & Avg number of stocks \\
\hline 30 days & $\begin{array}{c}11.32^{* *} \\
(2.13)\end{array}$ & $\begin{array}{c}5.34 \\
(0.93)\end{array}$ & $\begin{array}{c}5.98^{* * *} \\
(3.31)\end{array}$ & 206 \\
\hline 60 days & $\begin{array}{c}12.69^{* *} \\
(2.28)\end{array}$ & $\begin{array}{l}4.60 \\
(0.77)\end{array}$ & $\begin{array}{c}8.09^{* * *} \\
(4.28)\end{array}$ & 130 \\
\hline 90 days & $\begin{array}{c}13.52^{* *} \\
(2.08)\end{array}$ & $\begin{array}{c}6.60 \\
(1.02)\end{array}$ & $\begin{array}{l}6.92^{*} \\
(1.82)\end{array}$ & 57 \\
\hline \multicolumn{5}{|c|}{ Panel C: Maturity IV long end: 180 days } \\
\hline Maturity IV short end & returns low IV & returns high IV & investment strategy & Avg number of stocks \\
\hline 30 days & $\begin{array}{c}11.75^{* *} \\
(2.09)\end{array}$ & $\begin{array}{c}5.69 \\
(1.01)\end{array}$ & $\begin{array}{c}6.06^{* * *} \\
(3.25)\end{array}$ & 185 \\
\hline 60 days & $\begin{array}{c}12.34^{* *} \\
(1.96)\end{array}$ & $\begin{array}{l}4.84 \\
(0.85)\end{array}$ & $\begin{array}{l}7.51^{* * *} \\
(2.95)\end{array}$ & 109 \\
\hline 90 days & $\begin{array}{c}17.76^{* *} \\
(2.21)\end{array}$ & $\begin{array}{l}10.45 \\
(1.58)\end{array}$ & $\begin{array}{l}7.31 \\
(1.51)\end{array}$ & 40 \\
\hline
\end{tabular}

The table shows average returns for our investment strategy based on pairs (see Section 3), when implied volatility (IV) is taken from long- and short-term options with varying maturities. The results reported here refer to the median strategy (see Appendix A). The minimum difference in short-end IVs is 0.25 . Numbers in parentheses are $t$ - statistics adjusted according to Newey and West (1987) with 12 lags. ${ }^{* * *},{ }^{* *}$, and ${ }^{*}$ indicate significance at the 1\%, 5\%, and $10 \%$ level, respectively. The right column shows the average number of stocks rounded to the nearest integer that are assigned to pairs. The average absolute number of stocks in our sample is 2331 . The sample formation period is 01/1996 to $12 / 2014$. 


\section{Table C.6: Strategy returns - Non-overlapping strategy}

\begin{tabular}{|c|c|c|c|c|}
\hline $\begin{array}{l}\text { formation freq. / } \\
\text { inv. horizon (months) }\end{array}$ & $\begin{array}{l}\text { returns } \\
\text { low IV }\end{array}$ & $\begin{array}{l}\text { returns } \\
\text { high IV }\end{array}$ & $\begin{array}{l}\text { returns } \\
\text { investment } \\
\text { strategy }\end{array}$ & $\begin{array}{l}\text { avg. number } \\
\text { of stocks }\end{array}$ \\
\hline 1 & $\begin{array}{c}0.0073 \\
(1.38)\end{array}$ & $\begin{array}{c}0.0031 \\
(0.51)\end{array}$ & $\begin{array}{c}0.0042^{*} \\
(1.94)\end{array}$ & 230 \\
\hline 2 & $\begin{array}{c}0.0175^{*} \\
(1.71)\end{array}$ & $\begin{array}{c}0.0033 \\
(0.27)\end{array}$ & $\begin{array}{l}0.0143^{* * *} \\
\quad(2.97)\end{array}$ & 230 \\
\hline 3 & $\begin{array}{c}0.0235^{*} \\
(1.93)\end{array}$ & $\begin{array}{c}0.0031 \\
(0.22)\end{array}$ & $\begin{array}{l}0.0204^{* * *} \\
\quad(2.88)\end{array}$ & 232 \\
\hline 6 & $\begin{array}{c}0.0356^{*} \\
(1.82)\end{array}$ & $\begin{array}{c}0.0018 \\
(0.07)\end{array}$ & $\begin{array}{c}0.0339^{* *} \\
(2.25)\end{array}$ & 214 \\
\hline
\end{tabular}

The table shows average returns for our investment strategy based on pairs (see Section 3), when portfolios are not overlapping. With investment horizon of one month, this coincides with the usual strategy with one-month holding period. The results reported here refer to the median strategy (see Appendix A). Numbers in parentheses are $t$ - statistics adjusted according to Newey and West (1987) with 12 lags. ${ }^{* * *},{ }^{* *}$, and ${ }^{*}$ indicate significance at the $1 \%, 5 \%$, and $10 \%$ level, respectively. The sample periods are $01 / 1996$ to $08 / 2015$ (to $06 / 2015$ for 6 month horizon). The first formation period is always January 1996, the second is February 1996 (1 month freq.) (March 1996 (2 month freq.), April (3 month freq.) 1996, July 1996 (6 month freq.), and so on.) The order of stocks is from the median strategy (see Appendix A). The right column shows the average number of stocks rounded to the nearest integer that are assigned to pairs. The average absolute number of stocks in this longer sample is 2354 (2348 for the sample from 01/1996 to 06/2015). 


\section{Table C.7: Investment strategy returns split up by type of pairs}

\begin{tabular}{ccccc} 
& low $\mathrm{IV}_{30}$ & ${\text { High } \mathrm{IV}_{30}}$ & strategy & Avg. no of stocks \\
\hline downward/downward & 8.78 & 7.47 & 1.31 & 39 \\
& $(1.51)$ & $(1.41)$ & $(0.47)$ & \\
downward/flat & $13.72^{* *}$ & 7.00 & $6.72^{* *}$ & 29 \\
& $(2.09)$ & $(1.07)$ & $(2.20)$ & \\
downward/upward & $10.59^{* *}$ & 5.96 & $4.63^{* *}$ & 150 \\
& $(2.13)$ & $(1.01)$ & $(2.57)$ & \\
flat/upward & 9.68 & 2.83 & 6.85 & 2 \\
& $(1.04)$ & $(0.35)$ & $(1.48)$ & \\
upward/upward & 2.38 & 0.70 & 1.68 & $<1$ \\
& $(0.28)$ & $(0.09)$ & $(0.70)$ & \\
\hline
\end{tabular}

The table shows summary return statistics of the baseline investment strategy split up according to the shapes of the IV term structures within the pairs. For example, downward/flat means that the implied volatility term structure of the High $\mathrm{IV}_{30}$ stock is downward sloping, while that of the Low $\mathrm{IV}_{30}$ stock is flat. "Flat" means that the absolute distance between the 1-month and 1-year IVs is at most 0.01. Long-end IVs within a pair still differ by at most 0.01 . The results reported here refer to the median strategy (see Appendix A). Numbers in parentheses are $t$-statistics adjusted according to Newey and West (1987) with 12 lags. ${ }^{* * *},{ }^{* *}$, and ${ }^{*}$ indicate significance at the $1 \%, 5 \%$, and $10 \%$ level, respectively. The right column shows the average number of stocks that are assigned to pairs. The average absolute number of stocks rounded to the nearest integer in our sample is 2331 . The numbers in the fifth column add up to the total number of stocks in the baseline setting. The sample formation period is $01 / 1996$ to $12 / 2014$. 
Table C.8: Returns on investment strategy, value-weighted using size of smaller stock

\begin{tabular}{ccc} 
Low $\mathrm{IV}_{30}$ & High $\mathrm{IV}_{30}$ & Investment strategy \\
\hline $12.09^{* *}$ & 7.94 & $4.15^{* *}$ \\
$(2.57)$ & $(1.44)$ & $(2.37)$ \\
\hline
\end{tabular}

The table shows the average returns on the trading strategy based on pairs where the weighting between the pairs is value-weighted using the market capitalization of the stock in the pairs with the lower market capitalization. Pairs are formed such that the values for $\mathrm{IV}_{365}$ of the two stocks in a pair do not differ by more than one percentage point, while $\mathrm{IV}_{30}$ must differ by at least 25 percentage points. The positions are held over the subsequent 12 months. Numbers in parentheses are Newey and West (1987) $t$-statistics with 12 lags. The results reported here refer to the median strategy (see Appendix A). 


\section{Table C.9: Top IV quintile: Fama French Industry Classification}

\begin{tabular}{lcccccc}
\multicolumn{7}{c}{ Panel $A$ : Equally-weighted industry share } \\
\hline & early & 2 & 3 & 4 & late & sample \\
Consumer Non-durables & 0.0213 & 0.0217 & 0.0200 & 0.0197 & 0.0211 & 0.0449 \\
Consumer Durables & 0.0163 & 0.0166 & 0.0156 & 0.0153 & 0.0154 & 0.0227 \\
Manufacturing & 0.0568 & 0.0653 & 0.0636 & 0.0599 & 0.0576 & 0.1168 \\
Energy & 0.0391 & 0.0465 & 0.0472 & 0.0430 & 0.0355 & 0.0495 \\
High Technology & 0.3447 & 0.3782 & 0.3880 & 0.3715 & 0.3536 & 0.2111 \\
Telecom & 0.0471 & 0.0392 & 0.0379 & 0.0397 & 0.0404 & 0.0345 \\
Shops & 0.0650 & 0.0690 & 0.0669 & 0.0712 & 0.0584 & 0.1046 \\
Health & 0.1929 & 0.1660 & 0.1663 & 0.1744 & 0.2188 & 0.1036 \\
Utilities & 0.0048 & 0.0029 & 0.0033 & 0.0029 & 0.0034 & 0.0311 \\
Other & 0.2120 & 0.1946 & 0.1913 & 0.2023 & 0.1958 & 0.2813 \\
& & & & & & \\
& Panel & $B$ Value-weighted & industry & share & & \\
\hline Consumer Non-durables & 0.0182 & 0.012 & 0.0118 & 0.0130 & 0.0138 & 0.0589 \\
Consumer Durables & 0.0135 & 0.0206 & 0.0146 & 0.0122 & 0.0196 & 0.0299 \\
Manufacturing & 0.0417 & 0.0667 & 0.0594 & 0.0548 & 0.0450 & 0.1162 \\
Energy & 0.0415 & 0.0521 & 0.0560 & 0.0465 & 0.0367 & 0.0844 \\
High Technology & 0.3871 & 0.3945 & 0.4124 & 0.3934 & 0.3468 & 0.1584 \\
Telecom & 0.0732 & 0.0547 & 0.0554 & 0.0556 & 0.0766 & 0.0497 \\
Shops & 0.0412 & 0.0477 & 0.0469 & 0.0488 & 0.0437 & 0.0852 \\
Health & 0.1299 & 0.1210 & 0.1132 & 0.1296 & 0.1671 & 0.1106 \\
Utilities & 0.0070 & 0.0049 & 0.0043 & 0.0030 & 0.0064 & 0.0355 \\
Other & 0.2466 & 0.2258 & 0.2258 & 0.2430 & 0.2443 & 0.2713 \\
\hline
\end{tabular}

This table shows the share of stocks that are in the respective Fama-French 10 industry classification in each of the five IVD-sorted portfolios in the top $\mathrm{IV}_{365}$ quintile. Panel $A$ shows the equally weighted share. Panel $B$ shows the weights of each industry in terms of market capitalization. The column "sample" shows the sample average. The industry classification is from Kenneth French's website. 


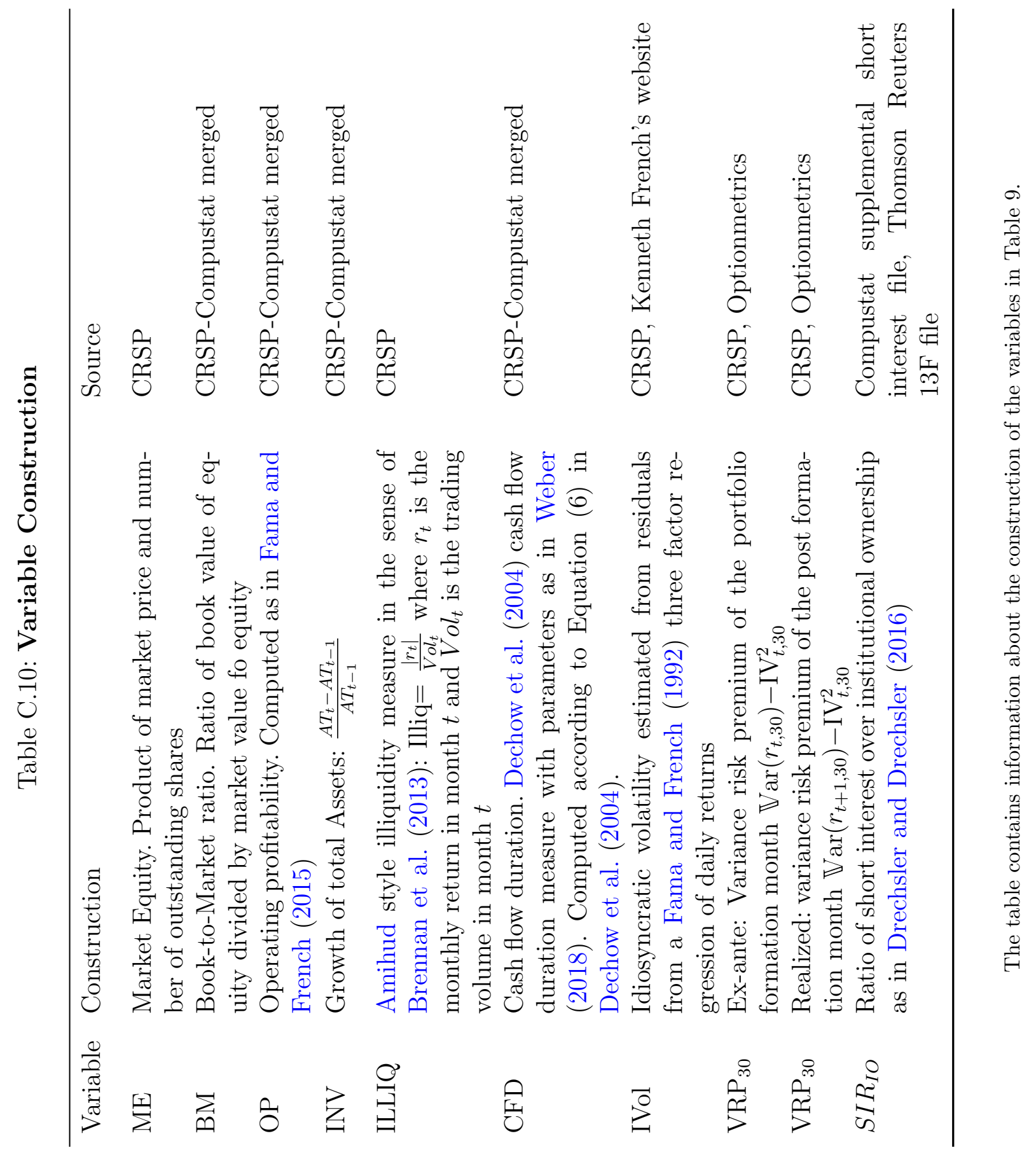


Table C.11: Idiosyncratic volatility

\begin{tabular}{cccccc}
\hline & $\begin{array}{c}\text { low IVD } \\
\text { (early) }\end{array}$ & 2 & 3 & 4 & $\begin{array}{c}\text { high IVD } \\
\text { (late) }\end{array}$ \\
low IV & 0.0138 & 0.0118 & 0.0115 & 0.0114 & 0.0108 \\
2 & 0.0171 & 0.0159 & 0.0156 & 0.0152 & 0.0148 \\
3 & 0.0219 & 0.0207 & 0.0202 & 0.0198 & 0.0192 \\
4 & 0.0285 & 0.0269 & 0.0264 & 0.0258 & 0.0248 \\
high IV & 0.0408 & 0.0385 & 0.0372 & 0.0373 & 0.0342 \\
\hline
\end{tabular}

The table shows idiosyncratic volatility relative to the Fama and French (1992) three factor model, computed as the daily standard deviation of the residuals, for 25 portfolios sorted on IVD and $\operatorname{IV}_{365}$. The sample formation period is $01 / 1996$ to $08 / 2015$. 
Table C.12: Fama-MacBeth regressions with variance risk premia

\begin{tabular}{|c|c|c|c|c|c|c|c|c|c|}
\hline & MKT & $\ln (M E)$ & $\ln (B M)$ & OP & Inv & $\mathrm{VRP}_{30}$ & $\mathrm{VRP}_{365}$ & $\mathrm{IV}^{2} \times \mathrm{IVD}$ & $\mathrm{R}^{2}$ \\
\hline CAPM & $\begin{array}{c}0.48 \\
(1.36)\end{array}$ & & & & & $\begin{array}{l}-1.32 \\
(-0.95)\end{array}$ & $\begin{array}{c}-0.82^{* *} \\
(-2.54)\end{array}$ & $\begin{array}{c}0.04^{* *} \\
(2.36)\end{array}$ & $2.23 \%$ \\
\hline FF3 & $\begin{array}{c}0.48 \\
(1.39)\end{array}$ & $\begin{array}{c}0.08 \\
(1.42)\end{array}$ & $\begin{array}{c}0.09 \\
(0.59)\end{array}$ & & & $\begin{array}{l}-1.74 \\
(-1.30)\end{array}$ & $\begin{array}{c}-0.91^{* * *} \\
(-3.22)\end{array}$ & $\begin{array}{c}0.06^{* * *} \\
(3.01)\end{array}$ & $4.19 \%$ \\
\hline FF5 & $\begin{array}{c}0.50 \\
(1.47)\end{array}$ & $\begin{array}{l}0.06 \\
(0.97)\end{array}$ & $\begin{array}{c}0.07 \\
(0.47)\end{array}$ & $\begin{array}{c}0.13^{* *} \\
(2.40)\end{array}$ & $\begin{array}{c}-0.23^{* * *} \\
(-4.25)\end{array}$ & $\begin{array}{c}-2.28^{*} \\
(-1.70)\end{array}$ & $\begin{array}{c}-0.91^{* * *} \\
(-3.31)\end{array}$ & $\begin{array}{c}0.06^{* * *} \\
(2.63)\end{array}$ & $4.62 \%$ \\
\hline
\end{tabular}

The table shows the coefficients from a second stage Fama-MacBeth-regression of single stock returns on market excess return (MKT), log market capitalization (ME), log book-to-market equity ratio (BM), operating profitability (OP) and asset growth (Inv), the variance risk premia over 30 and 365 days, $\mathrm{VRP}_{30}$ and $\mathrm{VRP}_{365}$, (measured as the difference between realized and implied variance), and $\operatorname{IVD} \times \mathrm{IV}_{365}^{2} . \mathrm{R}^{2}$ is the time-series average of the cross-sectional second-stage regressions. Numbers in parentheses are $t$-statistics adjusted according to Newey and West (1987) with four lags. Characteristics are demeaned. All factors are computed from the sample using the Compustat-CRSP merged database. For the first stage regressions, the MKT-betas assigned to each stock are the average valueweighted betas for the respective 5x5 size-and-book-to-market portfolio. FF3 and FF5 denote the model specification from Fama and French (1992) and Fama and French (2015), respectively. ${ }^{* * *},{ }^{* *}$, and ${ }^{*}$ indicate significance at the $1 \%, 5 \%$, and $10 \%$ level, respectively. The sample formation period is $01 / 1996$ to $08 / 2015$. 
Table C.13: Fama-MacBeth regressions with idiosyncratic volatility and the Stambaugh et al. (2015) mispricing measure

\begin{tabular}{cccccccccc} 
MKT & $\ln (M E)$ & $\ln (B M)$ & OP & Inv & $f($ MISP $)$ & IVol & $f(\mathrm{MISP}) \times$ IVol & IV $^{2} \times$ IVD & $\mathrm{R}_{2}$ \\
\hline $0.62^{* *}$ & -0.02 & 0.13 & $0.13^{* *}$ & $-0.18^{* * *}$ & $-0.02^{* * *}$ & $-11.51^{*}$ & & $0.09^{* * *}$ & $5.45 \%$ \\
$(1.94)$ & $(-0.48)$ & $(-0.86)$ & $(2.19)$ & $(-3.10)$ & $(-3.74)$ & $(-1.67)$ & & $(3.18)$ & \\
0.51 & -0.01 & 0.04 & $0.13^{* *}$ & $-0.21^{* * *}$ & & $-21.43^{* * *}$ & & $0.05^{* * *}$ & $5.03 \%$ \\
$(1.51)$ & $(-0.22)$ & $(-0.30)$ & $(2.42)$ & $(-4.12)$ & & $(-2.73)$ & & $(2.84)$ & \\
$0.61^{* *}$ & 0.05 & 0.11 & $0.18^{* *}$ & $-0.28^{* * *}$ & & & $-1.08^{* * *}$ & $0.10^{* * *}$ & $4.12 \%$ \\
$(1.95)$ & $(0.93)$ & $(0.69)$ & $(2.49)$ & $(-4.60)$ & & & $(-5.58)$ & $(3.02)$ & \\
$0.67^{* *}$ & -0.00 & 0.13 & $0.13^{* *}$ & $-0.15^{* * *}$ & $-0.02^{* * *}$ & -6.20 & $-1.10^{* * *}$ & $0.09^{* * *}$ & $5.64 \%$ \\
$(2.09)$ & $(-0.05)$ & $(0.92)$ & $(2.13)$ & $(-2.74)$ & $(-4.04)$ & $(-0.91)$ & $(-5.15)$ & $(3.15)$ & \\
\hline
\end{tabular}

The table shows the coefficients from a second stage Fama-MacBeth-regression of single stock returns on market excess return (MKT), log market capitalization (ME), log book-to-market equity ratio $(\mathrm{BM})$, operating profitability $(\mathrm{OP})$ and asset growth (Inv), IVD $\times \mathrm{IV}_{365}^{2}$ and Stambaugh et al.'s (demeaned) mispricing characteristic MISP interacted with idiosyncratic volatility. The MISP data are taken from Yu Yuan's website. Numbers in parentheses are $t$-statistics adjusted according to Newey and West (1987) with four lags. $\mathrm{R}^{2}$ is the time-series average of the cross-sectional second-stage regressions. Characteristics are demeaned. For the first stage regression of MKT-betas, the betas assigned to each stock are the average value-weighted betas for the respective $5 \times 5$ size-and-value portfolio. ${ }^{* * *}$, ${ }^{* *}$, and ${ }^{*}$ indicate significance at the $1 \%, 5 \%$, and $10 \%$, respectively. 
Table C.14: Fama-MacBeth regressions with idiosyncratic variance and the Stambaugh et al. (2015) mispricing measure

\begin{tabular}{cccccccccc}
$\mathrm{MKT}$ & $\ln (M E)$ & $\ln (B M)$ & OP & Inv & $f(\mathrm{MISP})$ & IVar & $f(\mathrm{MISP}) \times \mathrm{IVar}$ & $\mathrm{IV}^{2} \times \mathrm{IVD}$ & $\mathrm{R}^{2}$ \\
\hline $0.63^{*}$ & -0.01 & 0.14 & $0.13^{* *}$ & $-0.18^{* * *}$ & $-0.02^{* * *}$ & $-130.21^{* *}$ & & $0.09^{* * *}$ & $5.11 \%$ \\
$(1.93)$ & $(-0.11)$ & $(0.94)$ & $(2.17)$ & $(-3.20)$ & $(-3.60)$ & $(-2.10)$ & & $(3.08)$ & \\
0.51 & 0.03 & 0.08 & $0.13^{* *}$ & $-0.23^{* * *}$ & & $-210.87^{* * *}$ & & $0.05^{* * *}$ & $4.48 \%$ \\
$(1.45)$ & $(0.51)$ & $(0.52)$ & $(2.36)$ & $(-4.29)$ & & $(-3.79)$ & & $(2.80)$ & \\
$0.59^{*}$ & 0.05 & 0.12 & $0.18^{* *}$ & $-0.29^{* * *}$ & & & $-8.82^{* * *}$ & $0.10^{* * *}$ & $4.14 \%$ \\
$(1.89)$ & $(0.84)$ & $(0.71)$ & $(2.51)$ & $(-4.67)$ & & & $(-3.70)$ & $(2.95)$ & \\
$0.68^{* *}$ & 0.01 & 0.15 & $0.13^{* *}$ & $-0.17^{* * *}$ & $-0.03^{* * *}$ & -51.26 & $-11.57^{* * *}$ & $0.09^{* * *}$ & $5.32 \%$ \\
$(2.09)$ & $(0.26)$ & $(1.00)$ & $(2.16)$ & $(-2.93)$ & $(-3.93)$ & $(-0.75)$ & $(-3.47)$ & $(3.04)$ & \\
\hline
\end{tabular}

The table shows the coefficients from a second stage Fama-MacBeth-regression of single stock returns on market excess return (MKT), log market capitalization (ME), log book-to-market equity ratio $(\mathrm{BM})$, operating profitability $(\mathrm{OP})$ and asset growth $(\mathrm{Inv}), \mathrm{IVD} \times \mathrm{IV}_{365}^{2}$ and Stambaugh et al.'s (demeaned) mispricing characteristic MISP interacted with idiosyncratic variance. The MISP data are taken from Yu Yuan's website. Numbers in parentheses are $t$-statistics adjusted according to Newey and West (1987) with four lags. $\mathrm{R}^{2}$ is the time-series average of the cross-sectional second-stage regressions. Characteristics are demeaned. For the first stage regression of MKT-betas, the betas assigned to each stock are the average value-weighted betas for the respective $5 \times 5$ size-and-value portfolio. ${ }^{* * *}$, **, and ${ }^{*}$ indicate significance at the $1 \%, 5 \%$, and $10 \%$, respectively. 


\section{Table C.15: IV/IVD sorted portfolio returns, undervalued stocks}

\begin{tabular}{ccccccc}
\hline & & & & & & \\
low IV 365 & $0.75^{* * *}$ & $0.82^{* * *}$ & $0.61^{* *}$ & $0.79^{* * *}$ & $0.66^{* * *}$ & -0.09 \\
& $(3.48)$ & $(2.87)$ & $(2.51)$ & $(2.60)$ & $(2.78)$ & $(-0.39)$ \\
2 & $1.09^{* * *}$ & $1.20^{* * *}$ & $0.92^{* * *}$ & $0.68^{* *}$ & $0.92^{* * *}$ & -0.18 \\
& $(3.32)$ & $(2.78)$ & $(2.76)$ & $(2.16)$ & $(2.73)$ & $(-0.67)$ \\
3 & $1.29^{* * *}$ & $1.63^{* * *}$ & $1.34^{* * *}$ & $1.11^{* * *}$ & $1.17^{* * *}$ & -0.12 \\
& $(2.76)$ & $(3.53)$ & $(3.12)$ & $(2.71)$ & $(2.83)$ & $(-0.26)$ \\
4 & $2.00^{* * *}$ & $1.25^{* *}$ & $1.15^{* *}$ & $0.95^{* *}$ & 0.66 & $-1.34^{* * *}$ \\
& $(3.00)$ & $(2.38)$ & $(2.43)$ & $(2.18)$ & $(1.18)$ & $(-2.88)$ \\
high IV & 0.91 & $1.29^{* *}$ & 1.12 & $1.24^{*}$ & $2.25^{* * *}$ & $1.34^{* *}$ \\
& $(1.37)$ & $(2.41)$ & $(1.61)$ & $(1.95)$ & $(2.96)$ & $(1.97)$ \\
\multirow{2}{*}{ HML IV } & 0.16 & 0.48 & 0.51 & 0.46 & $1.59^{* *}$ & \\
& $(0.25)$ & $(0.83)$ & $(0.71)$ & $(0.69)$ & $(2.31)$ & \\
\hline
\end{tabular}

One month average returns on value-weighted portfolios sorted on IV and Implied Volatility Duration (IVD) that are undervalued according to Stambaugh et al.'s mispricing characteristic (values below 20\%). Stambaugh et al. (2015) show that (roughly) for the $20 \%$ of stocks that are most undervalued, the sign of the effect of idiosyncratic volatility is positive. Numbers in parentheses are $t$-statistics adjusted according to Newey and West (1987) with one lag. ${ }^{* * *},{ }^{* *}$, and ${ }^{*}$ indicate significance at the $1 \%, 5 \%$, and $10 \%$ level, respectively. The sample formation period is $01 / 1996$ to $08 / 2015$. 
Table C.16: Fama-MacBeth regressions with $E$

\begin{tabular}{|c|c|c|c|c|c|c|c|}
\hline MKT & $\ln (M E)$ & $\ln (B M)$ & $\mathrm{OP}$ & Inv & $E$ & $\mathrm{IV}^{2} \times \mathrm{IVD}$ & $\mathrm{R}^{2}$ \\
\hline $\begin{array}{l}0.39 \\
(1.14)\end{array}$ & & & & & $\begin{array}{c}-1.31^{*} \\
(-1.84)\end{array}$ & $\begin{array}{c}0.04^{* *} \\
(2.57)\end{array}$ & $2.28 \%$ \\
\hline $\begin{array}{l}0.38^{*} \\
(1.06)\end{array}$ & $\begin{array}{l}0.06 \\
(1.07)\end{array}$ & $\begin{array}{l}-0.12 \\
(-0.91)\end{array}$ & & & $\begin{array}{c}-1.55^{* * *} \\
(-2.98)\end{array}$ & $\begin{array}{c}0.06^{* * *} \\
(3.57)\end{array}$ & $3.45 \%$ \\
\hline $\begin{array}{l}0.42 \\
(1.23)\end{array}$ & $\begin{array}{l}0.03 \\
(0.63)\end{array}$ & $\begin{array}{l}-0.10 \\
(-0.79)\end{array}$ & $\begin{array}{c}0.13^{* *} \\
(2.26)\end{array}$ & $\begin{array}{c}-0.24^{* * *} \\
(-4.27)\end{array}$ & $\begin{array}{c}-1.35^{* *} \\
(-2.57)\end{array}$ & $\begin{array}{c}0.06^{* * *} \\
(3.20)\end{array}$ & $3.98 \%$ \\
\hline
\end{tabular}

The table shows the coefficients from a second stage Fama-MacBeth-regression of single stock returns on market excess return (MKT), log market capitalization (ME), log book-to-market equity ratio (BM), operating profitability (OP) and asset growth (Inv), Drechsler and Drechsler's Rf-expensive (E) factor and $I V D \times I_{365}^{2}$. Numbers in parentheses are $t$-statistics adjusted according to Newey and West (1987) with four lags. $\mathrm{R}^{2}$ is the time-series average of the cross-sectional second-stage regressions. Characteristics are demeaned. E is computed as in Drechsler and Drechsler (2016) from the stocks in our sample as the portfolio return of the portfolio that is long the risk-free rate and short the highest decile Short interest over institutional ownership ratio $\left(S I R_{I O}\right)$ portfolio. For the first stage regression of MKT-betas, the betas assigned to each stock are the average value-weighted betas for the respective $5 \times 5$ size-and-value portfolio. ${ }^{* * *},{ }^{* *}$, and ${ }^{*}$ indicate significance at the $1 \%, 5 \%$, and $10 \%$, respectively. The sample formation period is $01 / 1996$ to $08 / 2015$. 
Table C.17: Fama-MacBeth regressions with $C M E$

\begin{tabular}{cccccccc} 
MKT & $\ln (M E)$ & $\ln (B M)$ & OP & Inv & $C M E$ & $\mathrm{IV}^{2} \times$ IVD & $\mathrm{R}^{2}$ \\
\hline $\begin{array}{c}0.70^{* *} \\
(1.98)\end{array}$ & & & & & $\begin{array}{c}1.16^{*} \\
(1.66)\end{array}$ & $\begin{array}{c}0.05^{* * *} \\
(2.65)\end{array}$ & $1.87 \%$ \\
\hline $\begin{array}{c}0.68 \\
(1.61)\end{array}$ & 0.03 & 0.10 & & & 0.76 & $0.06^{* * *}$ & $3.38 \%$ \\
\hline 0.65 & 0.01 & 0.08 & $0.14^{* *}$ & $-0.25^{* * *}$ & 0.51 & $0.06^{* * *}$ & $3.91 \%$ \\
$(1.57)$ & $(0.19)$ & $(0.53)$ & $(2.37)$ & $(-4.41)$ & $(0.93)$ & $(3.19)$ & \\
\hline
\end{tabular}

The table shows the coefficients from a second stage Fama-MacBeth-regression of single stock returns on market excess return (MKT), log market capitalization (ME), log book-to-market equity ratio (BM), operating profitability (OP) and asset growth (Inv), a version of Drechsler and Drechsler's cheap-minus-expensive $(\mathrm{CME})$ factor and $\mathrm{IVD} \times \mathrm{IV}_{365}^{2}$ as stock characteristics. Numbers in parentheses are $t$-statistics adjusted according to Newey and West (1987) with four lags. $\mathrm{R}^{2}$ is the time-series average of the cross-sectional second-stage regressions. Characteristics are demeaned. CME is computed analogously to the factor CME in Drechsler and Drechsler (2016) from the stocks in our sample as the equally-weighted portfolio return of the portfolio that is long the lowest decile portfolio of stocks sorted by the ratio of short interest over institutional ownership $\left(S I R_{I O}\right)$ and short the highest decile portfolio. For the first stage regression of MKT-betas, the betas assigned to each stock are the average value-weighted betas for the respective $5 \times 5$ size-and-value portfolio. ${ }^{* * *},{ }^{* *}$, and ${ }^{*}$ indicate significance at the $1 \%, 5 \%$, and $10 \%$, respectively. The sample formation period is $01 / 1996$ to $08 / 2015$. 


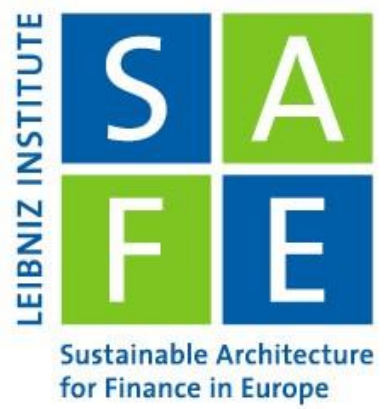

\section{Recent Issues}

No. 264 Hengjie Ai, Jun E. Li, Kai Li, Christian Schlag

No. 263 Vanya Horneff, Daniel Liebler, Raimond Maurer, Olivia S. Mitchell

No. 262 Andrea Bedin, Monica Billio, Michele Costola, Loriana Pelizzon

No. 261 Monica Billio, Michele Costola, Loriana Pelizzon, Max Riedel

No. 260 Matthias Thiemann, Tobias H. Tröger

No. 259 Inaki Aldasoro, Florian Balke, Andreas Barth, Egemen Eren

No. 258 Anderson Grajales-Olarte, Burak R. Uras, Nathanael Vellekoop

No. 257 Baptiste Massenot, Giang Nghiem

No. 256 Christian Schlag, Kailin Zeng

No. 255 Silvia Dalla Fontana, Marco Holz auf der Heide, Loriana Pelizzon, Martin Scheicher

No. 254 Martin R. Goetz

No. 253 Thomas Johann, Talis Putnins, Satchit Sagade, Christian Westheide

No. 252 Nicole Branger, Patrick Konermann, Christian Schlag
The Collateralizability Premium

Implications of Money-Back Guarantees for Individual Retirement Accounts:

Protection Then and Now

Credit Scoring in SME Asset-Backed Securities: An Italian Case Study

Buildings' Energy Efficiency and the Probability of Mortgage Default: The Dutch Case

It's the Tail-Risk, Stupid!

Spillovers of Funding Dry-ups

Rigid Wages and Contracts: Time- versus State-Dependent Wages in the Netherlands

Depressed Demand and Supply

Horizontal Industry Relationships and Return Predictability

The Anatomy of the Euro Area Interest Rate Swap Market

Financing Conditions and Toxic Emissions

Quasi-Dark Trading: The Effects of Banning Dark Pools in a World of Many Alternatives

Optimists and Pessimists in (In)Complete Markets 